\begin{abstract}
RAINES, JULIE BURBACH. Ethics, Integrity and Police Misconduct: Analyzing Ethical Awareness, Standards and Action of Law Enforcement Officers in the United States. (Under the direction of James H. Svara.)

The ethical behavior of public officials is critical to the performance of public agencies. Yet, it is rarely the subject of quantitative research. This study contributes to our understanding of the norms followed by police officers regarding misconduct that are shaped among street-level bureaucrats who, regularly and without warning, confront important value choices. A complete investigation of police ethics would need to consider both the factors that contribute to unethical behavior as well as ethical behavior. The literature focuses on the former. This study focuses on those factors that contribute to unethical, as well as ethical behavior. This study examines one type of street-level bureaucrat, namely police officers, and their attitudes towards misconduct using existing data from police officers in thirty police agencies. The specific issue examined is whether a police officer's tendency to report peer misconduct is influenced primarily by attitudes regarding misconduct or individual characteristics, peer behavior, the nature of the misconduct, organizational characteristics. Using descriptive statistics and regression models, this study concludes that an officer's willingness to report misconduct is influenced by attitudes, as well as the nature of the misconduct.
\end{abstract}




\title{
ETHICS, INTEGRITY AND POLICE MISCONDUCT: ANALYZING ETHICAL AWARENESS, STANDARDS AND ACTION OF LAW ENFORCEMENT OFFICERS IN THE UNITED STATES
}

\author{
by \\ JULIE BURBACH RAINES
}

\begin{abstract}
A dissertation submitted to the Graduate Faculty of
North Carolina State University in partial fulfillment of the requirements for the degree of

Doctor of Philosophy
\end{abstract}

\section{PUBLIC ADMINISTRATION}

Raleigh

2006

\section{APPROVED BY:}

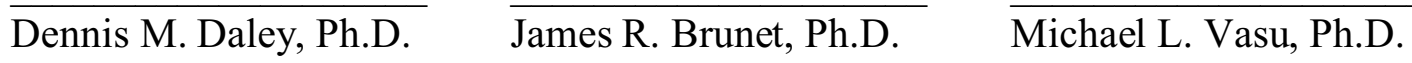

James H. Svara, Ph.D.,

Committee Chair 


\section{BIOGRAPHY}

Julie Raines will be an Assistant Professor at Northern Kentucky University beginning Fall, 2006. Dr. Raines received her J.D. from The Catholic University of America, Columbus School of Law, where she was Senior Lead Article Editor for ComLaw Conspectus. She received her undergraduate degree from North Carolina State University. Dr. Raines worked for American Airlines for five years after graduation as an International Security Agent, a reservation agent, and finally a ticket counter agent in Washington, D.C. Upon graduation from law school, she was an Associate with Sandman \& Strickland practicing a mixture of litigation and corporate law. She opened her own practice one year later specializing in entertainment law.

Dr. Raines' dissertation topic addresses ethical awareness, standards and action of police officers in the United States. Currently, she has published three articles which include The Gender Card v. The First Amendment, Dicta, Fall 1995 and The Fairness in Musical Licensing Act: The Tavern Bill Casts a Shadow, University of California, Hastings College of Law, Communications \& Entertainment Law Journal, Fall, 1997, and Law Enforcement Policy: Use of Force, Law Enforcement Executive Forum, 5(4) 2005. She has also published a teaching supplement for a Cyberlaw text. Courses she has taught include Intro to American Government, Legal and Regulatory Environments, Communication Law and Ethics, and Intro to Criminal Law. 


\section{ACKNOWLEDGMENTS}

I would like to express my deepest appreciation to Dr. James Svara for his advice and seemingly limitless patience. Dr. Dennis Daley, Dr. Michael Vasu, and Dr. James Brunet gave invaluable assistance in the completion of this study. Dr. Swiss has also given me advice from time to time that has greatly enhanced my Ph.D. experience. Without the time and loving support of my husband and parents, I would never have completed this journey. A special thanks to my daughters, Leila and Sarah, who constantly remind me that there is always time to play. 
LIST OF TABLES $\ldots \ldots \ldots \ldots \ldots \ldots \ldots \ldots \ldots \ldots \ldots \ldots \ldots \ldots \ldots$ viii

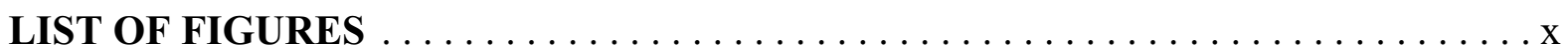

\section{CHAPTER ONE:}

Introduction to a Street-Level Bureaucrat:

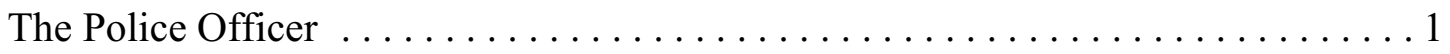

A. Theoretical Framework: Administrative Ethics ................... 5

B. The Role of the Police Officer ........................... 9

C. $\quad$ National Institute of Justice (NIJ) Data and Methods ............... 11

\section{CHAPTER TWO}

Police Attitudes, Behavior and Culture .......................... 14

A. $\quad$ Causes of Unethical Behavior in Street-Level Bureaucrats . ........... 17

1. Street-Level Bureaucrat Dilemmas of Public Service $\ldots \ldots \ldots 17$

2. Factors that Influence Police Officer Attitudes and Behavior . .....23

3. Sociological Theories and Socialization $\ldots \ldots \ldots \ldots \ldots \ldots \ldots 27$

4. Situational Factors Affecting Attitudes and Behavior .......... 29

5. Organizational Factors Affecting Attitudes and Behavior ........ 30

6. Individual Factors Affecting Attitudes and Behavior $\ldots \ldots \ldots 33$

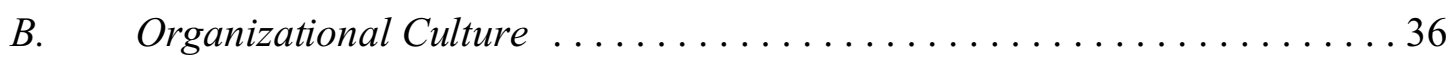


1. The Individual Police Officer and the Socialization Process . . . . . 39

(a) Moral Development .................40

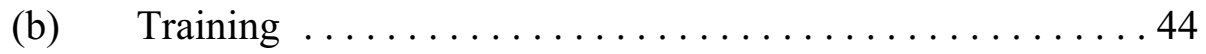

2. The NIJ Study, Ethical Awareness, Standards, and Action . . . . . . . 46

\section{CHAPTER THREE}

Research Methodology: Measuring Attitudes Towards Police Misconduct . . . . . . 48

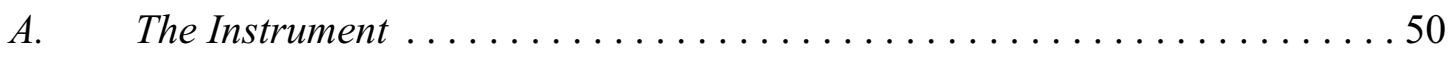

B. Statistical Analysis . . . . . . . . . . . . . . . . . . . . . 59

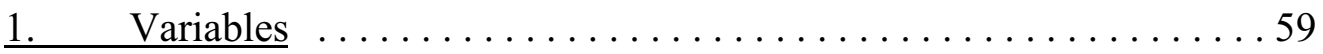

2. Categorizing Unethical Behavior $\ldots \ldots \ldots \ldots \ldots \ldots$

3. Hypotheses - Ethical Awareness, Ethical Standards, and Ethical Action

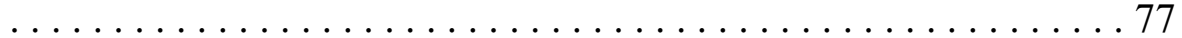

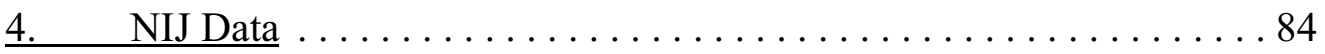

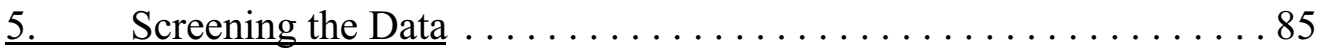

\section{CHAPTER FOUR}

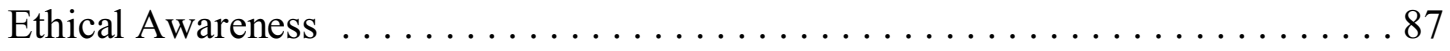

A. Ethical Awareness Hypotheses $\ldots \ldots \ldots \ldots \ldots \ldots \ldots \ldots$

B. Ethical Awareness, Situational, Individual, and Organizational Variables . 89

C. An Ethical Awareness Regression Model . . . . . . . . . . . . . . . . 110

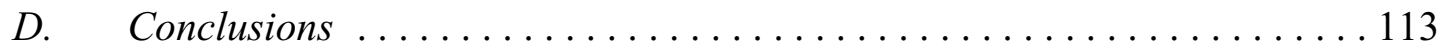




\section{CHAPTER FIVE}

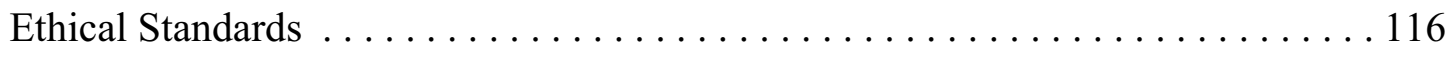

A. Hypotheses for Ethical Standards ....................... 117

B. Ethical Standards and Situational, Individual, and Organizational Variables

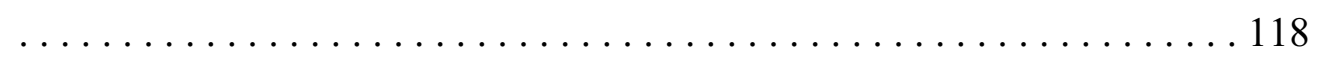

C. An Ethical Standards Regression Model ..................... 130

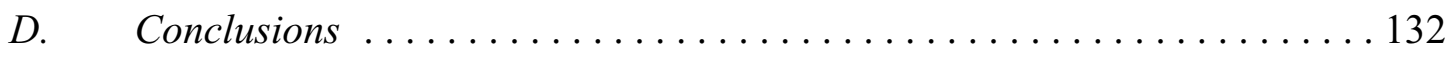

\section{CHAPTER SIX}

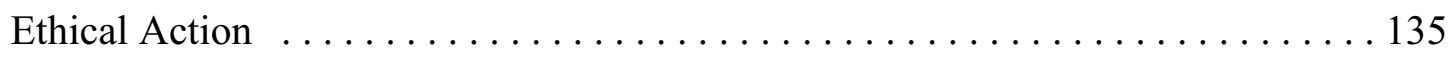

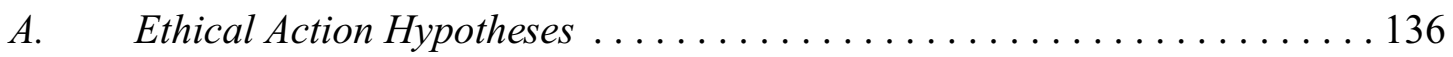

B. Ethical Action and Situational, Individual, and Organizational Variables . 137

C. An Ethical Action Regression Model . . . . . . . . . . . . . . . . . . . . . 149

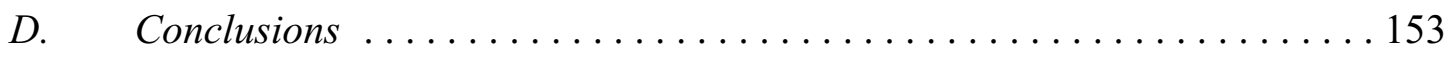

\section{CHAPTER SEVEN}

Conclusions, Implications, Recommendations and Summary . . . . . . . . 155

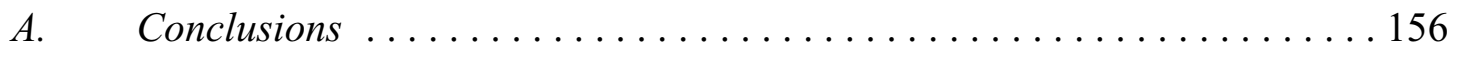

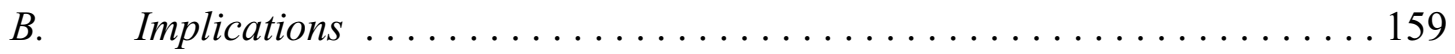

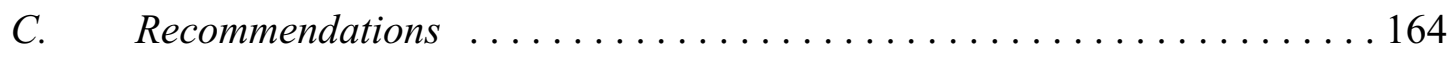

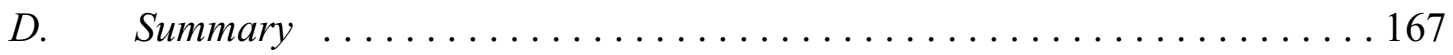




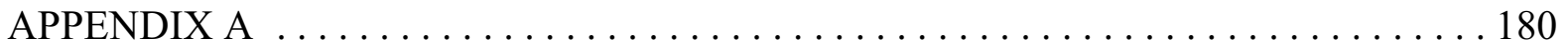

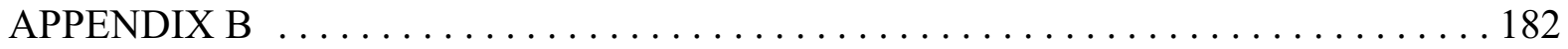

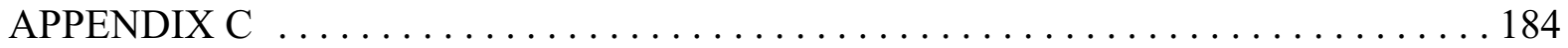

APPENDIX D .......................................... 192

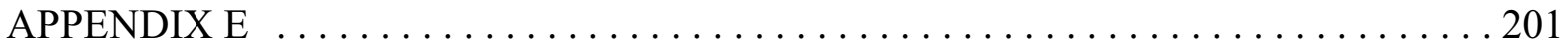

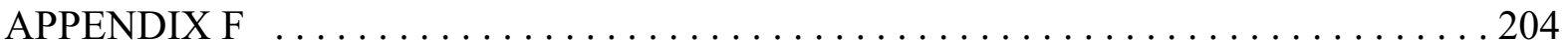

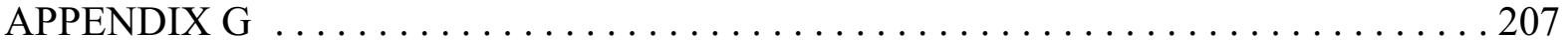




\section{LIST OF TABLES}

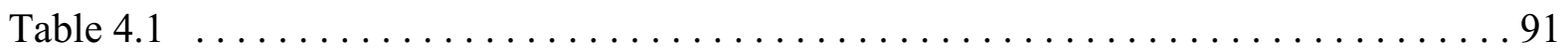

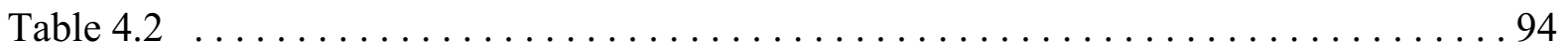

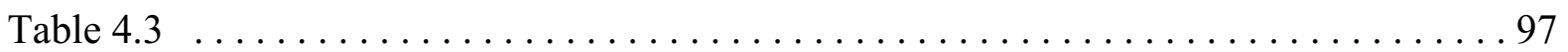

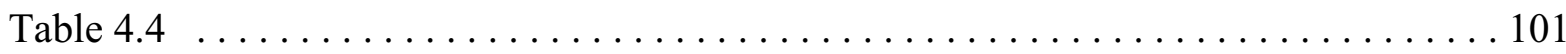

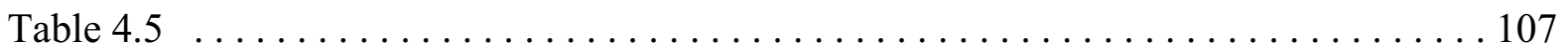

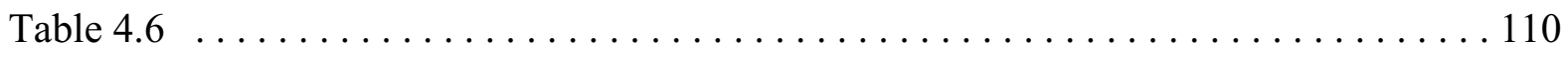

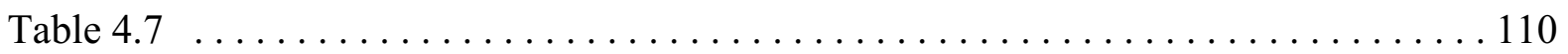

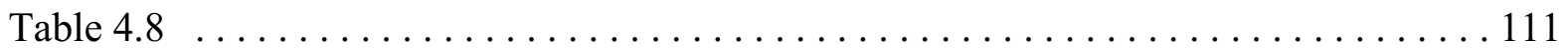

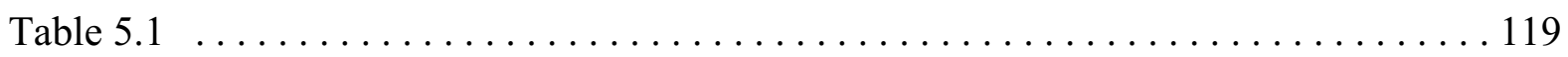

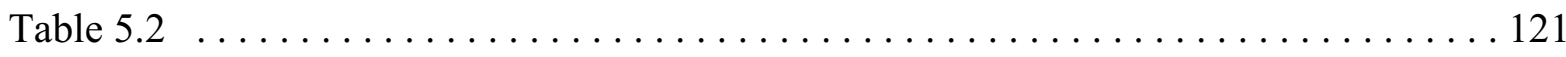

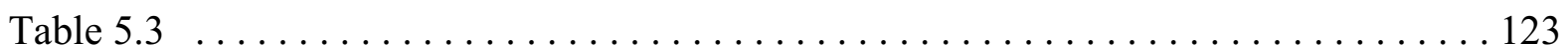

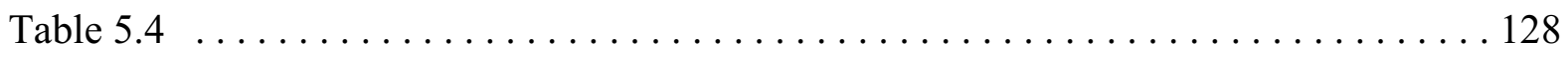

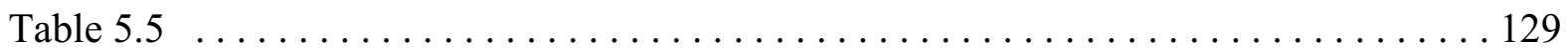

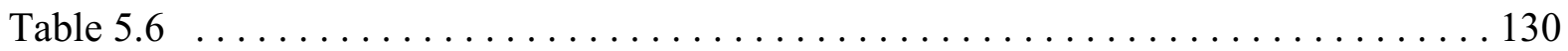

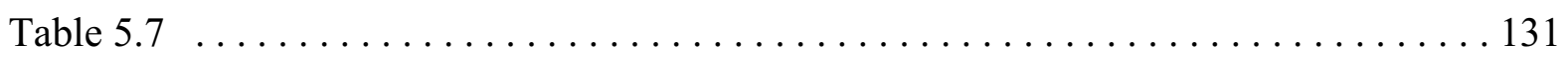

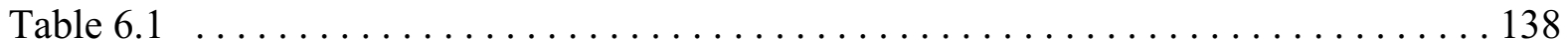

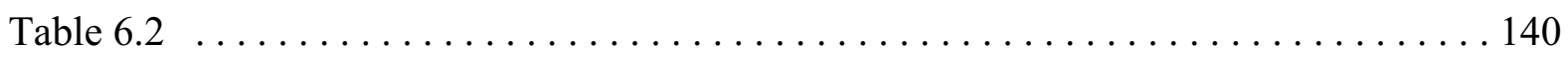

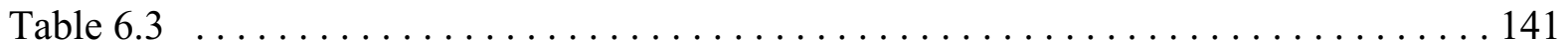

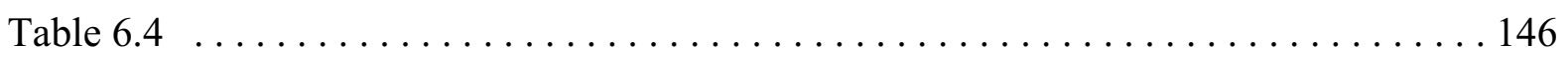

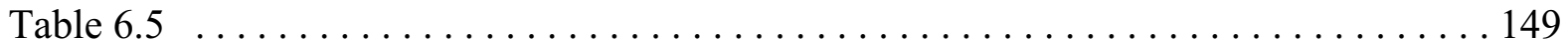

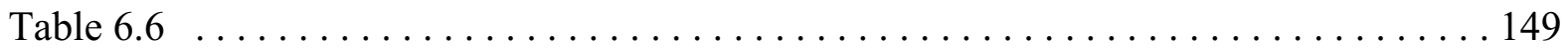

viii 
Table 6.7

Table 6.8 


\section{LIST OF FIGURES}

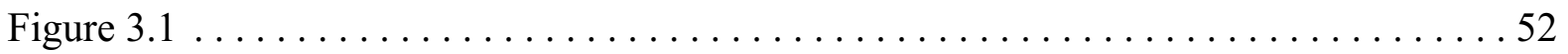

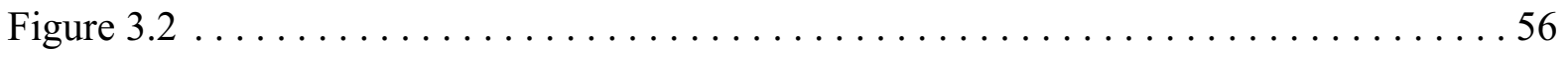

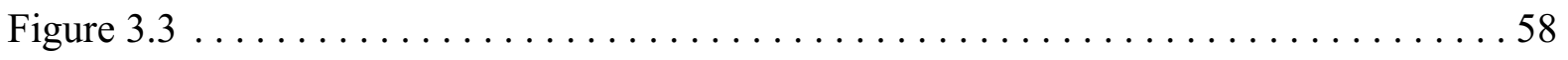

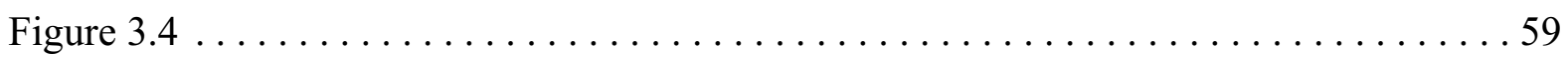

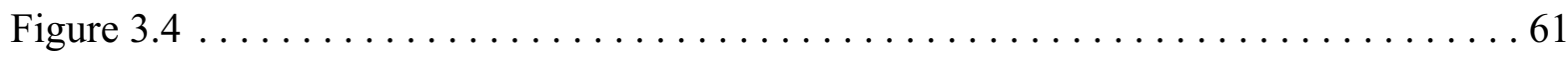

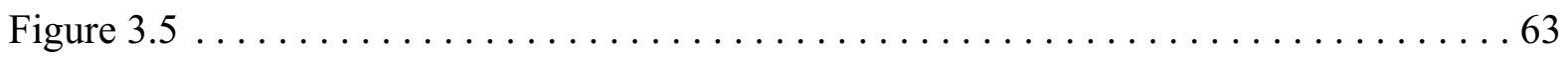

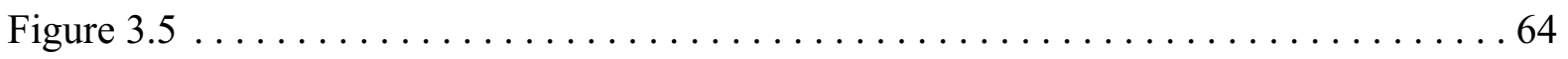

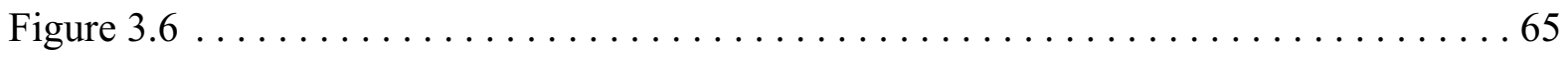

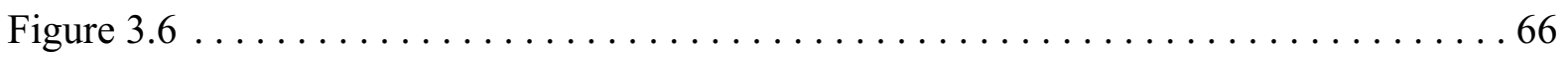

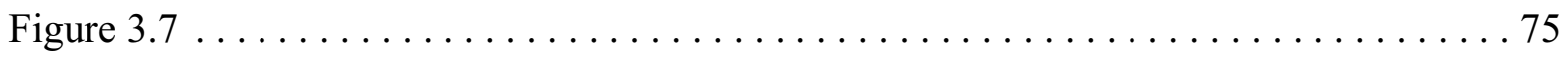

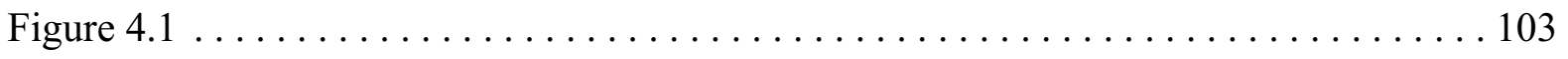

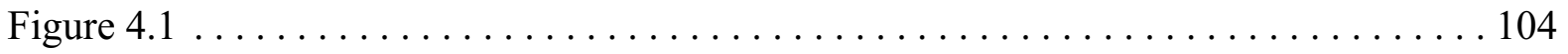

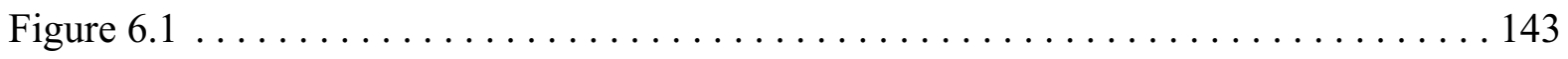




\section{CHAPTER ONE:}

Introduction to a Street-Level Bureaucrat: The Police Officer 
Spectacular scandals illustrate the underlying issue of the performance and accountability of public servants. The video taped Rodney King beating in Los Angeles, the torture of a Haitian immigrant with a plunger in New York, the Diallo shooting in New York, and the widespread corruption in the New Orleans police force are just a few of the examples found within law enforcement. In North Carolina, police officers struck up e-mail friendships with a 17 year old Chicago girl that quickly escalated into sexually explicit conversations (Atlanta Journal and Constitution 1998). In Wake County, eight deputies were disciplined for exchanging sexually suggestive messages with the girl while they were on duty. The girl's mother said one deputy sent her daughter a photo of his genitals. Wake County Sheriff John H. Baker Jr. demoted one deputy and suspended seven for two to four days (Atlanta Journal and Constitution 1998). The most compelling stories are those of officers who are willing to break the "code of silence" and report fellow officers for engaging in misconduct.

These incidents highlight the need for empirical research that will explain why some officers commit these acts and what might prompt other officers to report such examples of misconduct. In light of the heightened sensitivity to ethical decision-making, there is growing research interest in the areas of misconduct, corruption, ethics, and moral reasoning within government. In particular, attention has been placed on police ethics. Understanding the police officer's attitudes towards misconduct is an important step towards understanding ethical and unethical behavior within the ranks. This study analyzes police officer attitudes regarding officer misconduct and the impact attitudes have on one type of actual behavior. Police are a unique group of individuals because they seek to prevent crime as their 
career. Officers are entrusted with a somewhat unique responsibility in our society - to protect other members of society much like fire fighters and security guards. Officers are required to safeguard property and lives fairly, avoid unnecessary use of excessive force, avoid corruption, use consistent and wise discretion, keep confidences when appropriate, cooperate with other law enforcement agencies, and exhibit exemplary behavior off duty. The vast majority of officers accomplish these goals effectively, serving their communities honorably.

Only a very small percentage of officers are disciplined for misconduct in the United States annually. For example, approximately 3,104 officers, out of the over 600,000 sworn officers in state and local departments, were disciplined for unethical behavior from 1990 to 1995 in the United States (Trautman 1997). While a quite small proportion of the total, the nature of the police task makes even these few a matter of concern. When one officer commits a transgression, the entire agency suffers particularly when the news media reports the incident.

Steinberg and Austern (1990) summarize some of the reasons why officers might commit unethical acts. Some claim they did not realize it was against the law, policy or procedure. Some officers admitted that unethical conduct can be the result of basic stupidity. There are those police officers who believe corruption is a part of the job, that it is required in order to survive their job, or that it is a game. Some of the most destructive reasons in history center around those who believe that he/she is doing the right thing, going along with what the agency requires, or simply just following orders. Other officers admitted it was a way to speed up the way the system processes clients, to help out a friend, to abuse the system, to 
feed their ego, to satisfy their greedy nature, for personal gain, as a type of revenge, or to solve a financial problem (Steinberg and Austern 1990, 33-55).

Actual misconduct is hard to investigate due to an unwillingness on the part of public officials to admit wrong-doing (Klockars et al. 2000). Because answering questions regarding the behavior of others is less threatening, officers may be more willing to answer questions regarding whether they are willing to report others for misconduct as well as their attitudes regarding peer misconduct. This study analyzes a large existing data set to measure more precisely officer attitudes regarding peer misconduct and the propensity for those who would report the misconduct of peers. The study begins with a thorough examination of variations in behavior among police officers.

Individuals, in general, respond in a variety of ways to inefficient and/or inferior working conditions. According to Hirschman (1970), employees who face undesirable work environments can exit the organization, voice their discontent, remain loyal to the organization and ignore the situation, or neglect their work as a passive aggressive response (Rusbult, Zembrodt, and Gunn 1982; Farrell 1983; Rusbult et al. 1988; Withey and Cooper 1989). Police officers may accept misconduct in their personal values as a passive aggressive response to undesirable working conditions. Officers may tolerate the misconduct of other officers and not report those officers out of loyalty. Some officers, however, may report the misconduct of fellow officers, a form of voice more commonly called whistle-blowing behavior in public service.

Whistle blowers are not disgruntled employees. According to Brewer and Selden (1998), they rank among the most productive, valued, and committed members of their 
organizations. Whistle blowers are normal people who have a strong conscience, are high performers committed to the formal goals of their organization, and they have a strong sense of professional responsibility. Whistle blowers are less motivated by job security and more motivated by regard for the public interest. They report high levels of job commitment and job satisfaction (Brewer and Selden 1998).

Police officers, however, are not typically prone to reporting fellow officers for misconduct. The code of silence is well documented within the police culture literature (Klockars et al. 2004; Vila and Morris 1999; Human Rights Watch 1998; Skolnick and Fyfe 1993; Skolnick and Bayley 1986). Officers who violate the code of silence by reporting fellow officers are shunned by fellow officers and any transgressions committed by the reporting officer are exposed (Cancino and Enriquez 2004; Skolnick and Fyfe 1993). According to Klockars (2002), agencies weaken the code of silence if they strongly adhere to specific policies that encourage reporting misconduct and policies that impact both officers and supervisors.

The code of silence is just one of several factors influencing the ethical conduct of police officers. Other factors include hiring practices, the demands of the profession, socialization, personal morality, character, and supervision. The following section briefly explores these factors and the conditions under which they arise.

\section{A. Theoretical Framework: Administrative Ethics}

The questions analyzed by this study are fundamental to administrative ethics.

1. What are the differences in ethical attitudes and behavior in street-level bureaucrats and what causes these differences?

2. Do police officers come to public service with strong public service values?

3. Are officers socialized within their agency to commit unethical acts or to 
uphold ethical standards?

4. Are officers exposed to such stressful and/or unusual working conditions that it leads inevitably to erosion of their commitment to ethical behavior or do officers choose to remain more committed in their ethical values?

5. Is the ethical behavior of officers shaped by the attitudes of peers and the police and actions of their agency?

6. Which of these issues has the greatest impact on the ethical behavior of police officers?

That small percentage of officers who do commit unethical acts during their careers may not be properly screened during recruitment. Another possibility is that the job itself attracts officers of a certain personality type and/or disposition that is conducive to abandoning public service values when the right conditions exist. The minimum requirements for hiring new recruits may be inadequate by allowing inexperienced, young individuals into a career at a stage of moral development that is not appropriate to a job that demands the highest moral character. Police officers, in fact all adults, have a level of moral development that reflects in part their experience. The majority of the population has moral reasoning based on conventional stages of moral development that are guided by moral values, understanding the difference between what is right and what is wrong, maintaining social order and a sense of duty to others (Kohlberg 1984).

An alternate possibility is that young recruits have good intentions, but have weakly formed ethical attitudes and a naive view of police work. They may be subject to the influence of peers and become disillusioned and "hardened" by conditions they encounter on the force. The police officer's level of moral development before joining the police force will affect how they respond to ethical challenges. Socialization on the force, the process by which officers learn group values and established behaviors, will affect their level of moral development after joining the police force and will alter how they respond to ethical 
challenges (Lundman 1980). This study reviews the literature regarding the screening of new recruits, as well as the average stage of moral development for police officers.

Officers who come to the public service with strong public service values may still be ultimately socialized to commit unethical acts through training, peers and supervisors. Police officers, like public administrators generally, are greatly impacted by peers and supervisors with respect to their attitudes towards misconduct. Their values may be reinforced with professional ethical norms and organizational practices. If the organizational norms of an agency support unethical behavior, then eventually officers will either quit the force out of frustration, join in the undesirable behavior, or alienate themselves from their fellow peers who may be engaging in unethical conduct (Hirschman 1970). The individual officer's relationship with his/her peers and supervisors will greatly impact which direction the officer chooses. This study reviews the literature regarding officer training and formalized codes of ethics for law enforcement. This study also analyzes officer relationships with peers and supervisors.

The demands of the job may in itself be too much for some officers. Facing danger constantly, unusual working hours and sleep habits, and being continually surrounded by criminals may be too much stress particularly when experienced over a period of several years (Kenney and McNamara 1999; Lundman 1980; Paoline 2001; Wilson 1968). This study examines the literature regarding police culture.

This study also takes into consideration the factors that contribute to an officer's ability to commit unethical acts. Officers, in particular patrol officers, are difficult, if not impossible to monitor on a daily basis as they work outside the normal confines of an office 
setting (Walker 2004). Police officers, like most street-level bureaucrats, enjoy a great deal of autonomy in their jobs. Discretion does not automatically lead to unethical acts and is necessary in order for bureaucrats to effectively carry out their jobs. However, it does allow the opportunity for unethical acts to occur.

Those who can report misbehavior - the citizens who perceive that they have been mistreated by police officers - are at a disadvantage on several levels. Because most of the citizens who would be prone to complaining are in the process of being arrested, the veracity of their claims is suspect at best. Those that might complain are faced with the fear of reprisal. There is also a scepticism on the part of the citizen who feels that such complaints will fall on deaf ears (Maynard-Moody and Musheno 2000). In some instances, such complaints do, in fact, get ignored by supervisors who wish to protect their employees (Raines 2005).

The complaint process and lack of adequate monitoring are two factors that contribute to an officer's opportunity to commit unethical and/or illegal acts. There are two primary factors that contribute to the police officer's opportunity to commit unethical and/or criminal acts (Lipsky 1980; Vila and Morris 1999; Maynard-Moody and Musheno 2000). First, the role the police officer plays in society shapes the job he/she performs. The police officer's role also impacts attitudes towards that work. The role an officer plays contributes to the second factor - autonomy on the job. Discretion will be covered more extensively in the literature review. The section that follows briefly describes the evolution of the police officer's role in society. 


\section{B. The Role of the Police Officer}

1. The Political, Professional, and Community Policing Eras

The role of the police officer has changed dramatically over time. Initially, the police in the United States were merely average citizens without formal training who stood as night watchmen, collected taxes, caught and punished criminals, and enforced the law. As territories were settled and the railroads expanded westward, private police forces and elected governments kept the peace in the $19^{\text {th }}$ century, but some private citizens in smaller communities became involved in vigilante justice. During the $19^{\text {th }}$ century, however, with the growth of cities and the influx of immigrants, modern policing modeled after the London Metropolitan police force was born. Unfortunately, the American version was highly politicized and corrupt relying heavily on favoritism. This was known as the Political Era (Vila and Morris 1999).

The merit-based system reformed the organizational structure of the police in the early 1900's beginning what is known as the Professional Era of policing which lasted until the 1970 's. By the Depression, the role of the police was to protect the general public from crime, enforce the law, maintain order, and keep the peace. However, diversity was nonexistent and corruption was still widespread. Many laws were passed improving how officers were chosen and how police organizations were managed, but crime rates continued to increase due to growth in population and urbanization.

With the advent of new technologies in the 1970's, the end of the Professional Era lead to the beginning of Community Policing. Ultimately, the role of the police changed in the 1990's to reflect a growing need for officers to do more than simply respond to criminal 
activity, but to also work with communities in solving other crime related problems. And so, the concept of community policing was born. Community policing not only demands more interaction of the police with members of the community, it gives members of the community more control over how crime is controlled within their neighborhoods (Vila and Morris 1999).

Community policing has some drawbacks in that it produces "conflicting demands on police officers and police organizations" (Vila and Morris 1999, xxix). Officers are required to perform multiple roles within a community including counseling, mediating, and enforcing the law. This requires a great deal of autonomy which can lead to the rise of corruption and/or misconduct (Vila and Morris 1999). Discretion becomes a necessary evil, allowing both good and harm within the community.

\section{Discretion in Policing}

Discretion is inevitable for the street-level bureaucrat (Maynard-Moody, et al. 1990). Police officers, in particular, enjoy high levels of discretion given the nature of their job. Does discretion automatically lead to abuse? Are tighter controls and supervision the answer? One problem with tighter controls is that it causes abuse to become more secretive and harder to find. There are existing controls in that street-level workers self-monitor. They also rely on peers, supervisors, and clients to keep themselves in check (Maynard-Moody, et al. 2000). As Lipsky (1980) points out, "discretion provides opportunity to intervene on behalf of clients as well as to discriminate among them" (Lipsky 1980, 23). Discretion, then, can provide flexibility for bureaucrats and limiting discretion can create as many problems as it solves. 
Within the police force it is difficult, if not impossible, given the nature of the work to significantly increase supervision in as much as the officer works alone (Lipsky 1980). In addition to self controls, officers rely on peers and the complaints from the public to keep them in check. Relying on these resources, however, raises further problems. For example, citizens have difficulty reporting police misconduct (Maynard-Moody, et al. 2000).

Furthermore, peers can also be corrupt leading to the corrupt socialization of officers on-thejob (Lundman 1980).

A 2000 survey reveals that approximately $95 \%$ of police departments in the U.S. have currently adopted community policing (LEMAS 2000). Community policing allows policing to retain its autonomous characteristics. This autonomy, in turn, allows officers the opportunity to commit deviant acts. However, discretion alone does not mean that an officer will automatically turn to deviant behavior. The following section takes a more in-depth look at how unethical behavior can arise within an agency.

Given these circumstances, how can misconduct be detected in agencies? One possibility is to examine complaints, but these reports are incomplete and difficult to acquire. An alternative approach is to examine an employee's attitudes towards work, work environment, peers, supervisors, and the unethical behavior of peers and supervisors. The National Institute of Justice (NIJ) has collected data regarding police officer attitudes towards misconduct, officer behavior, and the officer's perception of peer attitudes and behavior.

\section{C. $\quad$ National Institute of Justice (NIJ) Data and Methods}

There are several ways to answer these questions regarding whether and how some officers turn to unethical behavior in their careers. These questions can be at least partially 
answered by looking at officer attitudes and those of their peers and by examining factors that might impact officer behavior. The NIJ conducted a study in 1997 that offers a rare opportunity to analyze police officer attitudes and behavior (Klockars et al. 2004).

The NIJ is an agency under the U.S. Department of Justice whose mission includes conducting research on crime control and justice issues. The NIJ funds millions of dollars annually to individuals and institutions for research and evaluation within the criminal justice system. The 1997 study was funded by the NIJ and conducted by several scholars from different universities. To date, the data has not been analyzed using advanced statistical methods to examine multiple explanations of variations in attitude and behavior. Nor has the data been analyzed regarding the impact socialization has on police attitudes and behavior.

The NIJ study measures the attitudes of police officers with experience ranging from one to more than twenty years of service in 30 different agencies within the United States. The researchers chose agencies with which they had existing relationships making the sample one of convenience (Klockars et al. 2004). The NIJ study includes responses from over 3,200 officers in the U.S. with an overall response rate of 55.5\% (Klockars et al. 2000). The NIJ study has been replicated internationally to over 10,000 officers worldwide.

Observational study of three police agencies in the U.S. have also been added to this body of work. The NIJ work is primarily used as research in the field of police integrity. The NIJ study has been used by its researchers to measure integrity at the organizational level and has been used to generate practical advice aimed at advising police administrators what they can do to improve organizational integrity through policy (Klockars et al. 2004).

This study begins in Chapter 2 by examining the institutional norms of the law 
enforcement profession. This is followed by a thorough review of the causes of unethical behavior in street-level bureaucrats, with an emphasis on the police officer. Police culture, police ethics, police use of discretion, and organizational deviance within law enforcement are reviewed including those issues raised above. Chapter 3 explores the NIJ study including the survey instrument, the variables, and the data collected. Chapters 4, 5, and 6 analyze that data using descriptive statistics and regression models. The focus of the analysis is on ethical awareness, standards, and action of police officers. The final chapter makes recommendations to law enforcement agencies striving to encourage ethical decision-making. 


\section{CHAPTER TWO}

Police Attitudes, Behavior and Culture 
Standards and institutionalized norms contribute to socialization within an organization. In private business, codes of ethics are considered a part of corporate culture. It is treated similarly to a mission statement for a company - a means of communicating the ethical mandates prescribed by the corporation (Simons 1995). The current Police Code of Conduct was originally a resolution passed in 1957 at the annual International Association of Chiefs of Police (IACP) conference. The code was not altered again until 1989 at the annual IACP conference. Further changes were made and the final result was the creation of the Law Enforcement Code of Ethics and the Police Code of Conduct which were approved by the IACP in 1991 at their annual conference.

The Law Enforcement Code of Ethics is more like an oath of office, than a traditional code of ethics. The creation of a separate code of ethics and code of conduct was in response to the desire to have an oath of office for use at graduation ceremonies. This required shortening the original code created in 1957 , which was undesirable as most agreed with the basic value statements contained in the original 1957 code. The solution was the creation of two separate documents, the Code of Ethics and the Police Code of Conduct. A copy of the Law Enforcement Code of Ethics is attached as Appendix A, and a copy of the Police Code of Conduct is attached as Appendix B.

The Police Code of Conduct contains nine main headings. These headings are referred to as ethical mandates that officers should turn to for guidance in performing their jobs. Each mandate contains a brief description of how a police officer should conduct him/herself on the job. The entire document fits onto one page. According to the 1992 Police Chief article introducing it, the Police Code of Conduct reprinted in their magazine is 
at least "suitable for framing."

The literature does not indicate whether the Police Code of Conduct is included in any training for officers. Some of the literature even advocates avoiding too much of a focus on codes as opposed to philosophical issues (IACP training materials available online at http://www.theiacp.org). After analyzing five police officer training programs in the United States who were promised anonymity, only one of the programs included a copy of the Police Code of Conduct in its entirety along with an in-depth discussion of its mandates. One other program included the Police Code of Ethics along with the American Society for Public Administration Code of Ethics. Essentially, these two documents combined cover all of the elements found in the Police Code of Conduct, especially the Police Code of Ethics. One of the sets of training materials did not include either, but the instructor always ends his lecture with a recitation of the Police Code of Ethics.

Whether the Police Code of Conduct can be viewed as a mission statement is not clear. It is only minimally beneficial as a communication tool, expressing what is expected by those in power to their subordinates. The mandates and accompanying explanations within the Police Code of Conduct are fairly obvious. Officers are required to safeguard property and lives fairly, avoid unnecessary use of excessive force, avoid corruption, use consistent and wise discretion, keep confidences when appropriate, cooperate with other law enforcement agencies, and exhibit exemplary behavior off duty. Arguably, even if not communicated within a code, most officers would recognize corruption.

These are the formal ethical standards of police officers. The International Association of Chief"s of Police advocates in their training materials that "Personal integrity 
and a conscious decision to do the right thing even in the face of sometimes overwhelming pressure to do otherwise are where the rubber hits the road in the ethical decision-making environment" (IACP online 2005). In other words, it is assumed that integrity will enable officers to stand up to challenges. This dissertation examines the extent to which officers comply with the code and achieve these ideals as they confront challenging situations. There are a number of factors in the environment of public servants that affect their decisionmaking. The following section reviews factors impacting the street-level bureaucrat's ethical decision-making process.

\section{A. Causes of Unethical Behavior in Street-Level Bureaucrats}

According to Michael Lipsky (1980), street-level bureaucrats face many challenges that can potentially lead to unethical behavior in public agencies. Resources, clients, goals, performance measures, alienation, discretion, hiring, training, personality, supervisors and coworkers each contribute to the street-level bureaucrat's ethical decision-making. For the street-level bureaucrat, generally, resources are limited, clients are non-voluntary, goals are ambiguous and performance measures are inadequate. The street-level bureaucrat has a great deal of discretion in carrying out his/her mission. Ultimately, the organizational culture, and in particular the attitudes and behavior of supervisors and coworkers, will impact how the street-level bureaucrat handles all of these issues. The following subsections explore each of these issues in turn with the exception of organizational culture which is addressed in the subsequent section.

\section{Street-Level Bureaucrat Dilemmas of Public Service}

Street-level bureaucrats enormously influence our lives every day. Agencies provide 
public benefits and have the authority to sanction the public. In essence, bureaucrats "hold the keys to a dimension of citizenship" (Lipsky 1980, 4). Unfortunately, the essential work bureaucrats perform is subject to conditions that hinder the effective and efficient delivery of services. Bureaucrats generally face inadequate resources, continually increasing demand for services, ambiguous/conflicting/vague goals, inadequate performance measures, and nonvoluntary clients (Lipsky 1980). Police officers certainly face all of these dilemmas in public service. Lack of resources, ambiguous and conflicting goals, community relations, performance measures, and the alienated nature of their work are common to police agencies. These problems coupled with the constant threat of violence makes for an extremely stressful work environment.

Bureaucrats are faced with limited resources that are generally inadequate to fulfill the requirements of their jobs. Should additional resources be made available, they are immediately used up by a public that constantly hungers for more services. In other words, demand will inevitably catch up with supply. This cycle eventually brings the agency back to its original position. Constantly facing inadequate resources is stressful and places a great amount of pressure on the bureaucrat's time. It also creates conflict as agencies must meet Constitutional requirements of equity, i.e. providing the same level of protection to each citizen, when providing services to the community (Lipsky 1980, 27-30).

While officers today have increased technology as a resource, lack of resources is commonplace for police officers. In particular, lack of "time to collect information, time to act" is perhaps the most difficult problem officers face daily. Officers also work under the threat of violence constantly creating added stress to their work. These two factors alienate 
officers from the community and strengthen the internal bond. Furthermore, they are forced to make split second decisions that given hindsight often do not pass public scrutiny (Lipsky 1980).

Working with this lack of resources, bureaucrats must face non-voluntary clients with whom they may experience conflict. This friction between bureaucrat and client makes it difficult sometimes to carry out the bureaucrat's tasks. One factor affecting this relationship is the fact that clients are usually not included as a reference group for bureaucrats which greatly impacts the way services are delivered. Ultimately, this allows the bureaucrat the ability to abuse the bureaucrat/client relationship given that the client cannot walk away from the transaction (Lipsky 1980, 56). The end result within the police culture is the creation of a "we/them" mentality attributed to police officers (Paoline 2001). A similar mentality exists between police supervisors and subordinates (Whetstone 2001; Scarborough et al. 1999). Lipsky (1980) argues that bureaucrats have ambiguous goals and inadequate performance measurement given that their tasks revolve around public service. Furthermore, goals can be diverse and contradictory. Officers still face overwhelming demand to not only catch criminals, but become involved in the community, and now to prevent terrorist attacks in all public places including public transportation. The more ambiguous the goals and the more dissimilar, the more important the relationship between bureaucrats and their coworkers in order to sustain morale at work. Lack of supervisor monitoring contributes to the inadequacy of performance measurement. Agencies are forced to use surrogate measures for performance measurement. This can cause bureaucrats to channel their focus in unintended ways. Police officers goals are ambiguous and sometimes conflicting - whether to maintain 
order or enforce the law (Lipsky 1980). As discussed in Chapter One, the role of the police officer has dramatically changed over time. Currently, the officer must juggle conflicting roles within society (Adcox 2000). The relationship between the officer and his/her supervisor influences how an officer will ultimately resolve this conflict (Engel and Worden 2003).

Another obstacle that police organizations face is the collection of performance measures since officers can not be directly monitored by supervisors. Surrogate measures are used such as arrest rates, citizen complaints, and conviction rates. These measures give an incomplete picture as to whether the officer is making positive value choices (Lipsky 1980). Early warning systems utilized to detect potentially problem officers can rely on any number of criteria including "citizen complaints, firearm-discharge and use-of-force reports, civil litigation, resisting-arrest incidents, and high-speed pursuits and vehicular damage.” However, a vast majority of departments do not utilize any type of early warning system (Walker et al. 2001).

Lipsky $(1980,75)$ points out that street-level bureaucratic work is alienated work. "Jobs that require workers to deny the basic humanity of others" can be considered alienating work. This results in the bureaucrat becoming "less concerned with protecting clients' interests and their own connection with clients" (Lipsky 1980, 79). Alienated workers can become dissatisfied with their jobs which leads to absenteeism and less than adequate job performance.

As for the police officer's attitude towards citizens, the street-level bureaucrat can easily become alienated from the client. Police are suspicious of the public they serve as a 
coping mechanism for dealing with the dangers of their profession. As a result, the police become socially isolated which contributes to the strong peer loyalty officers enjoy (Paoline 2003). However, one study contradicts the existence of the "we/them" mentality normally attributed to police officers. This same study found that officers were not generally distrustful of the public, but have a positive view of citizen cooperation (Paoline et al. 2000).

This concept of alienation still holds true today (Barker 1999). The officer's relationship with the community greatly impacts ethical decision-making. While this relationship is between the individual officer and the community, the results impact the community's relationship with that officer's agency. Ultimately, it is the agency's policy that dictates that relationship between the officer and individuals within the community. Jiao (1998) suggests that police departments can improve efficiency and effectiveness if the proper policing model is matched with the community it serves. Building such a policing model requires analyzing police activities, police orientations and the role of the community before major policy changes are made within a police organization (Jiao 1998). Organizational change within police departments occurs generally as a result of a scandal captured by the media which leads to public inquiry resulting in personnel changes within management (Robinette 1991). This cycle suggests that the ideal policing model may not be in place within each community.

A tenuous relationship with the community cannot help relationships with clients. Studies show that the public's attitude towards the police is as important as the police's attitude toward the public they serve. Suspects who act disrespectfully to police officers are more likely to be arrested, cited and/or subject to use of physical force (Engel 2003; Klockars 
2003). This does not mean that people, in general, have a negative view of police officers. Many studies show that the general public has a positive opinion of the police (Brown and Benedict 2002; Cao et al. 1996; Chermak et al. 2001; Priest and Carter 1999; Cheurprakobkit and Bartsch 1999).

According to Maynard-Moody \& Musheno (2000), discretion is inevitable for the street-level bureaucrat. The work is done without direct supervision, and officers encounter unexpected situations that do not clearly match guidelines. Citizens have difficulty reporting police misconduct and peers can be corrupt leading to the corrupt socialization of officers onthe-job. Maynard-Moody \& Musheno (2000) seek to analyze street-level work discretion from two different perspectives or views - the dominant view or state-agent narrative which says that self-interest is the guiding force behind decisions and the counter narrative of the citizen agent from the street-level worker who is responsive to the needs of the client basing decisions on their experience.

The dominant view sees street-level workers as policymakers whose job is to execute the laws the government passes. This view says that the street-level worker relies on selfinterest in decision-making - ie: what will make my life easier and what will get this case out of my life faster? This view acknowledges that sometimes the street-level worker will go above and beyond the call of duty - picking a small number of cases that seem worthy to give special attention to, but that the worker doesn't have the time or the resources to do so with every case (Maynard-Moody \& Musheno 2000).

The citizen-agent view sees the street-level worker as responsive to clients, experienced, relying on normative values rather than rules, distrustful of politicians and 
supervisors who only create obstacles to helping the client. This view is held by the streetlevel workers themselves. The Maynard-Moody \& Musheno (2000) article relies on observation, interviews, a questionnaire, and archival research from five sites including two police departments, two vocational rehabilitation agencies, and one middle school in the U.S.

One story involves a woman who comes to the police department to complain about the police roughing up her husband when mistakenly arresting him. The woman had to pray for several days before coming in because the original incident was so frightening to her. In the first instance of police discretion, the police used discretion to brutalize her husband. In the second instance, the police officer used his discretion to help the woman file a complaint (Maynard-Moody \& Musheno 2000).

Lieutenant Ken Adcox (2000) of the El Paso Police Department points out that both line officers and managers exercise discretion in their jobs. Adcox focuses on the unsupervised line officer making quick decisions with "immense autonomy and latitude" (Adcox 2000, 17). While Adcox (2000) recognizes the necessity of police discretion, relying on Lewis (1991), Adcox (2000) also recognizes the subsequent potential for unethical behavior.

The poor working conditions of street level bureaucrats alone do not account for unethical behavior. Several theories of deviant behavior are relevant to the hypotheses explored in this study. In particular, police officer attitudes, organizational deviance and several sociological theories deserve mentioning here.

2. Factors that Influence Police Officer Attitudes and Behavior

What is the relationship between attitudes and behaviors in individuals? Is there a 
relationship between the two? Finding a causal link between attitudes and behavior is challenging considering the multitude of factors that can influence both. Measuring attitudes and behavior for police officers has primarily focused on factors that influence arrest behavior since it is the most convenient data available. Very little has been explored with respect to police officer attitudes and behavior related to ethical decision-making.

Socialization begins for officers during their new recruit training and continues on the job throughout their careers. Measuring the impact of socialization is difficult given the nature of police work. One measure is officer attitudes. There are a significant number of qualitative and quantitative studies that explore police officer attitudes (Engel and Worden 2003). Most of these studies analyze what impact officer attitudes have on police service, arrest rates, detecting crime, use of coercion, and whether officers shirk their duties (Riksheim and Chermak 1993). Social-psychology research, in general, finds the link between attitudes and behavior is mediated by situational factors such as social norms, peer norms, and peer behavior (Engel and Worden 2003).

From about the mid 1960's through 1993, approximately 545 social science articles were published testing whether there is a relationship between attitudes and behavior in people generally. Of these studies, $40 \%$ have found no relationship, while the remaining studies have found either a positive or a negative relationship. Riksheim and Chermak (1993) analyzed these studies searching for those that pertain specifically to police officers according to service behavior, detection behavior, arrest behavior and use of force behavior and found approximately 135 articles that examine these relationships within police agencies. Approximately twenty-five studies have been conducted with respect to whether or 
not length of service has any impact on police behavior. Ten of those studies found either a positive or negative relationship while fifteen of those studies found no relationship. Meanwhile, fifty studies have been conducted that examine the relationship between attitudes of police officers and police behavior. Thirty-six of those studies found no relationship while fourteen found either a positive or negative relationship. For example, there is a positive relationship between seriousness of the offense and an officer's willingness to arrest. The more serious the offense, the more willing the officer is to make an arrest. Meanwhile, there is a negative relationship between gender of the suspect and an officer's willingness to make an arrest. Where one suspect is male and the other is female in a domestic violence situation, officers are less likely to make an arrest.

Fifty-five studies have explored the relationship between the seriousness of the crime committed and police behavior. Fifty-one of those studies found either a positive or negative relationship while four studies found no relationship. For example, where the seriousness of the crime committed is measured by weapon usage, the more serious the crime/weapon used, the more likely the officer will make an arrest as opposed to relying on mediation or referral to a third party for assistance. Departmental size has been studied five times with four of those studies finding either a positive or negative relationship (Riksheim and Chermak 1993). For example, some studies have shown that officers from smaller agencies conduct more traffic stops.

In other research, peer behavior and supervisory influence have been shown to impact officer behavior (Engel and Worden 2003). Officers with high levels of trust, cooperation, group cohesion, and social support will be more successful with community policing 
(Robinson 2003). However, officer assignment to community policing does not affect arrest rates (Novak et al. 2002). Also, studies exploring whether statutory language affects arrest rates has found mixed results (Finn et al. 2004). It is unclear whether departmental policies, such as having a proarrest policy in domestic disturbances, has an effect on officer behavior (Robinson and Chandek 2000).

One study found a relationship between negative police officer attitudes and police use of force. Officers who viewed the general public, legal restrictions, and supervisors negatively while holding favorable opinions regarding aggressive police tactics and crime fighting were more apt to use coercion in carrying out their duties (Terrill et al. 2003). The officer's attitude towards the victim has a profound affect on an officer's decision to arrest (Robinson and Chandek 2000). However, no relationship was found between police officers with authoritarian personality traits and police misconduct (Henkel and Sheehan 1997).

As for socialization effects, there has been some research that suggests the possibility of socialization impacting police misconduct. Limited research has shown a relationship between years of service and cynicism. Officers enter the force with low levels of cynicism which steadily increase during the first ten years on the force. Eventually cynicism declines somewhat creating a relatively curvilinear relationship (Hickman 2004). There is an intriguing similarity with the emergence of unethical behavior. Research shows that the average officer who commits an ethics violation is 32 years old with approximately five to ten years of law enforcement experience at the time of his/her transgression (Trautman 1997). Sociological theories that include the effects of socialization offer possible explanations of officer misconduct and are explored in the following section. 


\section{Sociological Theories and Socialization}

Sociological theories of crime and deviant behavior are useful in pursuing later analysis of socialization factors related to police culture. While deviant behavior theories are traditionally used to explain crime, deviant behavior by definition does not have to be criminal behavior. It can be any behavior considered deviant from social norms (Kornhauser 1978). Some of the misconduct explored in this study does include criminal behavior and all of the misconduct is a deviation from social norms. There are many sociological theories purporting to explain deviant behavior, however, two main theories are the basis for most other deviant behavior theories - differential association theory and social control.

Differential association theory argues that deviant behavior is learned in intimate relationships and personal groups. There are nine principles that explain deviant behavior. Individuals commit crime when they have learned "an excess of definitions favorable to violation of law over definitions unfavorable to violation of law" (Sutherland et al. 1970). Essentially, through communication, individuals learn within groups techniques, motives and rationalizations for committing deviant acts.

Not all social theorists subscribe to differential association theory. Some social scientists argue that the potential for deviant behavior is within each of us. Social control theory argues that we are all born delinquent, but controls within society constrain our behavior. Constraints on behavior can be internal or external, direct or indirect (Kornhauser 1978). Social bonds, particularly to parents, have the greatest impact on whether individuals will commit deviant acts. Hirschi describes these social bonds as attachment, commitment, involvement and belief (Hirschi 2002). 
According to social control, peers are not important, but parents are very important. Delinquents are unable to become attached to anyone, social controls are weak, and delinquents are then able to act out their innate desire to commit delinquent acts (Hirschi 2002; Kornhauser 1978). Within the context of this study, Hirschi's theory would suggest that some officers are born unethical. When these unethical officers come into departments with weak supervision and social bonds, then they commit unethical acts. Regardless of whether one is born with the desire to commit deviant acts or learns deviant behavior from others, close personal relationships dramatically impact whether individuals commit deviant acts. Hirschi's theory can be tested with the NIJ data used in this study, however, this study does not focus on Hirschi's theory. The scope of this study extends beyond Hirschi's theory. For example, Hirschi's approach somewhat contradicts Hickman's (2004) study that shows officers enter the force with low levels of cynicism. This study will explore this contradiction further in the analysis of data.

Another sociological theory suggests that deviance amongst police officers is a result of an imbalance between three key variables which include motivation, constraint and opportunity (Tittle 1995). Another study utilized the same scenarios from the NIJ study with additional control variables added to the survey instrument. The study administered the instrument to officers in Philadelphia. The results were analyzed to determine whether the amount of control that officers are subject to in relationship to the amount of control they have in their environment affects their decision to report peer misconduct (Hickman et al. 2001). The Hickman (2001) study relies on Tittle's (1995) control balance theory. This control balance theory is based on the potential deviant becoming aware of an imbalance of 
control in a given situation and using deviant behavior in order to regain control over the situation (Tittle 1995). The Hickman (2001) study did show a relationship such that officers with less control over the situation were more likely to report peer misconduct.

Therefore, officers may be impacted by poor working conditions, definitions favorable to crime and unethical behavior through intimate work relationships, weak social bonds, and/or an imbalance of motivation, constraint and opportunity (Tittle 1995). How do situational factors impact the police officer? These concepts are further explored in the following section.

\section{Situational Factors Affecting Attitudes and Behavior}

Situational variables that affect officer behavior in making arrests include the seriousness of the offense, harm to the victim, and whether or not a weapon is involved in the crime (Robinson and Chandek 2000). The decision to arrest is made expeditiously in response to a variety of situational factors including seriousness of the offense, characteristics of the suspect and the victim, harm to the victim, and the presence of a weapon. The attitudes about misconduct and an officer's decision to report misconduct reflect a different kind of decision process. It is not unreflective behavior directed at disconnected clients. The decision to report officer misconduct is made after the fact and is directed at peers. Despite these differences, the seriousness of the offense is a factor to consider in evaluating an officer's willingness to report misconduct.

Terrill and Mastrofski (2002) conducted a study that took situational determinants into consideration when observing police officers during arrests. Officers did respond to such factors as whether the suspect resisted and safety concerns. Other studies have shown 
that the more serious the offense involved, the more likely the officer will use force (Garner et al. 1996; Worden 1995; Kavanagh 1994; Friedrich 1977). These studies considered factors such as the seriousness of the offense and violent behavior of the suspect, as well as other factors such as race, intoxication of suspect, presence of bystanders, and whether the officer initiated contact.

5. Organizational Factors Affecting Attitudes and Behavior

Organizational factors such as size of agency, departmental bureaucratization, and police presence or the number of police officers patrolling within a community, have also been found to affect officer behavior (Klinger 2004). Organizational structure can also influence the ethical orientation of police officers. Van Wart (1998) argues that “organizational values are embedded in the organizational design" (Van Wart 1998, 15). Some deviant behavior happens as a result of a concerted effort of many individuals within an organization, supported by organizational internal norms, peers and supervisors. The hierarchical structure of an organization can also impact behavior within the organization. For example, Kraska and Kappeler (1997) attribute the military model with the creation of an environment that fosters the use of force.

There are essentially three primary similarities between military and police organizations. First, both institutions are highly structured, hierarchical command organizations. Each uses the same basic chain of command hierarchical structure which relies on rank for authority. Coupled with this similarity is the fact that both use similar jargon such as the names of rank and position. Finally, both institutions have similar communication structures. Each sees the flow of information within the organization as 
unidirectional - flowing from the top down through the hierarchy of authority (Hodgson 2001). The reason the military and law enforcement are so similar is a result of the direct involvement the military has had in law enforcement historically. Even today, law enforcement is directly impacted by the military. Since their inception in the mid 1960's, there has been a sharp increase in the number of Special Weapons and Tactical (SWAT) teams which are military units (Weber 1999).

Some scholars have examined the impact of size, although the findings are not conclusive. Etzioni (1975) and Slovik (1986) indicate that larger police departments result in coercive measures toward the public they serve due to a lack of adequate supervision. Chatterton (1983) adds that officers in large departments can become disconnected resulting in deviant behavior on the job. Other research demonstrates differences in behavior but does not attempt to show whether variations are inappropriate. The arrest rates for driving under the influence in very small agencies (five or fewer officers) were three times higher than arrest rates in large agencies (100 or more officers) (Mastrofski and Ritti 1996). On the other hand, research conducting in the 1970's showed that officers in larger agencies tended to arrest and use force more often than their counterparts in smaller agencies (Klinger 2004). According to these studies, it is not clear whether size of agency has a consistent impact on behavior.

Caiden and Caiden (1977) analyze organizational corruption and the relationship between the individual and the agency. Organizational corruption focuses on an agency culture where unethical acts are accepted by individuals within the organization. Unethical bureaucrats are protected and whistleblowers are not only discouraged, but punished for 
coming forward (Caiden and Caiden 1977). Adams and Balfour argue that where organizational goals and proper authority exist within an agency, the administrator's discretion in making value judgments is removed. Administrative evil occurs when administrators forget what history has shown, repackage something evil and define it as good. Administrators who forget their purpose and/or abandon their sense of accountability through neutral competence can cause great public harm (Adams and Balfour 1998).

According to Lundman (1980), in order for organizational deviance to occur, there have to be several conditions present. The deviant acts "must be contrary to norms or rules maintained by others external to the police department" and these acts "must be supported by internal operating norms which conflict with the police organization's formal goals and rules" (Lundman 1980,140). Recruitment, socialization, peers and supervisors must all support these internal operating norms of deviant behavior. These conditions combined support organizational deviance.

There is very limited research that explores Lundman's theory of organizational deviance. Cao (2000) tested Lundman's theory using citizen complaints against police officers with respect to the use of physical force and found partial support. Their study found that field training, in-service training, length of service, arrest rate, and the population size served each had an impact on the number of citizen complaints. Departments that had field training and in-service training regarding use of force had lower citizen complaint rates. The longer an officer served, the lower the complaint rate. Also, departments serving larger populations and with higher arrest rates, experienced higher citizen complaint rates (Cao et al. 2000). 
Alpert and MacDonald (2001) studied the impact that agency-level characteristics have on police use of force. Agency-level characteristics included whether an agency was accredited by the Commission on Accreditation for Law Enforcement Agencies, whether an agency was accredited by its state, whether the agency was unionized, whether an agency used data collected on use of force for management and administrative purposes, and whether use of force forms were completed by supervisors or individual officers. The study controlled for level of danger within the jurisdiction and the region within the U.S.

Alpert and MacDonald (2001) found that some agency characteristics impact an officer's use of force. Agencies that required supervisors to fill out use of force forms experienced lower rates of force by officers. Accreditation and unionization did not impact an officer's use of force, however, and those agencies that used data for management and administrative purposes experienced higher rages of force by officers. The agency characteristics utilized in the Alpert and MacDonald (2001) study are not available within the data set that is the subject of the present research, however, the results offer some partial support for the effect that organizational factors have on police behavior.

\section{Individual Factors Affecting Attitudes and Behavior}

Individual factors such as length of service, rank and job assignment affect officer behavior (McElvain and Kposowa 2004). Van Wart (1998) recognizes the impact that expertise has on the amount of discretion afforded to public administrators. Administrators with higher levels of expertise enjoy more discretion and decision-making within an agency. For example, officers and detectives are different. While detectives are considered a promotion, this position generally does not have supervisory responsibilities. Still, in a few 
studies that have looked at differences in specialization of job assignment in police agencies, no appreciable difference between how police officers carry out their duties in specialized versus non-specialized departments was found (Mastrofski et al. 1995; Novak et al. 1999).

What impact does expertise have on police officers? Controlling for race, gender, and age, officers with five to nine years of experience were twelve times more likely to be investigated for misuse of force than their colleagues who had served for twenty years or more (McElvain and Kposowa 2004). Race and gender were not found to be a significant factor in predicting misuse of force investigations, however, age and prior investigation were both significant. ${ }^{1}$ The younger the officer, the more likely to be investigated for misuse of force, and officers who had been investigated at least once were more likely to be investigated again during their careers (McElvain and Kposowa 2004). Unfortunately, there is a lack of research regarding the impact that rank, supervisory position and job assignment have on police behavior. Only a few studies have looked at differences in specialization of job assignment in police agencies and found no appreciable difference between how police officers carry out their duties in specialized versus non-specialized departments (Mastrofski et al. 1995; Novak et al. 1999).

Paoline (2001) identifies five types of police officers based on attitudes and background characteristics. These five types are Tough-Cops, Clean-Beat Crime-Fighters, Avoiders, Problem-Solvers, and Professionals. These groups affect relationships with citizens and supervisors, attitudes towards legal restrictions and community policing, and attitudes towards their role in society (Paoline 2001).

\footnotetext{
${ }^{1}$ Race, gender and age are not available in the NIJ study.
} 
Tough-Cops hold negative attitudes towards citizens, supervisors, legal restrictions, order maintenance, and community policing. This type of officer believes in pursuing the law enforcement role, aggressive policing and only handling serious violations. Clean-Beat Crime-Fighters are similar to Tough-Cops, but value legal restrictions, order maintenance, and pursuing all types of illegal behavior (Paoline 2001).

Avoiders are also like Tough-Cops, but they are neutral in their attitudes towards supervisors. Avoiders, as the name implies, avoid work and aggressive behavior in order to keep from drawing attention to themselves. Problem Solvers and Professionals have positive relationships with citizens and supervisors. Both value order maintenance and community policing. Problem-Solvers, however, see legal restrictions as an impediment to their work and are neutral in their attitude toward their role in enforcing the law. Problem-Solvers also believe in focusing their energies on serious problems (Paoline 2001).

Paoline's research questions the single moral order concept of police culture. He highlights the differences in attitudes within police culture and identifies an additional seven subcultures in his research. Van Maanen (1973) analyzes stages of cultural socialization for police officers instead of categorizing officers as Paoline and Wilson have done. According to Van Maanen (1973), there are four stages of police socialization into the organization which include a pre-entry choice, introduction, encounter and metamorphosis stages.

The first stage, pre-entry choice, acknowledges the individual's choice to become a police officer. This stage recognizes that most individuals who choose to become police officers hold similar values as those values held within the law enforcement profession. The second stage, introduction, involves the new recruit's training phase within formal 
instruction. The third stage, encounter, includes the new recruits on-the-job training with a senior police officer once initial new recruit training is completed. In the final stage, metamorphosis, the officer adapts to the nature of police work and is impacted by peer reinforcement of group norms.

While these four stages were first created over thirty years ago, the stages are still accurate today (Adcox 2000). The stages focus on the beginning of an officer's career where the primary socialization occurs. An officer's ethical decision making is most impacted within stage three. Relying in part on Sykes (1994), Adcox highlights the importance of stage three:

These initial experiences can either set the stage for ethical behavior or teach the rationalization of inappropriate conduct. The actions of others speak far louder than any written policy, and the peer group becomes the most powerful conveyor of the unwritten code of conduct (Adcox 2000, 22).

Stage three, or the period when officers are receiving on-the-job training, is critical to the development of an officer's ethical decision making. Stage three is when peers inculcate norms or as Adox characterizes it, the "unwritten code of conduct" (Adcox 2000, 22). Individual and organizational factors impact individual attitudes and values shaped by the organization's structure and culture. These factors impact officers through hiring, socialization, and training. The following section explores the organizational culture of police agencies.

\section{B. Organizational Culture}

Wilson (1989) explains that bureaucratic behavior depends upon the bureaucratic culture which includes "the situations they encounter, their prior experiences and personal beliefs, the expectations of their peers, and the array of interests in which their agency is 
embedded" (Wilson 1989, 27). There are numerous definitions of culture. Most definitions highlight the importance of attitudes, as well as the situationally dependant nature of bureaucratic behavior. Paoline (2001) utilizes a culmination of various definitions including "attitudes and values that are shared and socially transmitted among groups of people, in an attempt to cope with common problems and/or situations" (Paoline 2001, 7). Van Wart (1998) defines professional culture as one that is "expressed in norms, symbols, and a worldview" (Van Wart 1998, 63). What, then, is the organizational culture of law enforcement?

Wilson (1968) introduced the concept of the "bureaucracy problem" which is getting street-level bureaucrats to do the right thing. Wilson's (1968) study involved observing patrolmen in eight communities and describing their daily routine behavior. The study identifies three styles of policing - the watchman, legalistic and service styles. Each style guides the officer in the administration of daily duties (Wilson 1968).

Wilson's theories regarding policing styles has been extremely influential on the study of police culture. His study, however, was conducted over 35 years ago and limited to a highly selective sample of eight agencies in the Northeastern United States. As previously discussed, the role of the police officer in the U.S. has changed dramatically over time. Community policing is the latest change affecting the delivery of police services. Wilson's styles of policing are complimentary to the community policing model, however, the service style of policing is most congruent with community policing. This study does not analyze the impact of community policing on Wilson's styles of policing, however, as the data is not sufficient to explore these possibilities.

Smith (1984) has shown some support for Wilson's theory that arrest rates are 
affected by the level of professionalization and bureaucratization in a police agency. Smith (1984) examined sixty police agencies regarding professionalism and bureaucratization. Bureaucratization and professionalism did impact how officer's perform their duties, however, most of Wilson's theories, in particular the influence of local political culture, were not supported in Smith's study. Wilson (1968) defines political culture in four categories which include high-professional council-manager, low-professional councilmanager, nonpartisan mayor council, and partisan mayor-council. Wilson (1968) theorized that these forms of local government impacted the style of policing within the corresponding local police department. Wilson (1968) found support for his theory, however, since then several studies have been unable to support Wilson's theory (Hassell et al. 2003; Langworthy 1986; Smith 1984).

There are other public administration theories regarding public sector culture that are not specific to police culture, but are useful here. One such theory identifies four types of organizational culture and the impact each has on its members. These four types include rational cultures, hierarchical cultures, group or team cultures, and adaptive cultures. These organizational culture types are derived from the competing values approach (CVA) developed by Quinn and Rohrbaugh (1981). CVA is a framework argues that where values compete within an organization, there is conflict. When an organization favors one value it is to the detriment of the corresponding competing value. (Quinn and Rohrbaugh 1981).

Buenger et al. (1996) tested Quinn and Rohrbaugh's competing values within the Air Force. The study found support for CVA. Where an agency placed emphasis on one value, the corresponding competing value received less attention than its counterpart. Previous 
studies have found support for CVA in modeling organizational forms and studying leadership styles (Quinn and Rohrbaugh 1983; Quinn and Hall 1983; Quinn 1984).

The data available for analysis in this study does not permit examining the organizational differences explored in this section. The present study will address differences in officer attitudes at different stages of their careers through length of service and rank. The section that follows explores the officer's socialization process further. In the section that follows, an officer's attitudes, values and norms are investigated to determine how these characteristics exist and how they are shaped within the police culture.

1. The Individual Police Officer and the Socialization Process

There is conflicting research regarding the impact the socialization process has on an officer's ethical orientation. Recent research indicates that new recruits have a significantly different ethical perspective from that of seasoned officers. According to Catlin and Maupin (2004), new recruits tend to be idealistic in their ethical orientation while officers who have been on the job for at least one year are more relativistic in their ethical orientation. This difference highlights the importance of how officer's are hired, formally trained, and ultimately integrated into the police culture.

An officer's personality, the hiring process and their formal training each play a role in shaping the ethical decision-making of this street-level bureaucrat (Lyman 1999; Kappeler 1998). The officer's personality can be measured through the Myers-Briggs Type Indicator (MBTI). Stages of moral development are commonly measured through the Defining Issues Test (DIT). These two tests are not commonly utilized in the hiring process for police officers (Hughes 2003). Whether these tests should be used in hiring decisions is not the 
subject of this study, however, these tests do offer insight into the police officer psyche. This section explores the police officer's personality including research regarding their stages of moral development and MBTI results, as well as current screening practices for hiring law enforcement and formal training.

\section{(a) Moral Development}

Klockars et al. (2004) has shown that ethical awareness is a major factor in affecting ethical behavior, and this research will examine this relationship in depth. For background, it is important to understand how ethical awareness is formed in the individual. Lawrence Kohlberg (1984) proposed a theory of moral development with six stages. During the first two pre-conventional stages, the individual makes ethical decisions based on whether they will be punished and the concept of reciprocity. Decisions rest on external concerns and not standards or norms. The next two conventional stages are marked by moral values, right and wrong, expectations of others, maintaining the social order and a sense of duty to others. The final two post-conventional stages are characterized by rules, legality, duty of contract, mutual trust and respect, and utilitarianism.

Kohlberg's stages of moral development have been validated across cultures, age, and gender using primarily a written instrument, sometimes combined with personal interviews. There has been some discussion in the literature regarding whether there is a gender bias in the instrument, however, testing has validated the instrument to be between $70 \%$ and $80 \%$ reliable (Kohlberg 1984). The written instrument currently used was developed by Rest, Narvaez, Thoma and Bebeau (2000) and is known as the Defining Issues Test 2 (DIT 2). The DIT 2 consists of three moral dilemma scenarios followed by a series of 
questions regarding what outcome the respondent will choose and ranking their reasoning for choosing that particular outcome. Questions are assigned scores based on how respondent's rank their responses (Kohlberg 1984). The DIT has been administered to individuals of various professions and ages. Generally, as individuals age, as their IQ increases, and/or as they advance through their education, they progress through the stages of development.

Nolan (2000) applied Kohlberg's stages of moral development to police officers in Boston. The study tested new recruits, as well as seasoned officers, some who had been subjected to specialized ethics training. The findings indicated that respondents fell in the conventional stage of Kohlberg's moral development scale. There was no difference between officers who had received specialized training and those who had not in the study (Nolan 2000). Unfortunately, the study did not explore the implications of its results with respect to police misconduct.

The Nolan dissertation did find that the police officer participants had high Stage 4 scores in Kohlberg's stages of moral development. Stage 4 is characterized by making moral decisions based on rules, laws and regulations. Individuals who score high in stage 4 are interested in duty and social order, self-respect and societal obligations. The Nolan dissertation also found that participant officers scored at the level of moral development equal to an American child between the ages of eleven and thirteen (Nolan 2000).

Stewart and Sprinthall (1994) adapted Kohlberg's instrument to the public administration environment. The Stewart-Sprinthall Management Survey (SSMS) was administered to 485 public managers with most administrators falling within stage 4 and the highest stage, the principled stage which includes stages 5 and 6 . The tendency was for 
administrators to rely on stage 4 reasoning (Stewart and Sprinthall 1994).

What is the significance of stage 4 moral development for public administrators? Stewart and Sprinthall (1991) observe that stage 4 development "may provide some protection against the ruthless exploitation for personal gain" or lower stage reasoning, but "it may also provide a built-in resistance to learning principled reasoning" (Stewart and Sprinthall 1991, 253). Stewart and Sprinthall also note that Rohr (1978) would characterize stage 4 reasoning as "low road" decision making within administrative ethics. The next question becomes what factors influence the stages of moral development?

Studies have shown that age, IQ, occupation and education are the biggest factors impacting an individual's progression through the stages of moral development (Rest et al. 2000). The more education one has and the older one gets, the higher the level of moral development for the average adult (Wilson 1992). Some occupations actually foster moral development through positive mentoring practices like the study of medicine resulting in the advancement of doctors through the stages of moral development (Coleman and Wilkins 2002).

The Nolan DIT results correspond with the personality characteristics found in police officers through the MBTI. Lynch and McMahon (1984) found that law enforcement officers are Introverted, Sensing, Thinking and Judging (ISTJ). This combination includes individuals who are dependable, decisive, quiet, serious, thorough, detail-oriented, and logical. Sensing and Judging (SJ) individuals are responsible, duty bound, and feel a sense of obligation within society. They are known as society's stabilizers. The SJ is talented at "establishing policies, rules, schedules, routines, regulations and hierarchy" (Lynch and 
McMahon 1984, 14).

It is not surprising that police work would attract individuals who are rule-oriented in their personalities and level of moral development. The selection of individuals who meet organizational expectations may influence the socialization process as those with similar attitudes will be hired making socialization within the police culture easier (Bowen et al. 1991; Kristof-Brown 2000). What is surprising is that the moral development of police officers in the Nolan study ranked fairly low in comparison to other professions such as enlisted men in the Navy. The Nolan study respondents ranked at the same level as prison inmates (Coleman and Wilkins 2002). $\quad$ One would hope that the hiring process would screen out questionable moral development in potential cadets. The hiring process for police officers varies greatly across the U.S. Ideally, a department will take past behavior of the applicant into consideration, as well as age, IQ and education. Unfortunately, not all departments make intelligent hiring decisions. For example, one police applicant scored highly in cognitive ability during the hiring process and was denied employment on this basis (Hughes 2003). Normally, applicants who do well on hiring tests are accepted for employment on that basis, not denied for that very reason.

Authoritarian personality has been a major concern among scholars and observers of police behavior. There are several views of the origins of authoritarian attitudes in police behavior. One study found that the police do not necessarily attract persons with authoritarian personalities (Brown and Willis 1985). Authoritarianism may be linked to the demands placed on officers by their agency, an officer's job assignment, amount of contact with the general public, rank, and length of service (Carlson and Sutton 1975, Lefkowitz 
1974, Genz and Lester 1976, Hageman 1979, McNamara 1967). Many scholars argue that police officers take on authoritarian personalities after less than two years on the job (McNamara 1967). Authoritarian personalities are shaped by circumstances as opposed to socialization such as exposure to conflict, contact with the public, lower rank, and exposure to high crime areas. Henkel and Sheehan (1997) tested whether authoritarianism is the greatest factor influencing police misconduct. Henkel and Sheehan, however, found no support in their research for the hypothesis that authoritarianism is the greatest factor influencing police misconduct. If officers do harbor authoritarian attitudes, there is no support that these attitudes influence their behavior.

\section{(b) Training}

Even without screening out individuals in the hiring process who are not functioning at a high level of moral development, an agency could utilize training in order to promote an ethical work environment. Although the data set used in his analysis does not permit directly examining the effect of training, it is important to briefly review the general state of training in police departments. According to Trautman (2000), ethics training is rarely, if ever, conducted internally within police departments. A 1997 survey of ethics training for law enforcement discovered that over $70 \%$ of respondents offered four hours or less of ethics training (IACP 1998). Over $83 \%$ of respondents indicated that they offered ethics training to new officers and approximately $72 \%$ of agencies offer ethics training beyond new recruit training (IACP 1998).

Sherman (1982), Hodgson (2001), and Harrison (1999) each reveal that learning ethical decision-making for police officers most often occurs on-the-job with no time for the 
officer to reflect during the heat of the battle. Each author argues, however, that ethics education during Basic Law Enforcement Training (BLET) is preferable to give the officers an opportunity to work through ethical dilemmas prior to facing similar situations at work (Sherman 1982, Hodgson 2001, Harrison 1999).

Training that occurs after BLET is commonly referred to as In-Service Training (IST) and consists of a variety of topics, sometimes related to ethics. Unfortunately, some police administrators view IST ethics training as problematic. These administrators fear that requiring ethics training may make the administrator look incompetent (Trautman 2000). In other words, administrators who need to place their officers in ethics training must have unethical officers and/or must be bad leaders. An informal interview of a colleague revealed that while some departments may offer ethics training as IST, attendance is not required by officers.

In the 1992 national training package created by the Central Planning and Training Unit for police officers, no "explicit reference to the significance of ethics" was made with respect to investigative interviewing techniques utilized by police officers (Newton 1998). Trautman (2000) argues that a lack of ethical training, in general, is a recipe for corruption. Training and education in ethics for law enforcement is paramount to avoiding corruption (Harrison 1999). Donahue and Felts (1993) support this view and asserts that police ethics are in a state of crisis and ethical training is needed.

There seems to be a consensus that working through real life problems is the best ethics training for law enforcement. Relying on Sherman, Delattre (2002) supports ethics training that focuses on the value choices that law enforcement officers make and general 
ethical dilemmas that officers face in their day-to-day work. Kleinig (1999) suggests that simply relying on codes of ethics in training is not enough. Bristow (1975) and Kleinig (1999) advocate linking the police code of ethics with actual real-life problems and cases to help officers work through ethical dilemmas and issues in the classroom. Trautman (2000), Donahue and Felts (1993) also support open discussion and ethical-dilemma simulation training.

While there is some consensus regarding ethics training for law enforcement, there is also some diversity of opinion with respect to emphasis of material and training techniques advocated by different scholars. Not all scholars agree that codes of ethics should be the focus of law enforcement ethics training (IACP In-Service Training Manual). Meanwhile, Crawshaw (1998) advocates that law enforcement rely on codes of ethics for guidance in ethical decision-making. Donahue and Felts (1993) would agree with this analysis as they focus on codes as ethical guidance for officers. Crawshaw (1998) suggests using video tape recording, not only as evidence in interviewing suspects, but also as a training tool for officers to review interviewing techniques with their supervisors. No other literature mentions the use of video tape recording in their training. Trautman (2000) advocates implementing mandatory internal ethics training in every police department, however, this view is not mentioned by others.

\section{The NIJ Study, Ethical Awareness, Standards, and Action}

The fundamental questions that this study seeks to analyze revolve around the ethical attitudes of police officers and the impact these attitudes have on the officer's willingness to take one form of action. These attitudes are grounded in the officer's awareness of ethical 
and unethical behavior within the context of the officer's work environment. An individual's ethical awareness is derived from the individual's values and moral character. Ethical awareness is the basis for an individual's attitudes towards rules, regulations, and policy. An individual's ethical awareness ultimately determines whether an individual will take ethical action. The police officer's ethical awareness reflects the officer's cognizance of ethical and unethical behavior, as well as the rules, regulations, and policy of the agency. The rules, regulations and policy provide the backdrop, but the "working" standards by which the officer serves are those that he or she will apply to instances of misconduct. Combined, awareness and standards impact whether the individual is willing to take action (Truelson 1991; Guy 1991; Huddleston and Sands 1995).

Klockars (2004) has shown that ethical awareness is related to ethical standards and action. In this study, the analysis starts with an examination of the nature of the ethical awareness itself. Although it is clear that officers favor discipline and are more likely to report an offense if they believe that it is very serious, how do the attitudes of the police officers about seriousness compare to objective measures?

According to Lipsky (1980), police officers face limited resources, non-voluntary clients, ambiguous goals, inadequate performance measures, and alienation coupled with a great deal of discretion in carrying out duties. The officer's organizational culture, attitudes and behavior of supervisors and coworkers impact how the street-level bureaucrat handles the ethical decision making process. This study analyzes the attitudes and behavior of police officers in order to shed some light on their ethical decision making process. 


\section{CHAPTER THREE}

Research Methodology: Measuring Attitudes Towards Police Misconduct 
This study uses secondary analysis of data from a NIJ study conducted in 1997 . The NIJ study did not utilize random sampling in its data collection, but collected data from agencies based upon prior relationships and convenience. The authors do not indicate how many agencies were invited to participate, however, included in the NIJ study are agencies from eleven different states which are not identified in order to honor promises of anonymity made during administration of the instrument (Klockers et al. 2000). This lack of random sampling creates both an internal validity selection bias issue and an external validity issue. Thus, statistical significance cannot be established from data analysis and results may not be generalized to police officers in the United States.

However, this data set is unique. The survey instrument for the NIJ study was completed by 3,237 officers from 30 police agencies in the United States (Klockers et al. 2000). The study received a 55.5\% overall response rate. The size of the data set, the number of variables, and the subject matter are extremely valuable. The sampling unit for this study is the individual level and the agency level. The NIJ study also collected data at both the individual level and at the agency level. As the sample is a convenience sample and not random, this sample is treated as a population. ${ }^{2}$

In police agencies where officers rank misconduct as very serious, then officers are more willing to report peers for misconduct. There was very little difference between the officer's individual attitude towards the misconduct and what they believed their peer's attitudes would be towards the misconduct (Klockars et al. 2004). Unfortunately, the

\footnotetext{
${ }^{2}$ Tests of significance are used for illustrative purposes in subsequent chapters despite this limitation.
} 
Klockars study did not analyze the strength of the relationships, only a comparison of means. ${ }^{3}$

\section{A. The Instrument}

The instrument used by the NIJ captured police officer attitudes towards police misconduct. As mentioned in Chapter One, this study has been administered to over 10,000 officers worldwide thus bolstering content validity (Klockars et al. 2004). Asking officers directly whether they have engaged in unethical behavior yields mixed results, as most people are reluctant to admit to unethical behavior. Officer attitudes towards misconduct, on the other hand, yields more reliable results. The author claims that two additional questions asking officers whether they have been truthful and whether they believe their peers have been truthful increased reliability of the instrument. The independent variables available in this study are the agency size, job assignment, supervisory status, rank, length of service, knowledge of existing policy, and perception regarding peer attitudes and behavior. The dependent variables are an officer's ethical awareness, ethical standards and ethical action. A copy of the instrument is attached as Appendix C.

The authors selected police agencies and collected data from individual respondents. The NIJ report examines corruption by asking hypothetical questions regarding misconduct. Officers are more likely to respond to questions that do not ask officers directly whether they have been a party to corrupt behavior. The NIJ study asks officers for their perceptions regarding agency rules, corresponding punishment, and willingness to report a peer's unethical behavior (Klockars et al. 2000).

${ }^{3}$ Dr. Carl Klockars passed away on July 24, 2003, precluding additional analysis and publication on this topic. 
This research study will analyze the NIJ data using advanced statistical tools. To date, the NIJ data has been used to prepare descriptive studies that present the mean scores for questionnaire responses. One study exploring traditional sociological theories of crime and deviant behavior has utilized advanced statistical tools in analyzing the NIJ data (Hickman et al. 2001). The present study expands the analysis to examine the NIJ data in the context of public administration literature as it relates to street level bureaucrats and policing.

The survey instrument used in the NIJ study included eleven case scenarios describing police misconduct. The case scenarios involve behaviors that range from not very serious, to intermediately serious, to very serious in nature. Some of the activities included in the case scenarios are conflict of interest, bribery, theft and excessive force (Klockers et al. 2000). The first scenario, depicting a conflict of interest regarding off-duty employment, will not be utilized in this research, because it is not necessarily depicting misconduct. Many departments have policies regarding off-duty employment, however, most do not have a policy that such employment is a conflict of interest (Brunet 2005).

Content validity is supported by the methods used to create the scenarios. The scenarios were created to be culturally neutral by avoiding the mention of specific holidays and currency amounts. Respondents were asked to assume that the police officers depicted in each scenario had five years of service and no previous disciplinary problems. Some of the case scenarios relied on previously published studies using the case scenario approach (Klockars et al. 2000). Figure 3.1 below presents the case scenarios and the corresponding IACP National Law Enforcement Standards of Conduct violation: 
Figure 3.1:

Case Scenarios from the Survey Instrument and Relevant IACP Standards of Conduct 


\begin{tabular}{|c|c|}
\hline $\begin{array}{c}\text { Case } 1 \\
\text { busin }\end{array}$ & $\begin{array}{l}\text { A police officer runs his own private business in which he sells and installs } \\
\text { security devices, such as alarms, special locks, etc. He does this work during his } \\
\text { off-duty hours. } \\
\text { Does not violate any standard }\end{array}$ \\
\hline $\begin{array}{l}\text { Case } 2 \\
\text { meals }\end{array}$ & $\begin{array}{l}\text { A police officer routinely accepts free meals, cigarettes, and other items of small value } \\
\text { from merchants on his beat. He does not solicit these gifts and is careful not to abuse } \\
\text { the generosity of those who give gifts to him. } \\
\text { IV.A. } 8 \text { (a) Officers shall report any unsolicited gifts, gratuities, or other items of } \\
\text { value they receive and shall provide a full report of the circumstances of their } \\
\text { receipt if directed. }\end{array}$ \\
\hline $\begin{array}{l}\text { Case } 3 \\
\text { speed }\end{array}$ & $\begin{array}{l}\text { A police officer stops a motorist for speeding. The officer agrees to accept a personal } \\
\text { gift of half of the amount of the fine in exchange for not issuing a citation. } \\
\text { IV. A. } 8 \text { (b) Officers shall not use their authority or position for financial gain, for } \\
\text { obtaining or granting privileges or favors not otherwise available to them or others } \\
\text { except as a private citizen, to avoid the consequences of illegal acts for them selves } \\
\text { or for others, to barter, solicit, or accept any goods or services whether for the } \\
\text { officer or for another. }\end{array}$ \\
\hline $\begin{array}{l}\text { Case } 4 \\
\text { holi }\end{array}$ & $\begin{array}{l}\text { A police officer is widely liked in the community, and on holidays local merchants and } \\
\text { restaurant and bar owners show their appreciation for his attention by giving him gifts } \\
\text { of food and liquor. } \\
\text { IV.A. } 8 \text { (a) Officers shall report any unsolicited gifts, gratuities, or other items of } \\
\text { value they receive and shall provide a full report of the circumstances of their } \\
\text { receipt if directed. }\end{array}$ \\
\hline $\begin{array}{l}\text { Case } 5 \\
\text { burg }\end{array}$ & $\begin{array}{l}\text { A police officer discovers a burglary of a jewelry shop. The display cases are smashed } \\
\text { and it is obvious that many items have been taken. While searching the shop, he takes } \\
\text { a watch, worth about two days pay for that officer. He reports that the watch had been } \\
\text { stolen during the burglary. } \\
\text { IV. A. } 1 \text { (a) Officers shall not violate any law or any agency policy, rule or } \\
\text { procedure. } \\
\text { IV. A. } 8 \text { (c) Officers shall not purchase, convert to their own use, or have any claim } \\
\text { to any found, impounded, abandoned, or recovered property, or any property held or } \\
\text { released as evidence. }\end{array}$ \\
\hline $\begin{array}{l}\text { Case } 6 \\
\text { auto }\end{array}$ & $\begin{array}{l}\text { A police officer has a private arrangement with a local auto body shop to refer the } \\
\text { owners of the cars damaged in the accidents to the shop. In exchange for each referral, } \\
\text { he receives a payment of } 5 \% \text { of the repair bill from the shop owner. } \\
\text { IV.A. } 8 \text { (e) Officers are prohibited from using information gained through their } \\
\text { position as a law enforcem ent officer to advance financial or other private interests } \\
\text { of them selves or others. }\end{array}$ \\
\hline
\end{tabular}




\begin{tabular}{|c|c|}
\hline $\begin{array}{l}\text { Case } 7 \\
\text { super }\end{array}$ & $\begin{array}{l}\text { A police officer, who happens to be a very good auto mechanic, is scheduled to work } \\
\text { during coming holidays. A supervisor offers to give him these days off, if he agrees to } \\
\text { tune-up his supervisor's personal car. Evaluate the SUPER VISOR'S behavior. } \\
\text { IV. A. } 8 \text { (b) Officers shall not use their authority or position for financial gain, for } \\
\text { obtaining or granting privileges or favors not otherwise available to them or others } \\
\text { except as a private citizen, to avoid the consequences of illegal acts for them selves } \\
\text { or for others, to barter, solicit, or accept any goods or services whether for the } \\
\text { officer or for another. }\end{array}$ \\
\hline $\begin{array}{l}\text { Case } 8 \\
\text { alch }\end{array}$ & $\begin{array}{l}\text { At } 2 \text { A.M. a police officer, who is on duty, is driving his patrol car on a deserted road. } \\
\text { He sees a vehicle that has bean driven off the road and is stuck in a ditch. He } \\
\text { approaches the vehicle and observes that the driver is not hurt but is obviously } \\
\text { intoxicated. He also finds that the driver is a police officer. Instead of reporting this } \\
\text { accident and offense he transports the driver to his home. } \\
\text { IV. A. } 8 \text { (b) Officers shall not use their authority or position for financial gain, for } \\
\text { obtaining or granting privileges or favors not otherwise available to them or others } \\
\text { except as a private citizen, to avoid the consequences of illegal acts for them selves } \\
\text { or for others, to barter, solicit, or accept any goods or services whether for the } \\
\text { officer or for another. }\end{array}$ \\
\hline & $\begin{array}{l}\text { A police officer finds a bar on his beat which is still serving drinks a half hour past its } \\
\text { legal closing time. Instead of reporting this violation, the police officer agrees to } \\
\text { accept a couple of free drinks from the owner. } \\
\text { IV. A. } 8 \text { (b) Officers shall not use their authority or position for financial gain, for } \\
\text { obtaining or granting privileges or favors not otherwise available to them or others } \\
\text { except as a private citizen, to avoid the consequences of illegal acts for them selves } \\
\text { or for others, to barter, solicit, or accept any goods or services whether for the } \\
\text { officer or for another. } \\
\text { It is not clear whether the free drinks are consumed while on duty. If so, these } \\
\text { standards would also apply: } \\
\text { IV. A. } 6 \text { (a) Officers shall not consume any intoxicating beverage while on duty } \\
\text { unless authorized by a supervisor. } \\
\text { IV. A. } 6 \text { (c) An officer shall not be under the influence of alcohol in a public place, } \\
\text { whether on or off duty. }\end{array}$ \\
\hline $\begin{array}{l}\text { Case } 10 \\
\text { force }\end{array}$ & $\begin{array}{l}\text { Two police officers on foot patrol surprise a man who is attempting to break into an } \\
\text { automobile The man flees. They chase him for about two blocks before apprehending } \\
\text { him by tackling him and wrestling him to the ground. After he is under control both } \\
\text { officers punch him a couple of times in the stomach as punishment for fleeing and } \\
\text { resisting. } \\
\text { IV.A. } 5 \text { (c) While recognizing the need to demonstrate authority and control over } \\
\text { criminal suspects and prisoners, officers shall adhere to this agency's use-of-force } \\
\text { policy and shall observe the civil rights and protect the well-being of those in their } \\
\text { charge. }\end{array}$ \\
\hline
\end{tabular}




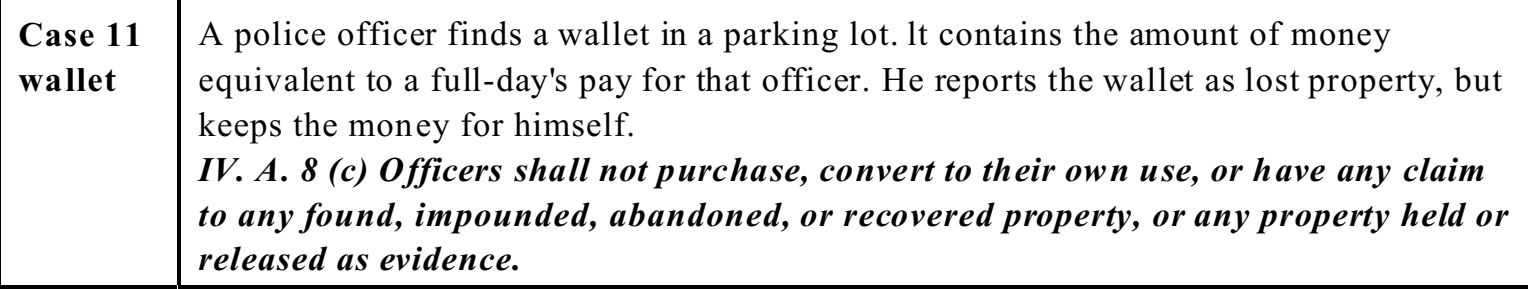

There are several general standards of conduct that apply to the scenarios including a provision that prohibits officers from violating the law. Officers are also not allowed to engage in conduct that would discredit the officer and/or the agency. It could be argued that one provision, in particular, applies to Case 8 that prohibits officers from interfering with or thwarting an internal or criminal investigation.

Each case scenario is followed by seven questions capturing the police officer's opinion regarding the misconduct scenario. Two questions asked officers to rate the seriousness of the case scenario from their own perspective and that of their peers. Two additional questions addressed what disciplinary action the officer felt should be taken and what disciplinary action the officer felt would be taken in the case scenario. The officer's willingness to report the misconduct was another question, as well as a question regarding whether the officer felt their peer's would report the misconduct. A final question addressed whether the officer believed the misconduct was a violation of their agency's official policy (Klockers et al. 2000). Figure 3.2 includes the questions, possible responses, and corresponding coding: 


\begin{tabular}{|c|c|}
\hline Abbreviations & Questions and Possible Responses \\
\hline \multirow[t]{2}{*}{ OS } & How serious do YOU consider this behavior to be? \\
\hline & 1 not at all serious - 5 very serious \\
\hline \multirow[t]{2}{*}{ MS } & $\begin{array}{l}\text { How serious do MOST POLICE OFFICERS IN YOUR AGENCY consider } \\
\text { this behavior to be? }\end{array}$ \\
\hline & 1 not at all serious -5 very serious \\
\hline \multirow[t]{2}{*}{ VI } & $\begin{array}{l}\text { Would this behavior be regarded as a violation of official policy in your } \\
\text { agency? }\end{array}$ \\
\hline & 1 definitely not - 5 definitely yes \\
\hline \multirow[t]{2}{*}{ OR } & $\begin{array}{l}\text { Do you think YOU would report a fellow police officer who engaged in this } \\
\text { behavior? }\end{array}$ \\
\hline & 1 definitely not -5 definitely yes \\
\hline \multirow[t]{2}{*}{ MR } & $\begin{array}{l}\text { Do you think MOST POLICE OFFICERS IN YOUR AGENCY would report } \\
\text { a fellow police officer who engaged in this behavior? }\end{array}$ \\
\hline & 1 definitely not - 5 definitely yes \\
\hline \multirow[t]{2}{*}{ OD } & $\begin{array}{l}\text { If an officer in your agency engaged in this behavior and was discovered doing } \\
\text { so, what if any discipline do YOU think SHOULD follow? }\end{array}$ \\
\hline & $\begin{array}{l}1 \text { none, } 2 \text { verbal reprimand, } 3 \text { written reprimand, } 4 \text { period of suspension } \\
\text { without pay, } 5 \text { demotion in rank, } 6 \text { dismissal }\end{array}$ \\
\hline \multirow[t]{2}{*}{ MD } & $\begin{array}{l}\text { If an officer in your agency engaged in this behavior and was discovered doing } \\
\text { so, what if any discipline do YOU think WOULD follow? }\end{array}$ \\
\hline & $\begin{array}{l}1 \text { none, } 2 \text { verbal reprimand, } 3 \text { written reprimand, } 4 \text { period of suspension } \\
\text { without pay, } 5 \text { demotion in rank, } 6 \text { dismissal }\end{array}$ \\
\hline
\end{tabular}

Figure 3.2: Questions, Possible Responses, and Coding from the Survey Instrument

The question asking respondents to consider how serious the behavior is will measure the officer's ethical awareness. The question regarding what discipline should follow from an officer engaging in the behavior will measure the officer's ethical standards. The question addressing the respondent's willingness to report the behavior will measure the officer's action. While these questions alone do not adequately measure awareness, standards, and 
action completely, they do provide partial measures. Relying on partial measures reduces construct validity, however, the NIJ researchers did not collect multiple measures nor did they use multiple methods in gathering their data.

The questions regarding what the respondent believes would be the responses of their peers to seriousness, punishment, and reporting allow a discrepancy measure. Whether or not there is a policy in a given agency is not as important as the respondent's knowledge of the existence of such policies and the certainty of that knowledge given the respondent's length of service and rank.

Finally, the survey asked officers general questions regarding their background and context, including rank, assignment of duties, and size of agency. Figure 3.3 includes the general background questions, possible responses, and corresponding abbreviations: 


\begin{tabular}{|l|l|}
\hline Abbreviation & \multicolumn{1}{|c|}{ Questions and Possible Responses } \\
\hline lengthg & How many years have you been a police officer? \\
\hline lengthpp & Hess than 1;1-2; 3-5; 5-10; 11-15; 16-20; over 20 \\
\hline rank & \begin{tabular}{l} 
Less than 1; 1-2; 3-5; 5-10; 11-15; 16-20; over 20 \\
\hline What is your rank?
\end{tabular} \\
\hline assign & $\begin{array}{l}\text { Recruit, Corporal, Lieutenant, Colonel, Officer, Deputy, Detective IO, sergeant, } \\
\text { Which of the following best describes your current assignment? }\end{array}$ \\
\hline agency & $\begin{array}{l}\text { Patrol, Detective/Investigative, Special Operations (vice. juvenile. etc.), } \\
\text { Communications, Administrative, Other }\end{array}$ \\
\hline supervis & $\begin{array}{l}\text { Are you a supervisor or non-supervisor? } \\
\text { Lery Large Municipal Police (more than 500 sworn officers), } \\
\text { Volice (76-200 sworn officers), Small Municipal Police (25-75 sworn officers), } \\
\text { State Police, Sheriff, County Police }\end{array}$ \\
\hline & \begin{tabular}{l} 
Non-Supervisor, Supervisor (unit supervisor, group supervisor, chief/sheriff) \\
\hline
\end{tabular} \\
\hline
\end{tabular}

Figure 3.3: Background Questions, Possible Responses, Corresponding Abbreviations 


\section{B. $\quad$ Statistical Analysis}

This research study seeks to identify the relationship between a police officer's attitude towards misconduct and whether that officer is willing to report peer misconduct. The appropriate statistical analysis tools include crosstabs, gamma, and regression. While gamma establishes the relationship between variables, multiple regression assesses the relative strength of this relationship. Multiple regression can also be used to determine the predictive nature of the independent variables with respect to the dependent variable in this study (Tabachnick and Fidell 2001).

1. Variables

The hypotheses explored in this study address the fundamental question of whether there is a relationship between officer characteristics, attitudes regarding misconduct, and an officer reporting the unethical behavior of peers. The variables that are available for analysis within this data include officer attitudes regarding misconduct, officer attitudes regarding agency misconduct policies, officer attitudes regarding reporting peer misconduct, rank, supervisory position, length of service within an agency, length of service within law enforcement, job assignment, and agency size. Background questions about officers are limited in order to protect confidentiality. Therefore, questions indicating sex and race were left off of the NIJ survey instrument (Klockars et al. 2004).

Figure 3.4 Percentages of Respondents and Supervisors by Agency Size explores the characteristics of respondents within the NIJ study. These characteristics are defined by the NIJ study. Over $70 \%$ of respondents work in very large agencies (over 500 sworn officers) while approximately 7\% of respondents work in large agencies (between 201-500 sworn 
officers). About $11 \%$ of respondents work in medium size agencies (76-200 sworn officers), $6.8 \%$ work in small agencies ( $25-75$ sworn officers), and the remaining less than $3 \%$ work in very small agencies (less than 25 sworn officers). The typical respondent has been an officer for approximately 10 years. Officers who work in patrol or traffic comprise $66.7 \%$ of respondents. One in five respondents is a supervisor. There was only one sheriff agency respondent and only one county police respondent in this study and so these agencies were added to the corresponding agency size. 


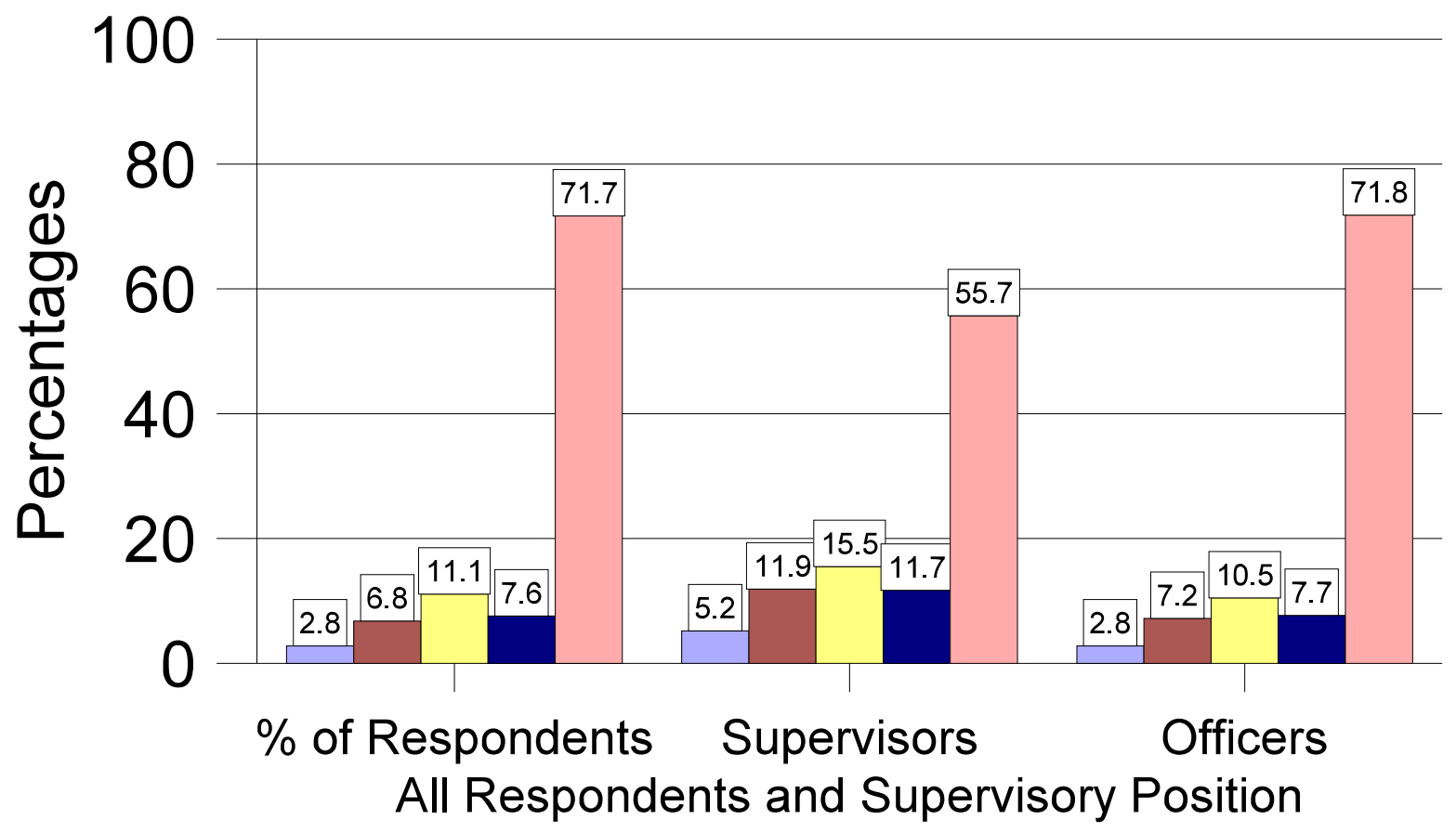

Agency Size

$\square$ Very Small less than
Small $25-75$
Medium $76-200$
Large 201-500
Very Large over 500

Figure 3.4

Percentages of Respondents and Supervisors by Agency Size - Number of Sworn Officers 
Several of the hypotheses explore whether an officer who is not promoted will view misconduct more or less favorably than an officer who is promoted. An officer may achieve various levels of rank during their career. Not all agencies utilize each of the ranks explored in this study. Each agency can use rank in a different hierarchical order and some ranks can be combined (i.e. lieutenant colonel). Rank within police agencies is similar to military organizations.

The ranks included in this study are listed in the table below and are in as close to ascending order as possible given rank inconsistencies nationwide. Officers include officers, deputies, and corporals who are not supervisors. Detectives include detectives and investigators only. First line managers include sergeants and corporals who are supervisors. Mid-level managers include captains and lieutenants. Senior managers include colonels, chiefs, and majors. These same labels are used throughout this study for analysis of ethical awareness, standards, and action.

This study also hypothesizes that length of service will have a curvilinear relationship to an officer's ethical awareness, standards, and action controlling for rank and supervisory status. It is important to examine an officer's experience or length of service with rank in mind as officers achieve higher rank and supervisory status as they gain more experience. This study, therefore, controls for supervisory status by examining length of service for nonsupervisors only.

Not surprisingly, managers have been in service longer than officers. The majority of mid-level and senior managers have been in service for more than 20 years. Over $90 \%$ of mid-level managers have been in service for over sixteen years. Almost $79 \%$ of senior 
managers have been in service for over sixteen years. First line managers consist of almost equal one-third portions of officers who have been in service for eleven to fifteen years, sixteen to twenty years, and over twenty years. Approximately one-third of all officers and one-third of all detectives have been in service for six to ten years. These results indicate that officers are likely to obtain promotion during years six through fifteen of their careers.

Figure 3.5 Percentages of Respondents According to Length of Service and Rank shows the characteristics of respondents by rank and length of service. 


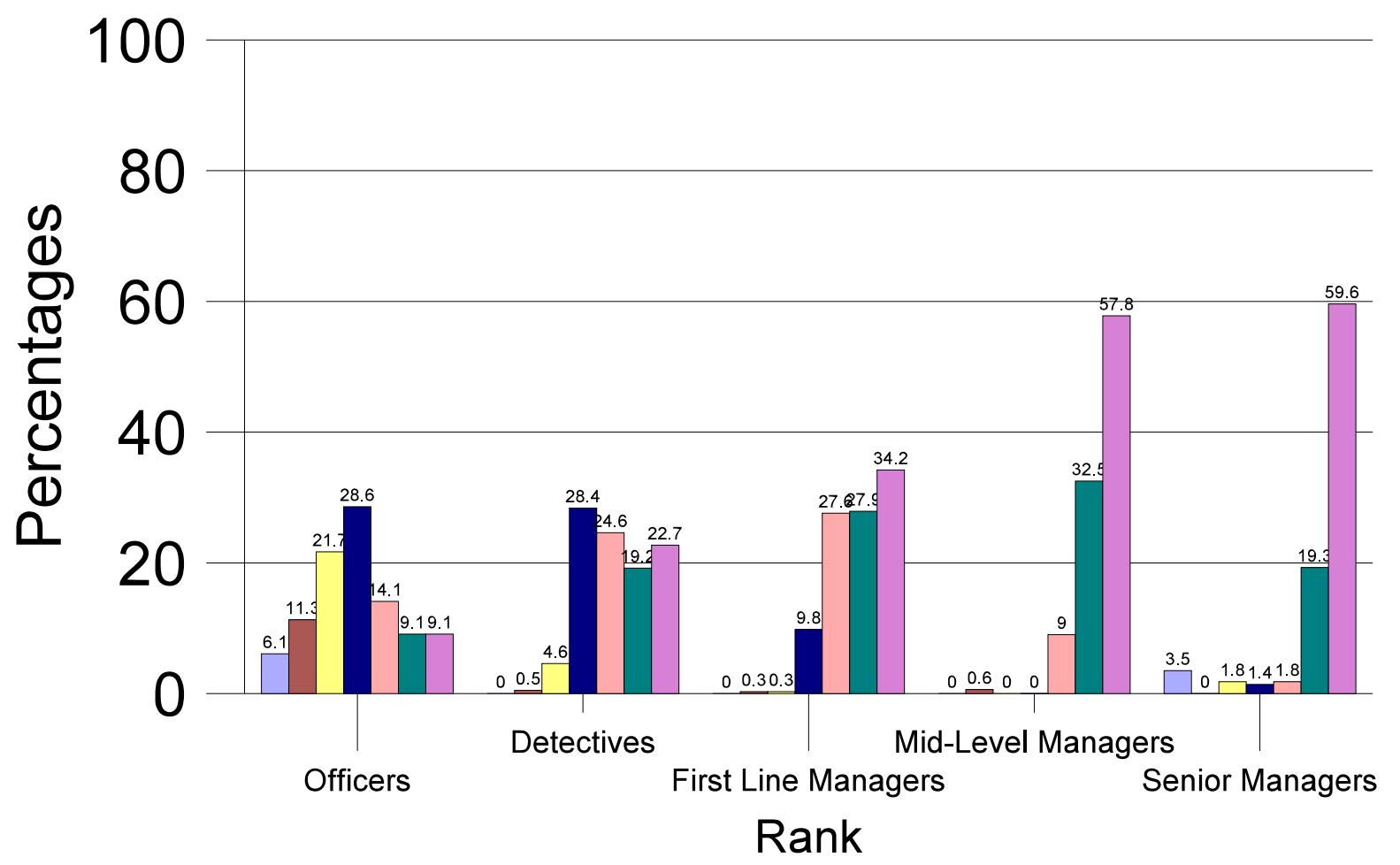

\section{Years of Service}

\begin{tabular}{|l|l|}
\hline & Less than 1 year \\
\hline & $1-2$ years \\
3-5 years & $6-10$ years \\
& $11-15$ years \\
Over 20 years & \\
\hline
\end{tabular}

Figure 3.5

Percentages of Respondents According to Length of Service and Rank 
The characteristics of rank and job assignment are somewhat redundant. The job assignment variable offers five possible categories which include patrol, detective/investigative, special operations, communications, administrative, and other. There were only eight communications officers within the sample and these officers were merged with patrol.

Approximately $85 \%$ of patrol officers categorized their rank as officer while $79.3 \%$ of detective/investigative officers characterized their rank as officer or detective/investigator. While detective rank is a promotion, it does not necessarily involve a supervisory responsibility. As the results below show, about $20 \%$ of detectives are managers, mostly first line managers. Administrative officers tended to (66.5\%) categorize their rank as management. As a result of this overlap, job assignment is not explored as a variable in the chapters that follow, although it is important to recognize that the assignments of patrol and investigation are embedded in the measure of rank for officers and detectives, respectively. Figure 3.6 Percentages of Respondents According to Rank and Job Assignment explores the characteristics of respondents by rank and job assignment. 


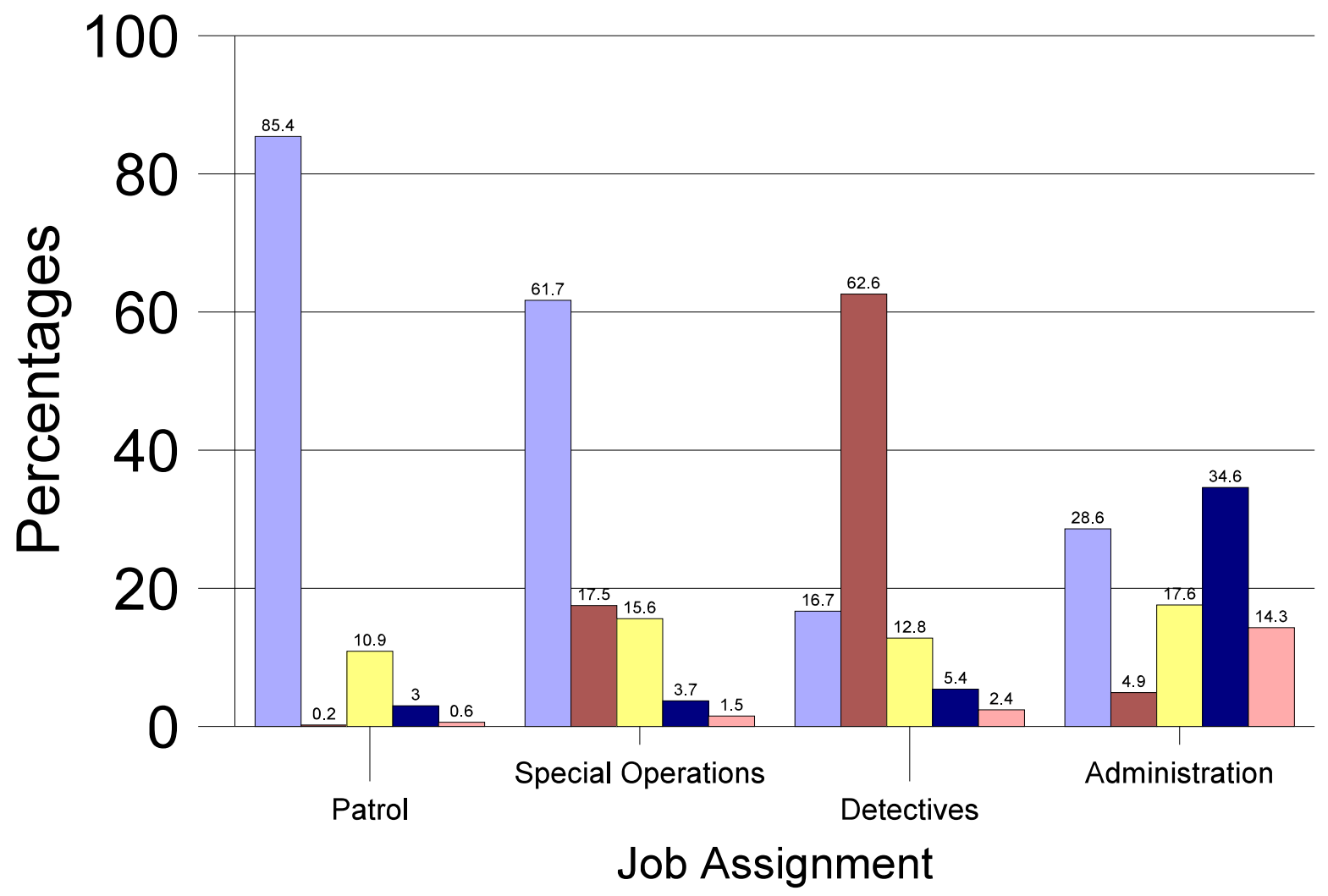

Rank

Officers

First Line Managers

Senior Managers
Detectives

Mid-Level Managers

Figure 3.6

Percentages of Respondents According to Rank and Job Assignment 
The independent variables that will be used for analysis in this study include the agency size, supervisory status (in crosstabs only), rank (in regression analysis), length of service controlling for supervisory status, knowledge of existing policy, and perception regarding peer attitudes and behavior. Respondents were asked questions regarding the agency size, supervisory status, rank and length of service as described earlier in this chapter. Respondents were also asked whether or not each scenario violated policy within their agency on a five point Lykert-type scale with 1 equaling definitely not a violation and 5 equaling definitely a violation. For each scenario, respondents were asked how peers would respond to the same scenario with respect to awareness, standards, and action.

There are three dependent variables. Two of these become independent variables during the analysis. These dependant variables are ethical awareness, ethical standards, and ethical action. Ethical awareness is the officer's attitude regarding the seriousness of the misconduct in each scenario. Ethical standards include the officer's attitude towards punishment that should follow the police misconduct. Ethical action is the officer's willingness to report misconduct. Both ethical awareness and ethical standards become independent variables during the analysis.

To provide an overview of hypotheses that will be presented later, there are certain assumptions about the relationship among variables that will be tested. For ethical awareness, the variation in responses may be explained by the independent variables such as size of agency, length of service, rank, supervisory position, the perception of peer attitudes, and the perception of official policy regarding discipline.

For ethical standards, the variation in responses may be explained by ethical 
awareness, although "slippage" is expected. The attitude that a behavior is serious can be undercut by preferring "weak" discipline. Thus, attitude about discipline is considered to be a better indicator of the real judgment about the behavior than the attitude about seriousness.

For ethical action, the variation in responses can be explained by ethical awareness and ethical standards, as well as discrepancies in attitude between the individual officer and the attitudes of their peers, as well as official policy. With regard to reporting, attitudes of peers and official policy are considered to have a reinforcing or deterrent effect. An officer is more likely to break the code of silence if expected by his or her peers to do so and if it will be sustained by appropriate official disciplinary action. On the other hand, an officer is less likely to risk alienating peers who disapprove of his or her behavior and also less likely to deviate from informal norms if it appears that the agency will not provide discipline the officer feels is appropriate.

The survey instrument used in the NIJ study included eleven case scenarios describing police misconduct. Each scenario is followed by a series of questions including one question asking the officer "Do you think you would report a fellow police officer who engaged in this behavior?" This question is a direct measure of whether an officer is willing to report a peer for misconduct. This question asks officers directly what they would do under the circumstances unlike the other questions in this instrument. These questions are designed to "probe the implications of the normative inclination to resist temptations to abuse the rights and privileges of one's office" (Klockars et al. 2004).

The officer's attitude towards misconduct is measured with the question "How serious do you consider this behavior to be?" This question is asked following each scenario. This 
question is a direct measure of the officer's attitude regarding misconduct. Since there is a broad range of misconduct in the case scenarios, the respondents are more likely to answer honestly. Their responses would seem unreliable if they simply answered accepting a free meal is as serious as accepting a money bribe (Klockars et al. 2004). We will not presume, however, that the officer's attitudes about seriousness match standards for police conduct that can be derived from external sources. This is one of the issues to explore in the research.

The officer's attitude regarding the discipline that should follow misconduct is also measured within the instrument. This is an operational measure of ethical standards. Regardless of the attitude about the seriousness of the behavior, the preferred action indicates how the seriousness would be translated into discipline. The options given for response are limited to actual forms of punishment which is problematic. The forms of punishment offered do not include formal sanctions such as transfer, fines, counseling, and delay in promotion or informal measures such as peer intervention or ostracism (Klockars et al. 2004).

Peer norms can be measured with the question "How serious do most police officers in your agency consider this behavior to be?" Norms are those attitudes shared by a group. This question is also asked of each peer and those responses could be used as the measure, however, what is important is the respondent's belief and not the actual response of peers. Similarly, peer behavior is measured with the question "Do you think most police officers in your agency would report a fellow police officer who engaged in this behavior?"

\section{Categorizing Unethical Behavior}

Measuring the impact that the nature of misconduct has on officer attitudes and behavior can be accomplished by categorizing the case scenarios. As noted above, the 
designers of the survey instrument intentionally presented cases that presented a broad range of misconduct, although no guide was provided by the authors indicating their ordering of the cases with respect to seriousness of misconduct. Two methods may be used: perception of respondents and external standards.

According to respondents, the case scenarios range from not very serious, to intermediately serious, to very serious in nature. Specifically, respondents ranked the least serious of the scenarios as conflict of interest, accepting free meals, accepting holiday gifts, and professional courtesy. The intermediately serious scenarios according to respondents included excessive force, supervisor misconduct, alcohol bribes, and kickbacks. The scenarios that were considered very serious to respondents include stealing a wallet, stealing a watch, and accepting a money bribe.

A method for classifying the seriousness of officer misconduct by objective standards would involve assessing uniform codes of punishment for such misconduct. The limitation of this approach is that the punishment for misconduct varies from jurisdiction to jurisdiction and can differ within a state from county to county and among various agencies. There is a movement to make punishment more standardized by individual states in the same way federal sentencing guidelines are used, but there would still be differences between states in how they punish various forms of misconduct (Walker 2004).

There is another way of classifying the data that reflects a principle-based approach to ethics. This approach uses external standards to judge the seriousness of actions rather than relying on the perceptions of officers, such as the respondents within the NIJ study. According to this approach, one can make independent judgments about officers' ethical 
sensitivity based on the extent to which their attitudes are consistent with ethical principles (Svara 1997).

There are numerous definitions from scholars and commissioned government reports for three types of unethical behavior: misconduct, brutality, and corruption. The consensus among these materials is that misconduct includes behavior that violates police policy and usually involves some type of personal gain for the officer engaging in the misconduct. Acts of misconduct include favoritism, graft, prejudice, perjury, and brutality. While considered misconduct, brutality or misuse of force is considered as serious as corruption and is treated separately in the literature. Corruption is considered to be even more serious misbehavior. It can include behavior for personal gain and most often includes some type of illegal behavior. Acts of corruption include burglary, theft, bribery, kickbacks, payoffs and other fixes (Hale 1989).

Huberts et al. (2005), relying on previous research by Huberts (1999), identify a typology of integrity violations for public officials. Their research is based upon research conducted in the Netherlands. The typology is useful within the context of the present study. The typology includes definitions of various types of corruption, as well as definitions of concepts such as bribing, theft, conflict of interest, improper use of authority, and private time misconduct.

Bribery falls under corruption and is defined to include the misuse of power for private gain and "asking, offering, accepting bribes" (Huberts et al. 2005, 5). Bribery within the U.S. is similarly defined as the "offering, giving, receiving, or soliciting of something of value for the purpose of influencing the action of an official in the discharge of his or her 
public or legal duties" (Black's Law Dictionary 1991, 191). Huberts et al. $(2005,5)$ define fraud and theft as "private gain from the organization (with no involvement of external actors)." Fraud and theft are treated separately under the law in the U.S. Black's Law Dictionary (1991) defines fraud as a deception with intent to cause injury to another, usually by convincing the victim to consensually part with something of value. Theft does not have the element of deception, but the two can be combined under the law.

The improper use of authority according to Huberts et al. $(2005,5)$ only considers abuse that occurs as a result of noble intent. Improper use of authority with bad intentions is called "corruption: nepotism, cronyism, patronage." This typology, however, does not consider abuse of authority with bad intentions that does not fall within the three narrowly defined categories provided. Huberts et al. (2005) does recognize conflict of interest as the acceptance of something of value that might interfere with the public interest.

This study creates a typology that is specific to the scenarios listed within the NIJ study relying on the typologies identified by Huberts et al. (2005) and Hale (1989). Analysis of the NIJ data will be done according to four categories of seriousness - conflict of interest, exploiting authority, abuse of authority and malfeasance. These classifications of misconduct and corruption are supported by the literature and neither contradicts the discipline that would be received within the departments surveyed in the NIJ study (Hale 1989).

In addition to categorizing the scenarios within this study based on current literature and existing legal definitions of crime and punishment, principal component factor analysis and bivariate correlation were utilized to confirm at least moderate correlation among the scenarios. Categorization according to the literature and correlation enhance construct 
validity including convergent and discriminant validity. Principal component factor analysis confirms strong correlations among scenarios within each of the four categories, but not overly high correlations. Correlations and factor analysis results can be found in Appendix D.

Categorizing the scenarios requires consideration of harm to third parties, benefits to the officer individually or collectively, and whether the misconduct is illegal behavior. The scenarios that involve minor instances of misconduct that do not involve harm to third parties or illegal behavior are categorized as conflict of interest. These scenarios include officers accepting gifts or food from local merchants. Scenarios where the officer uses their power as a police officer to take advantage of others for economic gain are characterized as exploiting authority. These two scenarios include receiving kickbacks and a violation of office policy.

The third group of misbehavior -abuse of authority - involves behavior not providing any direct economic benefit to the officer, but a psychic benefit instead. Abuse of authority is the wrongful exercise of lawful authority. The scenarios depict a violation of departmental policy, a human rights violation, and a violation of criminal law. Two of the three scenarios encourage what is considered professional courtesy where officers protect or shield one another from harm. The third scenario, although not professional courtesy, depicts conspiratorial behavior. Conspiracy is treated more seriously in criminal law as it is potentially more dangerous than crimes committed by individuals (Samaha 2005). One scenario depicts physical harm to a suspect which is considered more serious in criminal law than economic harm (Samaha 2005). 
The final group of misbehavior includes criminal behavior that is considered

malfeasance. A common law term, malfeasance includes illegal behavior that is attributed to public officials (Hale 1989). Each of the three scenarios depicted within malfeasance involve illegal officer behavior including bribery and theft. The table below in Figure 3.7 shows how the scenarios are categorized. 


\section{Conflict of Interest}

A police officer routinely accepts free meals, cigarettes, and other items of small value from merchants on his beat. He does not solicit these gifts and is careful not to abuse the generosity of those who give gifts to him.

A police officer is widely liked in the community, and on holidays local merchants and restaurant and bar owners show their appreciation for his attention by giving him gifts of food and liquor.

\section{Exploiting Authority}

A police officer has a private arrangement with a local auto body shop to refer the owners of the cars damaged in the accidents to the shop. In exchange for each referral, he receives a payment of $5 \%$ of the repair bill from the shop owner.

A police officer, who happens to be a very good auto mechanic, is scheduled to work during coming holidays. A supervisor offers to give him these days off, if he agrees to tune-up his supervisor's personal car. Evaluate the SUPER VISOR'S behavior.

\section{Abuse of Authority}

A police officer finds a bar on his beat which is still serving drinks a half hour past its legal closing time. Instead of reporting this violation, the police officer agrees to accept a couple of free drinks from the owner.

At 2 A.M. a police officer, who is on duty, is driving his patrol car on a deserted road. He sees a vehicle that has bean driven off the road and is stuck in a ditch. He approaches the vehicle and observes that the driver is not hurt but is obviously intoxicated. He also finds that the driver is a police officer. Instead of reporting this accident and offense he transports the driver to his home.

Two police officers on foot patrol surprise a man who is attempting to break into an automobile The man flees. They chase him for about two blocks before apprehending him by tackling him and wrestling him to the ground. After he is under control both officers punch him a couple of times in the stomach as punishment for fleeing and resisting.

\section{Malfeasance}

A police officer stops a motorist for speeding. The officer agrees to accept a personal gift of half of the amount of the fine in exchange for not issuing a citation.

A police officer discovers a burglary of a jew elry shop. The display cases are smashed and it is obvious that many items have been taken. While searching the shop, he takes a watch, worth about two days pay for that officer. He reports that the watch had been stolen during the burglary.

A police officer finds a wallet in a parking lot. It contains the amount of money equivalent to a full-day's pay for that officer. He reports the wallet as lost property, but keeps the money for himself.

Figure 3.7: Case Scenarios by Nature of the Misconduct 
One scenario has been omitted from this analysis - the scenario that involves off-duty work which potentially creates a conflict of interest. Not all departments in the United States have an off-duty conflict of interest policy for officers to follow. For most departments, having outside work is not a violation of policy at all, even work that is closely related to their job as a police officer (Brunet 2005). Those that do have policies enforce different rules with respect to whether and how an officer will pursue outside employment. The survey responses clearly indicated that there is no relationship between this scenario and any of the others offered in this study.

The scenarios are represented in the law enforcement code of ethics. Conflict of interest scenarios and unnecessary force are explicitly forbidden by the code mandating that officers should never accept gratuities and should never employ unnecessary force. The code also generally directs officers to "develop self restraint" which contradicts both exploiting authority and abuse of authority scenarios. The code also requires that officers "enforce the law courteously and appropriately without fear or favor" which would prohibit behavior depicted with both exploiting authority and abuse of authority. Malfeasance is generally not allowed in that the code states officers should be "honest in thought and deed."

The scenarios are also covered by the IACP National Law Enforcement Standards of Conduct. As noted in Figure 3.1, the standards generally prohibit officers from violating the law, accepting gratuities without filing a report, or using their position for gain or advantage. The standards provide specific language prohibiting drinking alcohol on duty and, in particular, from drinking in public whether on or off duty. There is also a specific provision prohibiting misuse of force. Misuse of force is prohibited by law in the sense that misuse of 
force is technically an assault.

The scenarios that fall within each of the four categories are highly correlated according bivariate correlations found in Appendix D. The categories are listed in order of seriousness according to the factors used to create the categories. For example, exploiting authority should be considered more serious than conflict of interest as there is greater harm to third parties. In order to condense the variables into these categories, means were used for the scenarios falling into each category. For example, conflict of interest is the mean of the two scenarios depicting an officer accepting gratuities and accepting gifts on holidays. The following section explores the nature of this relationship and the hypotheses to be tested in this study.

\section{Hypotheses - Ethical Awareness, Ethical Standards, and Ethical Action}

The hypotheses analyze what factors impact officer attitudes towards misconduct and standards, as well as whether an officer will report peer misconduct. This study analyzes organizational and situational variables that impact officer attitudes and behavior. Organizational variables are measured by the size of an agency, an officer's job assignment and rank, and whether an officer is a supervisor. Situational factors are measured by the nature of the misconduct. Attitudes of peers, expected behavior of other officers, and departmental policy are measures of organizational culture. An officer's ethical awareness is measured according to their attitudes towards misconduct. Ethical standards are measured according to what an officer believes should be the punishment for misconduct. Ethical action is measured by whether an officer is willing to report peer misconduct.

H1: The more serious the misconduct, the higher an officer's ethical awareness. 
H2: Officers who are supervisors will have higher ethical awareness.

H3: An officer's length of service controlling for rank and supervisory status will have a curvilinear relationship to an officer's ethical awareness.

H4: The size of the police agency will have no relationship to an officer's ethical awareness.

H5: An officer's awareness of existing policies regarding misconduct will positively impact that officer's ethical awareness.

H6: An officer's perceptions regarding peer ethical awareness will positively impact that officer's ethical awareness.

H7: The more serious the misconduct, the higher that officer's ethical standards.

H8: Officers who are supervisor will have higher ethical standards.

H9: An officer's length of service controlling for rank and supervisory status will have a curvilinear relationship to an officer's ethical standards.

H10: The size of the police agency will have no relationship to an officer's ethical standards.

H11: An officer's awareness of existing policies regarding misconduct will positively impact that officer's ethical standards

H12: An officer's perceptions regarding peer ethical awareness and standards will positively impact that officer's ethical standards.

H13: The higher an officer's ethical awareness, the higher that officer's ethical standards.

H14: The more serious the misconduct, the greater the likelihood of an officer's ethical action.

H15: Officers who are supervisor are more likely to take ethical action.

H16: An officer's length of service controlling for rank and supervisory status will have a curvilinear relationship to the officer's ethical action.

H17: The size of the police agency will have no relationship to an officer's ethical action.

H18: An officer's awareness of existing policies regarding misconduct will positively impact that officer's willingness to take ethical action. 
H19: An officer's ethical and perceptions regarding peer ethical awareness, standards, and action will positively impact that officer's willingness to take ethical action.

H20: The higher the officer's ethical awareness and standards, the greater the likelihood of an officer's ethical action.

The first six hypotheses examine the variation in awareness levels of officers. These hypotheses involve situational, individual and organizational variables. Situational measures include seriousness of the misconduct for each misconduct scenario. The measures for individual factors include supervisory position, rank, and length of service in general. The organizational factors included in this study are agency size and policy.

H5, H11, and H18 explore an officer's awareness of existing policies regarding misconduct. This variable may be an indicator of how much an officer has been exposed to ethics training during his career. This variable also may indicate to some degree how committed supervisors are to communicating agency policy to subordinates. The results explored in this study regarding whether officers are aware of agency policies in and of itself will suggest whether further training is necessary within an agency or systemwide. Given that not much ethics training exists for officers the expectation is that officers will be uncertain about whether policies exist regarding less serious misconduct depicted in the scenarios. Educators and police supervisors agree that ethics training is important for law enforcement suggesting that this variable with have a substantial impact on an officer's ethical awareness, standards, and action.

H6, H12, and H19 explore an officer's awareness of perceptions regarding peer ethical awareness. This variable measures the importance an officer places on peer opinions particularly when considering its impact on whether an officer will report misconduct. This 
variable essentially gives insight into the weight indirect peer pressure may have on an officer's ethical awareness, standards and action. The solidarity depicted within law enforcement amongst peers suggests that this variable will have a big impact on an officer's awareness, standards, and action.

$\mathrm{H} 2, \mathrm{H} 8$ and $\mathrm{H} 15$ explore supervisory status while $\mathrm{H} 4, \mathrm{H} 10$, and $\mathrm{H} 17$ explore the size of the agency. Individual and organizational variables have had mixed results with respect to impact on officer attitudes and behavior (Riksheim and Chermak 1993). These hypotheses follow the police culture literature which suggests that socialization and police culture shape attitudes (Paoline 2001). If these hypotheses are correct, then supervisors and higher ranking officers believe that officer misconduct is more serious than non-supervisors and lower ranking officers. Supervisors and higher ranking officers will also believe more discipline is necessary and will be more likely to report misconduct than non-supervisors and lower ranking officers.

Hypotheses that explore length of service - H3, H9, and H16 - are supported by Catlin and Maupin's (2004) findings that socialization on the job impacts an officer's ethical orientations. Analyzing the data to determine whether support exists for this hypothesis requires a comparison of means between officers at varying years of service. Actual years of service are not available in the NIJ data, only the categories indicated earlier in this chapter. In view of the expected impact of rank and supervisory status, length of service will be analyzed with a control for supervisory status.

There is very little research exploring the issue of agency size - H4, H10, and H17 and its impact on officer attitudes. Recent research suggests that local political culture has no 
impact on the organizational structure of law enforcement agencies (Hassell 2003). Most studies that do consider the organizational structure of a law enforcement agency do so within the context of the size of the city serviced by the officers and not the size of the agency itself (Riksheim and Chermak 1993). Research that does exist related to size of agency is conflicting suggesting that there is no relationship between size of agency and an officer's attitudes.

As for the impact of policy on officer attitudes - H5, H11, and H18 - some studies have found a relationship between agency policy and officer behavior (Robinson and Chandek 2000). Their study relies on hierarchical structure to influence the officer's attitude towards misconduct. One can argue, however, that community policing is changing the long established relationship between size and hierarch. Larger organizations are more likely to have eliminated formal hierarchical bureaucratic structures in community-based approaches (Kenney and McNamara 1999).

In addition, larger agencies will have more resources for training and that can narrow the amount of discrepancy in attitudes between officers and their peers. This study hypothesizes that community policing and more extensive resources in larger agencies will have a positive effect on an officer's ethical awareness, standards and action. On the other hand, bureaucratization and the stress-producing conditions of large cities where one finds larger agencies have a negative effect. Given the contradictory expectations regarding size, the hypothesis predicts no relationship.

From two perspectives, the nature of the misconduct itself -H1, H7, and $\mathrm{H} 14$ - has an impact on an officer's attitude towards that misconduct, the discipline that should follow, and 
whether an officer is willing to report that misconduct. First, virtue-based approaches to ethics would suggest that the more an action violates norms of integrity, the more likely it is to be considered wrong, as should the disparity between principle and action (DeLattre 2002). Second, some studies have shown a relationship between situational variables and officer behavior (Engel and Worden 2003). This suggests that the nature of the misconduct itself has an impact on an officer's attitude towards that misconduct, the discipline that should follow, and whether an officer is willing to report that misconduct. The more serious the nature of the misconduct consistent with objective standards, the more serious the officer is likely to view that misconduct, the more discipline the officer will believe should follow, and the more likely the officer will report that misconduct.

Supervisors -H2, H8, and H15 - will have been in police work long enough for the socialization process to shape their attitudes towards misconduct such that it will be in line with the attitudes of their peers. Furthermore, they have been selected to be supervisors because they meet agency standards and expectations and have incentives to uphold ethical norms. Similarly, as officers progress through their careers, they hold more prestigious job assignments and attain higher status through rank. Persons selected for promotion meet agency standards and expectations (Whetstone 2001; Scarborough et al. 1999). Each of these variables - supervisory position, rank, length of service - contribute to the officer's attitude towards misconduct. The analysis will examine the separate and combined effects.

New officers -H3, H9, and H16 - should have higher values than officers who have been in service for three to ten years for two primary reasons. In part, this view is inferred from the finding that officers who are disciplined for misconduct are generally in their 
seventh year of service as Troutman (1997) has shown. In addition, officers become more cynical during this phase of their careers (Hickman 2004). As officers progress through their careers their commitment to ethical values rise as they either receive promotion or come to terms with their careers (Barker 1999). The exception to the standard expectation regarding length of service is officers who have been passed over for promotion or selection as supervisors. Negative socialization and/or the cumulative effects of longer service in stressful conditions together with possible resentment for not being promoted can lead to a decline in ethical values. Toward the end of a long period of service, however, self-selection may leave highly experienced officers with higher values than their colleagues who have intermediate periods of service.

All of these situational, individual, and organizational variables combined contribute to an officer's ethical awareness, ethical standards, and ethical action. An officer's socialization shapes the officer's attitude regarding how serious misconduct is in any given situation, whether discipline is warranted, and whether or not the officer will report the peer misconduct. Ethical awareness and standards ultimately affect an officer's ethical action.

Hypotheses fourteen through twenty address the issue of what impacts an officer's decision to report misconduct. Klockars (2002) points out that police departments that have successfully broken the police code of silence have consistently upheld fair ethical standards for all officers. Ethical awareness and standards each contribute ultimately to whether or not an officer is willing to report peer misconduct. One possible explanation for mixed results in the literature when tying socialization, situational, individual and organizational factors to behavior could be that these factors may only play an indirect role in shaping behavior. 
Attitudes may more directly impact behavior while these socialization, situational, individual and organizational factors may more directly impact attitudes.

\section{4. $\quad$ NIJ Data}

The NIJ study provides data at the individual level of analysis, making it accessible to multiple forms of data analysis. One advantage of using this data set is that it is very large and missing values did not impact the overall number of respondents. A second advantage is that it contains responses creating approximately 88 variables including a broad range of misconduct and background information. The majority of variables, 77 questions in the survey, explore the respondent's attitudes towards eleven different specific scenarios depicting officer behavior. The remaining 11 variables inquire into the respondents background.

The statistical analysis tools that are appropriate to this study include gamma and regression. Each offers a different perspective for interpreting the data. Gamma is a measure of association that measures the strength of relationships between variables (Garson 2006). Gamma ranges from +1 to -1 and measures the independent variables ability to predict the dependent variable's rank (Garson 2006). Regression can establish the predictive power independent variables have with respect to a dependent variable (Tabachnick and Fidell 2001). Combined, these tools offer a deeper understanding of the NIJ data than has been provided in earlier published reports.

The hypotheses explored in this study ask two basic questions. First, what is the strength of the relationship between the variables including organizational, situational, attitudinal and behavioral variables? This question is best explored through gamma results. 
The second question revolves around the combined relative impact these variables have on the dependent variables. This question is best analyzed with the help of regression analysis.

Regression assumes linearity, interval level data, normal error terms, homoscedasticity, minimal measurement error, normal distributions, non-recursivity, absence of multicollinearity and additivity (Tabachnick and Fidell 2001). Gamma assumes ordinal level data and is used in place of Yule's $Q$ when using dichotomous variables. Gamma also does not assume a random sample as is the case with this study (Garson 2006).

\section{Screening the Data}

The first step in screening the data that was unique to this data set involved honesty of the respondents in completing the survey data. One question added to the end of the survey instrument asked officers who did respond to the survey whether they were truthful in responding to the survey questions. According to the authors, approximately $2.2 \%$ of the officers responded "no" to this question, with approximately $1.8 \%$ not responding. These $4 \%$ of respondents were deleted from the analysis in this paper. The NIJ study chose only to delete the "no" responses to this question.

The next step involved meeting assumptions for regression. The assumptions discussed below include interval level data, linearity, homoscedasticity, normal distributions, normal error terms, multicollinearity and no overfitting of data. Most of the data is discrete in the form of a five point Likert-type scale which may be treated as if continuous (Tabachnick and Fidell 2001). It is necessary to check the data for normality by running skew and kurtosis tests and requesting outliers. The test results show no significant skewness or kurtosis problems and the results are attached as Appendix E. 
Scatterplots are used to determine whether observed variables have linear relationships, as this is not possible with unobserved variables. Although not perfect, linearity was not problematic with these variables. The $\mathrm{p}$ values are shown in Appendix E. Residual plots and analysis of outliers are tools used to determine violation of this assumption. Lack of homoscedasticity would be indicated on the residual plots by a funnel shaped pattern. The homoscedasticity assumption was met with the NIJ data as indicated by the residual plots shown in Appendix F.

Regression assumes absence of multicollinearity or singularity amongst variables. Squared multiple correlations were analyzed from the data. The variable length of service in general was virtually identical to length of service for the agency making the two variables redundant. As this study does not analyze data at the agency level, the variable length of service for the agency was dropped in order to avoid multicollinearity issues.

Analysis of a histogram for standardized residuals is the proper tool for determining whether this assumption has been met. If the histogram shows a normal curve, then the residual error terms can be assumed normally distributed. A copy of the histograms for normal residual error terms is attached as Appendix G. 


\section{CHAPTER FOUR}

\section{Ethical Awareness}


This chapter analyzes the characteristics of the NIJ study with an emphasis on officer ethical awareness. This chapter looks at the individual characteristics of the officers who responded to the NIJ study followed by an analysis of ethical awareness crosstabs, gamma, and regression analysis. The variables explored provide some insights into the individual characteristics of the officers responding to the study. Individual characteristics included the length of time an officer has served within law enforcement, the length of time an officer has served within the agency being surveyed, and the rank an officer holds. Since the length of time an officer has served within the agency being surveyed was highly correlated to the length of time the officer has served within law enforcement, only one of these two variables is used. Because the length of time the officer has been in law enforcement is more relevant to the results, it is used.

\section{A. Ethical Awareness Hypotheses}

Ethical awareness is a measure of the officer's attitude regarding the seriousness of the misconduct in each scenario. The ethical awareness measure below was created averaging all of the scenario responses regarding seriousness of the misconduct. The scenarios were condensed for three reasons. First, condensing the scenarios from eleven to four greatly simplifies the analysis. Second, condensing the scenarios highlights the similarities in the scenarios and explores the categories of police misconduct. Finally, condensing the scenarios makes analysis of the nature of the misconduct simpler.

The scenarios fall into four categories which include conflict of interest, exploiting authority, abuse of authority, and malfeasance. For each hypothesis explored in this study, the issue is whether there is a relationship between an officer's ethical awareness and the 
nature of the misconduct, individual, organizational and behavioral variables. The first six hypotheses posit a relationship between these variables:

H1: The more serious the misconduct, the higher an officer's ethical awareness.

H2: Officers who are supervisors will have higher ethical awareness.

H3: An officer's length of service controlling for rank and supervisory status will have a curvilinear relationship to an officer's ethical awareness.

H4: The size of the police agency will have no relationship to an officer's ethical awareness.

H5: An officer's awareness of existing policies regarding misconduct will positively impact that officer's ethical awareness.

H6: An officer's perceptions regarding peer ethical awareness will positively impact that officer's ethical awareness.

Analyzing the nature of the misconduct requires including variables that distinguish

the degree of seriousness of the misconduct. The seriousness of the misconduct is separated into four categories: conflict of interest, exploiting authority, abuse of authority, and

malfeasance. The ethical awareness measure is the mean of all misconduct scenarios used in this study measured through the question "how serious do you consider this behavior to be?" The section that follows explores these hypotheses and analyzes the data using descriptive statistics.

\section{B. Ethical Awareness, Situational, Individual, and Organizational Variables}

This chapter focuses on an officer's ethical awareness by analyzing the nature of the misconduct, supervisory position, rank, years of service, agency size, policy, and the officer's perception of peer attitudes towards misconduct. The first hypothesis asserts that the more serious the misconduct, the higher an officer's ethical awareness. However, the strength of 
this relationship does not increase strictly in correspondence to the seriousness of the misconduct. Officers rate exploiting authority as more serious than abuse of authority which contradicts objective standards based on harm to third parties, benefits to the officer, and legality. Objective measures would indicate that minor misconduct on the same 5-point Lykert-type scale in this study should receive a three score as moderately serious. Exploiting authority should receive a four score as serious while abuse of authority and corruption should each receive scores of five indicating very serious misconduct. The 5-point Lykerttype scale used in the study offers five levels of seriousness for respondents.

The dependent variables explored in this study include the four types of police misconduct - conflict of interest, exploiting authority, abuse of authority, and malfeasance. Each type of misconduct was rated by respondents according to the level of seriousness of the misconduct. The four types of misconduct are presented in the order of seriousness expected within the results, not in the order of seriousness according to respondents. Percentages, number of respondents, and means are indicated in Table 4.1 below according to the dependent variables. 
Table 4.1: Ethical Awareness Dependent Variable Summary

\begin{tabular}{|l|l|l|l|l|}
\hline \multicolumn{5}{|c|}{ (1) Not Serious - (5) Very Serious } \\
\hline & $\begin{array}{l}\text { Conflict of } \\
\text { Interest }\end{array}$ & $\begin{array}{l}\text { Exploiting } \\
\text { Authority }\end{array}$ & $\begin{array}{l}\text { Abuse of } \\
\text { Authority }\end{array}$ & Malfeasance \\
\hline Not serious $\leq 1.5$ & $24.3 \%(756)$ & $0.5 \%(16)$ & $7.6 \%(234)$ & $.2 \%(6)$ \\
\hline Slightly serious 1.6 - 2.5 & $29.3 \%(909)^{*}$ & $2.4 \%(74)$ & $15.1 \%(468)$ & $.3 \%(9)$ \\
\hline Moderately serious $2.6-3.5$ & $23.9 \%(741)$ & $8.1 \%(250)$ & $30.2 \%(936)$ & $.6 \%(17)$ \\
\hline Serious 3.6 - 4.5 & $14.3 \%(444)$ & $32.0 \%(992)$ & $30.3 \%(940)^{*}$ & $4.8 \%(149)$ \\
\hline Very Serious 4.6 - 5 & $8.2 \%(253)$ & $57.0 \%(1771)^{*}$ & $16.8 \%(523)$ & $94.1 \%(2923)^{*}$ \\
\hline Means & 2.72 & 4.40 & 3.54 & 4.91 \\
\hline
\end{tabular}

*largest percentage/(n)

Three important points emerge from these descriptive statistics. First, respondents generally view exploiting authority as more serious than abuse of authority. Virtually all $(89 \%)$ respondents rate exploiting authority as serious to very serious with a majority rating this category of misconduct as very serious. In contrast, over half view abuse of authority as only moderately or less serious to serious. It is striking that using unnecessary force and overlooking the misconduct of an officer would be tolerated as relatively minor infractions by a majority of officers.

Second, respondents view exploiting authority almost as seriously as malfeasance. Certainly, malfeasance is in a class by itself with virtually unanimity that these actions are very serious violations of ethical norms. A majority of respondents view exploiting authority as very serious (whereas only one sixth view abusing authority in this way). It appears that 
officers are sensitive to the ethical inappropriateness of taking action to secure personal gain.

Finally, the manifestations of conflict of interest - accepting but not soliciting gratuities and holiday gifts - are not viewed to be as serious as objective standards would indicate that they should be. Despite the extensive attention focused on the free donut problem, a majority of officers view these behaviors as only slightly serious at worst. One in four respondents rated conflict of interest as not serious at all. Whereas taking steps to secure personal benefits is generally perceived to be wrong, accepting the gifts that come the officer's way is not.

Thus, the overall tendency of the respondents is to treat the cases as either very serious or serious for three of the four types of behavior. Abuse of authority, however, is considered less serious than exploiting authority and conflict of interest is generally viewed as less than moderately serious. Abuse of authority is also considered by respondents almost as serious as malfeasance. Except for the response to malfeasance, there are also significant majorities in the case of conflict of interest and abuse of authority whose level of awareness is well below what law enforcement professionals would consider to be acceptable, whereas only one in ten consider exploiting authority to be no more moderately serious. Even if ethical awareness is strongly related to ethical standards and ethical action in subsequent analysis, it is important to recognize that the level of awareness itself does not fully accord with objective standards of the seriousness of behavior and is uneven across law enforcement officers. Thus, these results show mixed support for hypothesis one which asserts that the more serious the misconduct, the higher the ethical awareness.

It is hypothesized that supervisory position will impact an officer's ethical awareness. 
Approximately $20 \%$ of respondents in this survey are supervisors ranging from sergeants to captains. The typical officer (including detectives who are not supervisors) has been in service approximately three to five years while the typical supervisor has been in office over sixteen years. Table 4.2 provides percentages, number of respondents, and means for ethical awareness attitudes according to supervisory position. 
Table 4.2: Ethical Awareness and Supervisory Position

\begin{tabular}{|c|c|c|c|c|}
\hline \multicolumn{5}{|c|}{ (1) Not Serious - (5) Very Serious } \\
\hline & $\begin{array}{l}\text { Conflict of } \\
\text { Interest }\end{array}$ & $\begin{array}{l}\text { Exploiting } \\
\text { Authority }\end{array}$ & $\begin{array}{l}\text { Abuse of } \\
\text { Authority }\end{array}$ & Malfeasance \\
\hline $\begin{array}{l}\text { Supervisor } \\
\text { Not at all serious } 1.5 \\
\text { Slightly serious } 1.6-2.5 \\
\text { Moderately serious } 2.6-3.5 \\
\text { Serious } 3.6-4.5 \\
\text { Very Serious } 4.6-5\end{array}$ & $\begin{array}{l}9.8 \%(60) \\
22.1 \%(136) \\
29.0 \%(178)^{*} \\
23.6 \%(145) \\
15.5 \%(95)\end{array}$ & $\begin{array}{l}0.0 \%(0) \\
0.6 \%(4) \\
3.0 \%(18) \\
20.2 \%(124) \\
76.2 \%(468)^{*}\end{array}$ & $\begin{array}{l}3.1 \%(19) \\
11.9 \%(73) \\
25.0 \%(153) \\
37.4 \%(230)^{*} \\
22.6 \%(139)\end{array}$ & $\begin{array}{l}0.2 \%(1) \\
0.5 \%(3) \\
0.3 \%(2) \\
2.8 \%(17) \\
96.2 \%(591)^{*}\end{array}$ \\
\hline Means & $3.34 *$ & $4.69 *$ & $3.84 *$ & $4.94 *$ \\
\hline $\begin{array}{l}\text { Non-Supervisor } \\
\text { Not at all serious } 1.5 \\
\text { Slightly serious } 1.6-2.5 \\
\text { Moderately serious } 2.6-3.5 \\
\text { Serious } 3.6-4.5 \\
\text { Very Serious } 4.6-5\end{array}$ & $\begin{array}{l}28.0 \%(693) \\
31.1 \%(770)^{*} \\
22.6 \%(557) \\
11.9 \%(295) \\
6.4 \%(157)\end{array}$ & $\begin{array}{l}0.6 \%(16) \\
2.8 \%(70) \\
9.4 \%(231) \\
34.8 \%(860) \\
52.4 \%(1295)^{*}\end{array}$ & $\begin{array}{l}8.7 \%(215) \\
15.9 \%(393) \\
31.4 \%(776)^{*} \\
28.7 \%(707) \\
15.3 \%(379)\end{array}$ & $\begin{array}{l}0.2 \%(5) \\
0.2 \%(6) \\
0.6 \%(15) \\
5.4 \%(132) \\
93.6 \%(2315)^{*}\end{array}$ \\
\hline Means & 2.57 & 4.33 & 3.46 & 4.90 \\
\hline Gamma & $.402 * *$ & $.401 * *$ & $.229 * *$ & $.366^{* *}$ \\
\hline
\end{tabular}

There are important differences in attitudes between supervisors and non-supervisors, as indicated in Table 4.2. Among supervisors, $60 \%$ view abuse of authority as serious or very serious compared to $44 \%$ of non-supervisors. There is greater awareness of the seriousness of these actions, although a significant minority does not see the behaviors as serious. Among non-supervisors, however, a clear majority has lax attitudes about these forms of abuse of authority. Similarly, one third of supervisors view conflict of interest as no more than slightly serious compared to three out of five non-supervisors. 
Despite the clear difference, one must question what kind of example or leadership supervisors provide when two in five consider abuse to be no more than moderately serious and one in three do not consider conflict of interest to be more than slightly serious. The differences are not as always as great at the other end of the awareness scales. For example, $76 \%$ versus $52 \%$ of supervisors and non-supervisors, respectively, consider exploiting authority to be very serious. A high consensus about ethical norms is reflected in shared agreement that malfeasance is a very serious offence. There is also, however, a shared avoidance of classifying abuse of authority as very serious, a view held by only $23 \%$ of supervisors and $15 \%$ of non-supervisors.

Means for seriousness of misconduct are higher with supervisors than with nonsupervisors. The differences between means is larger for conflict of interest than the other types of misconduct with the least difference in means with respect to serious misconduct. Both supervisors and non-supervisors find exploiting authority more serious than abuse of authority. Neither group, however, lends support to higher levels of ethical awareness according to type of misconduct as abuse of authority is rated lower than exploiting authority. The only support for hypothesis one is that malfeasance has higher means than conflict of interest and both exploiting authority and abuse of authority have higher means than conflict of interest.

Gamma scores are moderately strong across all types of misconduct indicating a positive relationship between whether or not an officer is a supervisor and that officer's attitude towards misconduct. These results lend further support to hypothesis two that supervisors have higher ethical awareness than non-supervisors. The lowest gamma weight 
occurs within abuse of authority indicating a weaker relationship with respect to this type of misconduct.

Rank is utilized as a control variable in this study. Officer rank is strongly tied to supervisory position and length of service. Officers may or may not achieve higher rank as they progress through their careers. Rank is explored in this chapter in Table 4.3 below and will be used as a control in the regression model later in this chapter. 
Table 4.3: Ethical Awareness and Rank

\begin{tabular}{|c|c|c|c|c|}
\hline \multicolumn{5}{|c|}{ (1) Not Serious - (5) Very Serious } \\
\hline & $\begin{array}{l}\text { Conflict of } \\
\text { Interest }\end{array}$ & $\begin{array}{l}\text { Exploiting } \\
\text { Authority }\end{array}$ & $\begin{array}{l}\text { Abuse of } \\
\text { Authority }\end{array}$ & Malfeasance \\
\hline Officers & & & & \\
\hline Not at all serious 1.5 & $29.0 \%(609)$ & $0.7 \%(14)$ & $9.2 \%(192)$ & $0.2 \%(4)$ \\
\hline Slightly serious $1.6-2.5$ & $31.3 \%(656)^{*}$ & $2.9 \%(61)$ & $15.3 \%(321)$ & $0.2 \%(5)$ \\
\hline Moderately serious $2.6-3.5$ & $22.2 \%(466)$ & $9.6 \%(201)$ & $31.6 \%(663)^{*}$ & $0.6 \%(12)$ \\
\hline Serious $3.6-4.5$ & $10.9 \%(229)$ & $35.6 \%(748)$ & $28.3 \%(593)$ & $5.8 \%(121)$ \\
\hline Very Serious 4.6 - 5 & $6.6 \%(139)$ & $51.2 \%(1075)^{*}$ & $15.6 \%(328)$ & $93.2 \%(1958)^{*}$ \\
\hline Means & 2.54 & 4.32 & 3.46 & 4.90 \\
\hline Detectives/Investigators & & & & \\
\hline Not at all serious 1.5 & $21.3 \%(79)$ & $0.6 \%(2)$ & $6.2 \%(23)$ & $0.3 \%(1)$ \\
\hline Slightly serious $1.6-2.5$ & $29.9 \%(111)^{*}$ & $2.4 \%(9)$ & $18.9 \%(70)$ & $0.0 \%(0)$ \\
\hline Moderately serious $2.6-3.5$ & $25.1 \%(93)$ & $7.8 \%(29)$ & $30.7 \%(114)^{*}$ & $0.8 \%(3)$ \\
\hline Serious $3.6-4.5$ & $18.3 \%(68)$ & $31.0 \%(115)$ & $29.1 \%(108)$ & $3.5 \%(13)$ \\
\hline Very Serious 4.6 - 5 & $5.4 \%(20)$ & $58.2 \%(216)^{*}$ & $15.1 \%(56)$ & $95.4 \%(354) *$ \\
\hline Means & 2.77 & 4.41 & 3.49 & 4.93 \\
\hline First Line Managers & & & & \\
\hline Not at all serious 1.5 & $12.4 \%(47)$ & $0.0 \%(0)$ & $2.6 \%(10)$ & $0.0 \%(0)$ \\
\hline Slightly serious $1.6-2.5$ & $24.0 \%(91)$ & $0.5 \%(2)$ & $13.2 \%(50)$ & $0.6 \%(2)$ \\
\hline Moderately serious $2.6-3.5$ & $29.0 \%(110)^{*}$ & $2.7 \%(10)$ & $25.9 \%(98)$ & $0.0 \%(0)$ \\
\hline Serious $3.6-4.5$ & $22.2 \%(84)$ & $22.4 \%(85)$ & $35.1 \%(133)^{*}$ & $2.6 \%(10)$ \\
\hline Very Serious 4.6 - 5 & $12.4 \%(47)$ & $74.4 \%(282)^{*}$ & $23.2 \%(88)$ & $96.8 \%(367)^{*}$ \\
\hline Means & 3.18 & 4.68 & 3.81 & $4.96^{*}$ \\
\hline Mid-Level Managers & & & & \\
\hline Not at all serious 1.5 & $6.5 \%(11)$ & $0.0 \%(0)$ & $3.6 \%(6)$ & $0.0 \%(0)$ \\
\hline Slightly serious $1.6-2.5$ & $20.8 \%(35)$ & $0.6 \%(1)$ & $11.9 \%(20)$ & $0.6 \%(1)$ \\
\hline Moderately serious $2.6-3.5$ & $29.8 \%(50)^{*}$ & $4.1 \%(7)$ & $23.2 \%(39)$ & $0.6 \%(1)$ \\
\hline Serious $3.6-4.5$ & $25.6 \%(43)$ & $16.1 \%(27)$ & $42.3 \%(71)^{*}$ & $3.0 \%(5)$ \\
\hline Very Serious $4.6-5$ & $17.3 \%(29)$ & $79.2 \%(133)^{*}$ & $19.0 \%(32)$ & $95.8 \%(161)^{*}$ \\
\hline Means & $3.49 *$ & 4.69 & 3.85 & 4.94 \\
\hline Senior Managers & & & & \\
\hline Not at all serious 1.5 & $14.0 \%(8)$ & $0.0 \%(0)$ & $3.5 \%(2)$ & $1.8 \%(1)$ \\
\hline Slightly serious $1.6-2.5$ & $15.8 \%(9)$ & $1.8 \%(1)$ & $7.0 \%(4)$ & $1.8 \%(1)$ \\
\hline Moderately serious $2.6-3.5$ & $26.3 \%(15)^{*}$ & $1.8 \%(1)$ & $22.8 \%(13)$ & $1.8 \%(1)$ \\
\hline Serious $3.6-4.5$ & $19.3 \%(11)$ & $17.5 \%(10)$ & $42.1 \%(24)^{*}$ & $0.0 \%(0)$ \\
\hline Very Serious 4.6 - 5 & $24.6 \%(14)$ & $78.9 \%(45)^{*}$ & $24.6 \%(14)$ & $94.6 \%(54)^{*}$ \\
\hline Means & 3.46 & $4.72 *$ & $3.91 *$ & 4.84 \\
\hline Gamma & $.289 * *$ & $.279 * *$ & $.143 * *$ & $.320 * *$ \\
\hline
\end{tabular}

*largest percentage/(n)/mean

$* * \mathrm{p}<.05$ 
Regardless of rank, respondents rate exploiting authority as more serious than abuse of authority. Regardless of rank, respondents rate exploiting authority almost as seriously as malfeasance. A majority of officers (51\%) and detectives/investigators (58\%) view exploiting authority as very serious whereas an overwhelming majority of first line managers (74\%), mid-level managers (79\%), and senior managers (79\%) take this view. A majority of officers and detectives (56\%) view abuse of authority as no more than moderately serious, whereas only $43 \%$ of first line managers, $39 \%$ of mid-level managers, and $33 \%$ of senior managers rate abuse of authority at the same relatively low level of seriousness. It would be expected that the managers would rate abuse of authority as more serious than non-managers, but at least managers are more likely to consider abuse of authority to be at least serious.

In support of hypothesis two, conflict of interest percentages show supervisors (managers) have higher ethical awareness than non-supervisors (officers and detectives/investigators). A majority of officers (60\%) rate conflict of interest as either not serious at all or only slightly serious. In contrast, $36 \%$ of first line managers, $26 \%$ of midlevel managers and $30 \%$ of senior managers take this view. As noted with regard to supervisors, however, even though the proportions who take a lax attitude are lower, there is a substantial minority of leaders sending an accommodating message about conflict of interest.

Mid-level managers have the highest overall means while officers have the lowest overall means. There is a large range between supervisors (first line managers, mid-level managers, and senior managers) and non supervisors (officers). Managers (first line, mid, and senior) rate misconduct as more serious than other types of officers. Officers consistently 
rate misconduct as much less serious than other types of officers. All officers, regardless of rank, place exploiting authority as more serious than abuse of authority. Also, the range of means for conflict of interest is much larger than the other three types of misconduct.

Within rank, two interesting gaps in means emerge. The first notable mean gap is between first line managers and officers. First line managers include sergeants and corporals who are supervisors. First line managers are first promotions for most officers so there is most likely the smallest gap in time between the transition from officer to first line manager. The second notable gap occurs between detectives and mid-level managers. Detectives are usually somewhere in between first line and mid-level managers within the hierarchical structure of the police organization. Their ethical awareness, however, is closer to officers than to first line supervisors and substantially lower than the awareness level of mid-level managers.

As with supervisory status, gamma scores are moderately strong, although somewhat weaker within rank than supervisory status. These results indicate that the higher the rank, the higher the officer's ethical awareness. The lowest gamma score, again, is within abuse of authority.

The findings for analysis of supervisory status and rank show very similar patterns. To simplify the presentation of data in future chapters, only supervisory status will be presented. Rank will be used, however, in regression analysis.

An officer's rank is also closely related to that officer's length of service within law enforcement as those officers who are promoted have been in service longer than nonsupervisors. For this reason, it is important to control for these additional responsibilities 
when analyzing length of service. It is expected that an officer's length of service, controlling for rank and supervisory status, will have a curvilinear relationship to an officer's ethical awareness. In order to analyze the complex issue of length of service, it is necessary to control for supervisory status. The association of tenure and ethical awareness for nonsupervisors is presented in Table 4.4. 
Table 4.4: Ethical Awareness and Years of Service Non-supervisors only

\begin{tabular}{|c|c|c|c|c|}
\hline \multicolumn{5}{|c|}{ (1) Not Serious - (5) Very Serious } \\
\hline & $\begin{array}{l}\text { Conflict of } \\
\text { Interest }\end{array}$ & $\begin{array}{l}\text { Exploiting } \\
\text { Authority }\end{array}$ & $\begin{array}{l}\text { Abuse of } \\
\text { Authority }\end{array}$ & Malfeasance \\
\hline $\begin{array}{l}\text { Less than } 1 \text { Year } \\
\text { Not at all serious } 1.5 \\
\text { Slightly serious } 1.6-2.5 \\
\text { Moderately serious } 2.6-3.5 \\
\text { Serious } 3.6-4.5 \\
\text { Very Serious } 4.6 \text { - } 5\end{array}$ & $\begin{array}{l}20.9 \%(27) \\
31.8 \%(41)^{*} \\
27.9 \%(36) \\
14.7 \%(19) \\
4.7 \%(6)\end{array}$ & $\begin{array}{l}0.8 \%(1) \\
0.8 \%(1) \\
4.6 \%(6) \\
38.8 \%(50) \\
55.0 \%(71)^{*}\end{array}$ & $\begin{array}{l}0.8 \%(1) \\
9.3 \%(12) \\
27.9 \%(36) \\
38.0 \%(49)^{*} \\
24.0 \%(31)\end{array}$ & $\begin{array}{l}0.8 \%(1) \\
0.8 \%(1) \\
0.0 \%(0) \\
5.4 \%(7) \\
93.0 \% \\
(120)^{*}\end{array}$ \\
\hline Means & 2.72 & 4.45 & 3.94 & 4.87 \\
\hline $\begin{array}{l}1-2 \text { Years } \\
\text { Not at all serious } 1.5 \\
\text { Slightly serious } 1.6-2.5 \\
\text { Moderately serious } 2.6-3.5 \\
\text { Serious } 3.6-4.5 \\
\text { Very Serious } 4.6-5\end{array}$ & $\begin{array}{l}30.0 \%(72) \\
34.1 \%(82)^{*} \\
22.1 \%(53) \\
9.6 \%(23) \\
4.2 \%(10)\end{array}$ & $\begin{array}{l}0.4 \%(1) \\
2.9 \%(7) \\
13.4 \%(32) \\
38.1 \%(91) \\
45.2 \%(108)^{*}\end{array}$ & $\begin{array}{l}8.8 \%(21) \\
15.1 \%(36) \\
30.1 \%(72)^{*} \\
26.8 \%(64) \\
19.2 \%(46)\end{array}$ & $\begin{array}{l}0.0 \%(0) \\
0.4 \%(1) \\
0.0 \%(0) \\
7.1 \%(17) \\
92.5 \% \\
(222)^{*} \\
\end{array}$ \\
\hline Means & 2.46 & 4.25 & 3.52 & 4.89 \\
\hline $\begin{array}{l}3-5 \text { Years } \\
\text { Not at all serious } 1.5 \\
\text { Slightly serious } 1.6-2.5 \\
\text { Moderately serious } 2.6-3.5 \\
\text { Serious } 3.6-4.5 \\
\text { Very Serious } 4.6-5\end{array}$ & $\begin{array}{l}31.6 \%(148) \\
33.7 \%(158)^{*} \\
21.1 \%(99) \\
8.7 \%(41) \\
4.9 \%(23)\end{array}$ & $\begin{array}{l}0.2 \%(1) \\
4.5 \%(21) \\
10.4 \%(49) \\
38.3 \%(180) \\
46.6 \%(219)^{*}\end{array}$ & $\begin{array}{l}9.6 \%(45) \\
15.3 \%(72) \\
32.1 \%(151)^{*} \\
27.5 \%(129) \\
15.5 \%(73)\end{array}$ & $\begin{array}{l}0.0 \%(0) \\
0.2 \%(1) \\
1.3 \%(6) \\
6.0 \%(28) \\
92.5 \% \\
(435)^{*}\end{array}$ \\
\hline Means & 2.40 & 4.25 & 3.45 & 4.88 \\
\hline $\begin{array}{l}6-10 \text { Years } \\
\text { Not at all serious } 1.5 \\
\text { Slightly serious } 1.6-2.5 \\
\text { Moderately serious } 2.6-3.5 \\
\text { Serious } 3.6-4.5 \\
\text { Very Serious } 4.6-5\end{array}$ & $\begin{array}{l}31.6 \%(222)^{*} \\
30.4 \%(214) \\
22.5 \%(158) \\
10.5 \%(74) \\
5.0 \%(35)\end{array}$ & $\begin{array}{l}1.0 \%(6) \\
2.6 \%(18) \\
9.3 \%(65) \\
36.7 \%(258) \\
50.4 \%(354)^{*}\end{array}$ & $\begin{array}{l}8.7 \%(61) \\
17.4 \%(122) \\
31.0 \%(217)^{*} \\
28.9 \%(203) \\
14.0 \%(98)\end{array}$ & $\begin{array}{l}0.0 \%(0) \\
0.0 \%(0) \\
0.7 \%(5) \\
5.5 \%(39) \\
93.8 \% \\
(659)^{*}\end{array}$ \\
\hline Means & 2.47 & 4.31 & 3.42 & 4.92 \\
\hline
\end{tabular}


Table 4.4 (continued)

\begin{tabular}{|c|c|c|c|c|}
\hline \multicolumn{5}{|c|}{ (1) Not Serious - (5) Very Serious } \\
\hline $\begin{array}{l}11-15 \text { Years } \\
\text { Not at all serious } 1.5 \\
\text { Slightly serious } 1.6-2.5 \\
\text { Mo derately serious } 2.6-3.5 \\
\text { Serious } 3.6-4.5 \\
\text { Very Serious } 4.6-5\end{array}$ & $\begin{array}{l}25.4 \%(97) \\
35.1 \%(134) * \\
19.1 \%(73) \\
12.0 \%(46) \\
8.4 \%(32)\end{array}$ & $\begin{array}{l}0.2 \%(1) \\
2.9 \%(11) \\
7.6 \%(29) \\
30.9 \%(118) \\
58.4 \%(223)^{*}\end{array}$ & $\begin{array}{l}12.1 \%(46) \\
17.0 \%(65) \\
29.3 \%(112)^{*} \\
28.5 \%(109) \\
13.1 \%(50)\end{array}$ & $\begin{array}{l}0.2 \%(1) \\
0.0 \%(0) \\
0.5 \%(2) \\
3.9 \%(15) \\
95.3 \% \\
(364) *\end{array}$ \\
\hline Means & 2.62 & 4.39 & 3.35 & $4.93^{*}$ \\
\hline $\begin{array}{l}16-20 \text { Years } \\
\text { Not at all serious } 1.5 \\
\text { Slightly serious } 1.6-2.5 \\
\text { Moderately serious } 2.6-3.5 \\
\text { Serious } 3.6-4.5 \\
\text { Very Serious } 4.6-5\end{array}$ & $\begin{array}{l}27.9 \%(74)^{*} \\
27.2 \%(72) \\
24.9 \%(66) \\
13.6 \%(36) \\
6.4 \%(17)\end{array}$ & $\begin{array}{l}1.5 \%(4) \\
2.3 \%(6) \\
9.8 \%(26) \\
30.9 \%(82) \\
55.5 \%(147)^{*}\end{array}$ & $\begin{array}{l}8.3 \%(22) \\
18.1 \%(48) \\
34.0 \%(90)^{*} \\
24.5 \%(65) \\
15.1 \%(40)\end{array}$ & $\begin{array}{l}0.4 \%(1) \\
0.7 \%(2) \\
0.0 \%(0) \\
5.7 \%(15) \\
93.2 \% \\
(247) *\end{array}$ \\
\hline Means & 2.60 & 4.34 & 3.39 & 4.89 \\
\hline $\begin{array}{l}\text { Over } 20 \text { Years } \\
\text { Not at all serious } 1.5 \\
\text { Slightly serious } 1.6-2.5 \\
\text { Moderately serious } 2.6-3.5 \\
\text { Serious } 3.6-4.5 \\
\text { Very Serious } 4.6-5\end{array}$ & $\begin{array}{l}18.7 \%(51) \\
24.6 \%(67) \\
25.4 \%(69)^{*} \\
19.5 \%(53) \\
11.8 \%(32)\end{array}$ & $\begin{array}{l}0.7 \%(2) \\
2.2 \%(6) \\
7.4 \%(20) \\
28.7 \%(78) \\
61.0 \%(166)^{*}\end{array}$ & $\begin{array}{l}6.6 \%(18) \\
14.0 \%(38) \\
35.3 \%(96)^{*} \\
29.8 \%(81) \\
14.3 \%(39)\end{array}$ & $\begin{array}{l}0.7 \%(2) \\
0.4 \%(1) \\
0.7 \%(2) \\
4.1 \%(11) \\
94.1 \% \\
(256) *\end{array}$ \\
\hline Means & $2.99 *$ & $4.44^{*}$ & $3.51 *$ & 4.89 \\
\hline $\mathrm{Gamma}^{4}$ & $.079 * *$ & $.074 * *$ & $-.052 * *$ & $.131 * *$ \\
\hline
\end{tabular}

*largest percentage/(n)/mean

$* * \mathrm{p}<.05$

Regardless of the number of years an officer has served, respondents rate exploiting authority as more serious than abuse of authority. A majority of officers with less than one

${ }^{4}$ Gamma scores for supervisors are $.174 * *$ for conflict of interest, $.131 * *$ for exploiting authority, $.112 * *$ for abuse of authority, and -.016 for malfeasance. 
year of service (55\%) and officers with more than six years of service ranging from 50-61\% rate exploiting authority as very serious. In contrast, less than a majority of officers with one to five years of experience rate exploiting authority as very serious ranging from $45-47 \%$. The percentages of officers who believe exploiting authority is very serious increases as years of service increase over six years of service. Officers with less than one year of service have a higher percentage of respondents (55\%) that believe exploiting authority is very serious than officers with six to ten years of service (50\%). These results highlight the curvilinear relationship hypothesized with years of service where officers have higher ethical awareness with less than one year of service, ethical awareness declines in years one through five, and ethical awareness rises after six years of service. Figure 4.1 Ethical Awareness by Years of Service below compares means. 


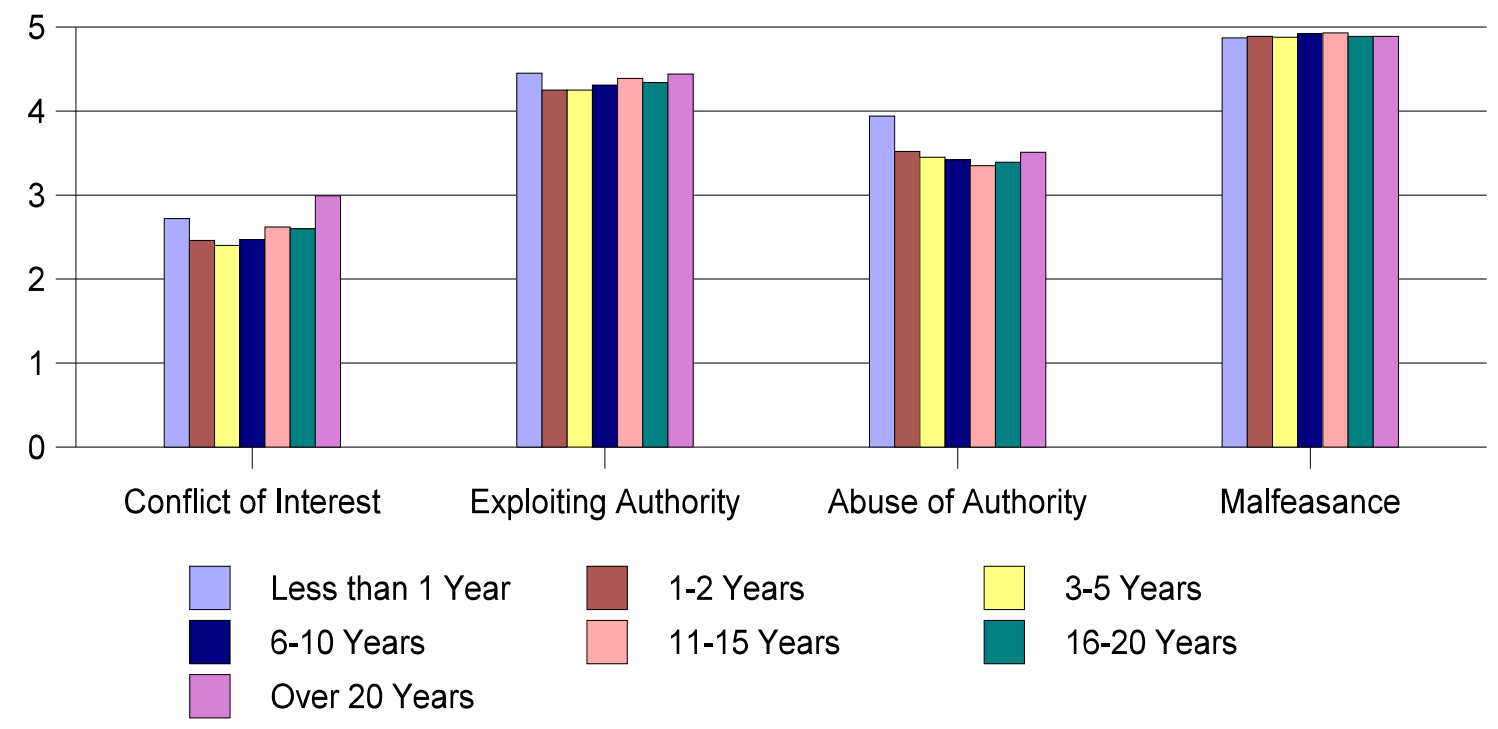

Figure 4.1: Ethical Awareness by Years of Service Non-Supervisors

Within abuse of authority, the largest percentage of officers with less than one year of service rate abuse of authority as serious (38\%), as compared to officers with one to two years of service (27\%) and officers with three to five years of service (28\%). These percentages, however, do not steadily increase until after the officer has been in service at least fifteen years.

There is a modestly curvilinear relationship within conflict of interest. Officers with less than one year of service have the highest percentage of respondents (28\%) that view conflict of interest as moderately serious. There is a slight decline in these percentages which range from $19-22 \%$ with officers who have one to fifteen years of service followed by a moderate increase of around $25 \%$ with officers who have more than fifteen years of service.

Officers with less than one year of service have the highest overall means while officers who have over twenty years of service hold the second largest overall means. The 
lowest overall means are with officers who have between three to five years of service. As noted, the exception is abuse of authority which continues to drop slightly through the 11-15 year group. The levels of awareness even among the highest two length of service categories are lower than for those with less than two years of service. There is an increase in means with officers who have more than six years of experience, however, there are large ranges between officers who have six to ten years of service and officers who have eleven to fifteen years of service. There is an even larger range between officers who have sixteen to twenty years of service and officers who have over twenty years of experience. Regardless of years on the force, officers rate exploiting authority as more serious than abuse of authority.

Two interesting findings emerge from length of service means. First, there is gap in means between officers who have been in service for less than one year and officers who have been in service for one to two years. Research indicates that officer's attitudes and behaviors are impacted during the first year of service in that new recruits come to service with high ideals. Second, there is a gap between officers who have been in service for three to five years and officers who have been in service for more than twenty years. Research shows that the average officer who is disciplined for misconduct has served approximately seven years. It is possible that negative attitudes form prior to the seventh year and that officers engage in misconduct over a period of time before eventually being formally disciplined or even reported to superiors.

Gamma scores are substantially lower for length of service than for the previous two variables. This is to be expected when the relationship is more or less curvilinear. These results highlight the need to control for supervisory status when analyzing length of service as 
factoring in supervisors gives noticeably different results as footnote three indicates.

An organizational factor that is considered within this study is the size of agency.

Respondents for this survey typically work in very large agencies with over 500 sworn

officers while more than half of the agencies that participated in this study are either small or very small. Table 4.5 below shows percentages, number of respondents, and means for ethical awareness according to the size of agency. 
Table 4.5: Ethical Awareness and Agency Size

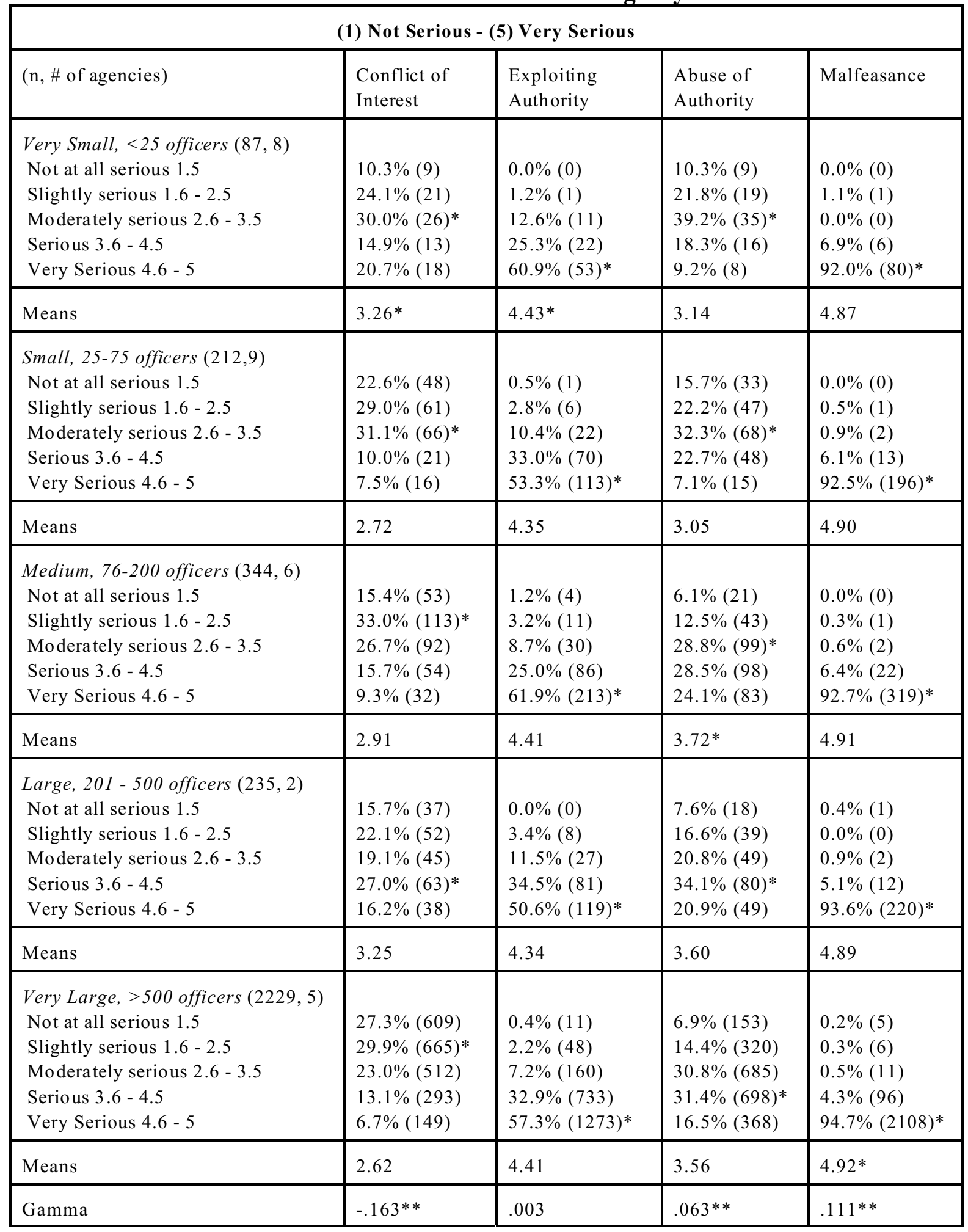

*largest percentage/(n)/mean

$* * \mathrm{p}<.05$ 
Regardless of size of agency, a majority of respondents rate exploiting authority as more serious than abuse of authority and exploiting authority is considered to be almost as serous as malfeasance. There are three different patterns of variation for the four awareness indices. There is little difference for exploiting authority which is viewed as at least a serious offense by $85-90 \%$ of the respondents in the department size categories or for malfeasance which is viewed as a very serious offense by $92-95 \%$ of the respondents.

Regarding conflict of interest, there is no consistent difference related to size. A majority of respondents from small and very large see these behaviors as no more than slightly serious. In contrast, only $34 \%$ and $38 \%$, respectively, from very small and large agencies offer a slightly serious rating. The medium-sized agencies are in the middle.

Abuse of authority, on the other hand, shows a size difference. Less than three in ten respondents in smaller size agencies rate these behaviors at least serious whereas $48-55 \%$ of the respondents in the medium-sizes and larger agencies take this view. These results suggest that the social bond among officers may be stronger in smaller organizations in which officers are likely to know each other personally, as well as sharing a professional/occupational association.

Large agencies have the highest overall means with medium agencies holding the second highest overall means. Small agencies have the lowest overall means. Size of agency shows some differences in ethical awareness amongst officers. Abuse of authority had the largest range in means with conflict of interest fairly close behind. No agency consistently had the highest means across the different types of misconduct. Very small agencies hold the highest means for conflict of interest and exploiting authority while medium agencies have 
the highest means for abuse of authority. Small agencies had lower means overall than other agencies. Officers did rate exploiting authority as more serious than abuse of authority. The gamma scores for agency size are weak and show the lack of any clearly defined relationship between agency size and officer attitudes towards misconduct. The complete results regarding size of agency demonstrate the unclear and potentially shifting impact of this variable on the attitudes of police officers. The same uncertainty is reflected in the literature.

Some trends that coincide with previous results do emerge. Respondents rate exploiting authority and malfeasance as more serious than conflict of interest. Exploiting authority is rated as more serious than abuse of authority, and almost as serious as malfeasance. While exploiting authority has a majority of officers rating it as very serious, the percentages are much lower than those rating malfeasance as very serious.

Two additional variables that have not been explored thus far deserve attention. First, the variable that measures an officer's perceptions of existing agency policy and second, the variable that measures officer perceptions of peer attitudes towards misconduct. These two variables have the potential to influence officer awareness moreso than any other variable explored in this study. There is a strong correlation, as indicated in the table below, between agency policy and an officer's attitude towards misconduct. This strong correlation suggests that at the very least an officer's awareness of existing policy does impact their attitudes towards misconduct. 
Table 4.6: Correlations between Agency Policy and Officer Attitudes

\begin{tabular}{|l|l|}
\hline & \multicolumn{1}{|c|}{ Correlation } \\
\hline Conflict of Interest awareness and knowledge of policy & $.569^{* *}$ \\
\hline Exploiting Authority awareness and knowledge of policy & $.577^{* *}$ \\
\hline Abuse of Authority awareness and knowledge of policy & $.488^{* *}$ \\
\hline Malfeasance awareness and knowledge of policy & $.763^{* *}$ \\
\hline
\end{tabular}
$* * \mathrm{p}<.05$

There is an even higher correlation, as indicated in the table below, between an officer's perception of peer attitudes towards misconduct and the officer's attitude towards misconduct. This very high correlation could be attributed to a solidarity amongst officers within an agency or it could be an officer projecting his/her own views on peers. To some extent the former may be true given the low standard deviations and variances for exploiting authority and malfeasance. Standard deviations and variances are much higher, however, for conflict of interest and abuse of authority suggesting officers may be projecting views.

Table 4.7: Correlations between Officer Attitudes and Perceptions of Peer Attitudes

\begin{tabular}{|l|l|}
\hline & \multicolumn{1}{c|}{ Correlation } \\
\hline Conflict of Interest awareness and peer attitudes & $.844^{* *}$ \\
\hline Exploiting Authority awareness and peer attitudes & $.775^{* *}$ \\
\hline Abuse of Authority awareness and peer attitudes & $.815^{* *}$ \\
\hline Malfeasance awareness and peer attitudes & $.721^{* *}$ \\
\hline
\end{tabular}
$* * \mathrm{p}<.05$

\section{An Ethical Awareness Regression Model}

Thus far, this chapter has explored the independent variables separately (with the exception of years of service which is controlled for supervisory position). Two new variables are included in the regression model - the officer's perception of peer attitudes and 
the officer's perception of existing agency policy. Regression permits assessing the combined and relative impact of the independent variables. The regression model that follows explores the predictive nature of all the variables coupled with the variables explored in the previous section.

Table 4.8: Ethical Awareness Regression

\begin{tabular}{|c|c|c|c|c|}
\hline $\begin{array}{l}\text { Independent } \\
\text { Variables }\end{array}$ & $\begin{array}{c}\text { Conflict of } \\
\text { Interest } \\
\text { B(t) }\end{array}$ & $\begin{array}{c}\text { Exploiting } \\
\text { Authority } \\
\text { B(t) }\end{array}$ & $\begin{array}{c}\text { Abuse of } \\
\text { Authority } \\
\text { B(t) }\end{array}$ & $\begin{array}{c}\text { Malfeasance } \\
\text { B(t) }\end{array}$ \\
\hline Others Seriousness & $.741(68.927)^{* *}$ & $.643(51.647)^{* *}$ & $.750(67.564)^{* *}$ & $.423(35.064)^{* *}$ \\
\hline Policy & $.160(14.793)^{* *}$ & $.235(18.922)^{* *}$ & $.152(13.697)^{* *}$ & $.520(43.186)^{* *}$ \\
\hline Rank & $.122(11.580)^{* *}$ & $.101(8.182)^{* *}$ & $.126(10.943)^{* *}$ & $.034(2.958)^{* *}$ \\
\hline Length of Service & $.007(.667)$ & $.012(1.006)$ & $-.020(-1.792)$ & $.004(.333)$ \\
\hline Agency Size & $-.014(-1.539)$ & $.008(.702)$ & $-.007(-.646)$ & $-.005(-.459)$ \\
\hline Adjusted $\mathrm{R}^{2}$ & .748 & .653 & .700 & .703 \\
\hline$F$ & 1816.754 & 1151.997 & 1427.034 & 1449.488 \\
\hline s.e. & .606 & .429 & .605 & .185 \\
\hline
\end{tabular}

According to the conflict of interest model, $75 \%$ of an officer's attitude towards the seriousness of this type of misconduct can be explained by the variables included in the model. The other types of misconduct had high percentages, as well, with $65 \%$ of the exploiting authority model, $70 \%$ of the abuse of authority model, and $70 \%$ of the malfeasance model explained by the independent variables.

Regardless of the nature of the misconduct, the factors that influence an officer's 
attitudes towards misconduct the most consistently are the officer's perception of peer attitudes towards misconduct, the officer's perception of whether a policy exists within their agency, and the officer's rank. The officer's perception of peer attitudes is the strongest predictor for conflict of interest $(\beta=.741)$, exploiting authority $(\beta=.643)$, and abuse of authority $(\beta=.750)$. The officer's perception of whether a policy exists within their agency is the strongest predictor for malfeasance misconduct $(\beta=.520)$ with peer attitudes $(\beta=.423)$ a close second. As indicated in the earlier discussion, when controlling for rank and supervisory status, length of service is not related to awareness. Also, agency size appears to have little, if any, separate impact on an officer's ethical awareness across all types of misconduct. Unstandardized coefficients yielded similar results. Using stepwise and hierarchical regression did not impact these results.

The regression model is presumably impacted by the high correlation between an officer's own attitudes regarding the misconduct and the officer's perception of the peer's attitudes towards misconduct. Although excessively high levels of collinearity $\left(\mathrm{R}^{2} \geq .80\right)$ are not present, $\mathrm{R}^{2}$ comes dangerously close to the threshold. None of the correlations between these variables exceeds .90 eliminating singularity or perfect multicollinearity (Tabachnick and Fidell 2001). Still, in considering future regressions, care will be taken to distinguish between what may be a tightly clustered set of mutually reinforcing attitudes, on the one hand, and other more objectively measurable characteristics on the other. ${ }^{5}$

${ }^{5}$ A regression model that excludes perceptions regarding peer attitudes influences the results yielding an adjusted $\mathrm{R}^{2}$ of .347 for conflict of interest, .280 for exploiting authority, .250 for abuse of authority and .583 for malfeasance. 


\section{Conclusions}

Descriptive statistics in this section have shown officers consistently believe abuse of authority is less serious than exploiting authority misconduct regardless of years of service, rank, supervisory position or size of agency. This contradicts hypothesis one which asserts that the more serious the misconduct, the higher the officer's ethical awareness. Support can be found for hypothesis one in that exploiting authority, abuse of authority and malfeasance consistently have higher means than conflict of interest. Also, malfeasance consistently has the highest means. Officers from medium and large agencies, who have been in service longer, who are administrators, detectives, or supervisors tend to rate misconduct more seriously than other officers. These results lend partial support to hypotheses two and three.

An officer's ethical awareness is most impacted by the nature of the misconduct and whether the officer is a supervisor. Other factors that contribute include the size of the officer's agency, the length of service, and the officer's rank. The longer an officer has been in service, the higher that officer's rank and supervisory position will have higher ethical awareness. Finally, the size of the police agency has a negative impact on conflict of interest while size of agency has a positive impact on attitudes towards abuse of authority. Therefore, officers in smaller agencies may view conflict of interest more seriously while officers in larger agencies view abuse of authority more seriously. The following section explores an ethical awareness regression model that takes into consideration the officer's perception of peer attitudes and agency policy, rank, length of service, and agency size.

Analysis of association and comparison of mean ratings of seriousness, comparison of officer perceptions with objective measures of seriousness, and the regression model lend 
partial support to the first six hypotheses. Hypothesis one asserts that the more serious the misconduct, the higher an officer's ethical awareness. Malfeasance consistently has higher means than the other types of misconduct. Exploiting authority, however, was consistently rated more seriously than abuse of authority, contradicting hypothesis one in part.

Hypothesis two asserts that officers who are supervisors (or higher rank) will have higher ethical awareness. Both supervisors and managers had higher levels of ethical awareness although they shared the same tendency as observed in the overall sample to rate abuse of authority lower than exploiting authority. In subsequent chapters, only supervisor status will be used in crosstabulations, and rank which separates non-supervisors from supervisors will be used in regression. Rank impacted ethical awareness according to the regression model.

Hypothesis three asserts that length of service controlling for rank and supervisory position will have a curvilinear relationship with ethical awareness. The results support hypothesis three in that officers with less than one year of service consistently had higher ethical awareness than officers with one to ten years of service. Also, officers with eleven or more years of service generally increased in ethical awareness creating the curvilinear relationship hypothesized in this study.

Hypothesis four asserts that size of police agency will not impact an officer's ethical awareness. This hypothesis is supported by the data. There were no clear trends across the four measures. Size does not have a significant effect in the regression model.

Hypothesis five asserts that policy will impact an officer's ethical awareness and this is supported by the data. The regression model shows awareness of policy as the second 
strongest predictor of ethical awareness. Hypothesis six asserts that an officer's perceptions regarding peer ethical awareness will impact an officer's ethical awareness. The regression model showed this variable to be the strongest predictor of an officer's ethical awareness. What impact does an officer's ethical awareness have on an officer's ethical standards? Do officers feel as strongly about punishment for police misconduct as they do about the behavior itself? The following chapter explores ethical standards. 
CHAPTER FIVE

Ethical Standards

116 
The NIJ study addresses ethical standards through questions regarding punishment. Officers are asked to assess what punishment should follow from the various misconduct scenarios as well as what punishment would follow the misconduct described and whether their agency has an established policy regarding the misconduct. Standards were measured in this study according to six categories of possible punishment for officer misconduct rated on a scale from one to six. Punishments offered as responses in the NIJ instrument include and are coded as follows:

(1) no punishment,

(2) verbal reprimand,

(3) written reprimand,

(4) period of suspension without pay,

(5) demotion in rank, and

(6) dismissal.

These are not the only punishment options available to agencies. For example, officers can be transferred to undesirable units or requested transfers can be denied. This chapter focuses on responses to what punishment officers believe should follow misconduct and what punishment would follow. This chapter begins by analyzing the descriptive statistics for ethical standards followed by a regression model for ethical standards.

\section{A. Hypotheses for Ethical Standards}

Hypotheses seven through thirteen focus on the relationship between ethical standards and the nature of the misconduct, individual and organizational factors. These individual and organizational factors include supervisory position, rank, years of service, agency size, policy, ethical awareness, and perceptions of peer attitudes.

H7: The more serious the misconduct, the higher that officer's ethical standards.

H8: Officers who are supervisor will have higher ethical standards. 
H9: An officer's length of service controlling for rank and supervisory status will have a curvilinear relationship to an officer's ethical standards.

H10: The size of the police agency will have no relationship to an officer's ethical standards.

H11: An officer's awareness of existing policies regarding misconduct will positively impact that officer's ethical standards

H12: An officer's perceptions regarding peer ethical awareness and standards will positively impact that officer's ethical standards.

H13: The higher an officer's ethical awareness, the higher that officer's ethical standards.

Ethical standards are measured according to what an officer believes should be the punishment for misconduct. The ethical standards measure below was created averaging all of the scenario responses regarding punishment that should follow misconduct. The scenarios fall into four categories which include conflict of interest, exploiting authority, abuse of authority and malfeasance and means were used for the scenarios falling into each category.

\section{B. Ethical Standards and Situational, Individual, and Organizational Variables}

How do officer attitudes regarding discipline compare against objective measures regarding misconduct? Objective measures would indicate that conflict of interest misconduct should warrants a verbal or written reprimand. Exploiting authority should receive at least a suspension without pay or perhaps a demotion in rank. Abuse of authority and malfeasance warrant dismissal.

The dependent variables are a little different when analyzing ethical standards as opposed to ethical awareness. First, ethical standards are not rated on a Lykert-type scale, but are actual categories of punishment. Second, ethical standards are measured on a scale from 
one to six, that increases in severity. Table 5.1 below utilizes the same four types of ethical awareness misconduct as dependent variables.

Table 5.1: Ethical Standards Dependent Variable Summary

\begin{tabular}{|l|l|l|l|l|}
\hline \multicolumn{5}{|c|}{ (1) no punishment (2) verbal reprimand (3) written reprimand } \\
(4) period of suspension without pay (5) demotion in rank (6) dismissal
\end{tabular}

*largest percentage/(n)

As with ethical awareness, respondents generally view exploiting authority as more serious than abuse of authority. A majority of respondents (69\%) rate exploiting authority as deserving suspension without pay, demotion or dismissal. Only half as many respondents $(35 \%)$ rate abuse of authority as deserving the same disciplinary actions. These results contradict objective measures that rate abuse of authority as deserving demotion or dismissal. These results also contradict hypothesis five which posits that the more serious the misconduct, the higher the ethical standards for officers.

Unlike the ethical awareness results, in which respondents view exploiting authority as almost as serious as malfeasance, respondents do not view exploiting authority as 
deserving the same level of punishment as malfeasance. An overwhelming majority of respondents (82\%) indicate malfeasance deserves demotion or dismissal, while only $30 \%$ indicate that exploiting authority deserves demotion or dismissal. This finding may suggest that attitude about discipline is a more demanding measure of ethical attitudes than awareness. In support of hypothesis five, exploiting authority, abuse of authority and malfeasance are all rated as deserving more punishment than conflict of interest and malfeasance is rated as deserving the strongest punishment.

Objective measures would dictate a verbal or written reprimand for conflict of interest misconduct. Less than a majority of respondents (42\%), however, believe that conflict of interest deserves a verbal reprimand and even fewer (19\%) would give a written reprimand.

Supervisors are the individuals responsible for determining, administering and enforcing the appropriate punishment for officer misconduct. This responsibility gives the supervisor a somewhat different perspective with respect to punishment. Table 5.2 below explores the impact of supervisory position has on ethical standards. 
Table 5.2: Ethical Standards and Supervisory Position

\begin{tabular}{|c|c|c|c|c|}
\hline \multicolumn{5}{|c|}{$\begin{array}{l}\text { (1) no punishment (2) verbal reprimand (3) written reprimand } \\
\text { (4) period of suspension without pay (5) demotion in rank (6) dismissal }\end{array}$} \\
\hline & $\begin{array}{l}\text { Conflict of } \\
\text { Interest }\end{array}$ & $\begin{array}{l}\text { Exploiting } \\
\text { Authority }\end{array}$ & $\begin{array}{l}\text { Abuse of } \\
\text { Authority }\end{array}$ & Malfeasance \\
\hline $\begin{array}{l}\text { Supervisor } \\
\text { No punishment } 1.5 \\
\text { Verbal reprimand } 1.6-2.5 \\
\text { Written reprimand } 2.6-3.5 \\
\text { Suspen sion without pay } 3.6-4.5 \\
\text { Demotion or dismissal } 4.6-6\end{array}$ & $\begin{array}{l}13.9 \%(85) \\
39.6 \%(243) * \\
27.7 \%(170) \\
13.1 \%(80) \\
5.7 \%(35)\end{array}$ & $\begin{array}{l}0.0 \%(0) \\
1.2 \%(7) \\
15.8 \%(97) \\
37.9 \%(233) \\
45.1 \%(277)^{*}\end{array}$ & $\begin{array}{l}4.6 \%(28) \\
16.8 \%(103) \\
32.2 \%(198) \\
33.9 \%(208)^{*} \\
12.5 \%(77)\end{array}$ & $\begin{array}{l}0.0 \%(0) \\
0.2 \%(1) \\
0.8 \%(5) \\
6.5 \%(40) \\
92.5 \%(568)^{*}\end{array}$ \\
\hline Means & $2.78^{*}$ & $4.36^{*}$ & $3.55^{*}$ & $5.56^{*}$ \\
\hline $\begin{array}{l}\text { Non-Supervisor } \\
\text { No punishment } 1.5 \\
\text { Verbal reprimand } 1.6-2.5 \\
\text { Written reprimand } 2.6-3.5 \\
\text { Suspen sion without pay } 3.6-4.5 \\
\text { Demotion or dismissal } 4.6-6\end{array}$ & $\begin{array}{l}32.4 \%(801) \\
42.9 \%(1059) * \\
17.2 \%(425) \\
5.6 \%(137) \\
1.9 \%(48)\end{array}$ & $\begin{array}{l}0.7 \%(17) \\
5.5 \%(136) \\
28.3 \%(700) \\
39.0 \%(962)^{*} \\
26.5 \%(654)\end{array}$ & $\begin{array}{l}9.7 \%(240) \\
24.8 \%(611) \\
33.5 \%(828)^{*} \\
22.2 \%(547) \\
9.8 \%(242)\end{array}$ & $\begin{array}{l}0.3 \%(7) \\
0.3 \%(7) \\
3.5 \%(87) \\
17.1 \%(422) \\
78.8 \%(1949) *\end{array}$ \\
\hline Means & 2.22 & 3.91 & 3.21 & 5.13 \\
\hline Gamma & $.363 * *$ & $.303 * *$ & $.221 * *$ & $.411 * *$ \\
\hline
\end{tabular}

*largest percentage/(n)/mean

There are important differences in attitudes between supervisors and non-supervisors.

A third of supervisors view abuse of authority as deserving suspension without pay (34\%)

compared to $22 \%$ of non-supervisors. These results show support for hypothesis eight which asserts that supervisors will have higher ethical standards than non-supervisors.

Exploiting authority is viewed as deserving high levels of punishment by supervisors where $45 \%$ of supervisors would punish officers who exploit authority with either demotion or dismissal. Meanwhile, $27 \%$ of non-supervisors rate exploiting authority as deserving the 
same form of punishment. Regardless of supervisory position, respondents rate abuse of authority as deserving less punishment than exploiting authority. These results contradict hypothesis seven in part as ethical standards did not increase steadily where misconduct became more serious. There is partial support for hypothesis seven in that malfeasance, abuse of authority, and exploiting authority all rated higher means for harsher punishment than conflict of interest.

Only two in five supervisors (40\%) rate conflict of interest as deserving a verbal reprimand and approximately the same percentage of non-supervisors (43\%) rate conflict of interest as deserving the same discipline. The difference between supervisors and nonsupervisors within conflict of interest can be seen in the percentage of supervisors $(14 \%)$ and non-supervisors $(32 \%)$ that believe no punishment is warranted for conflict of interest violations. These results lend further support to hypothesis eight showing supervisors to be more ethically aware than non-supervisors.

As was the case for ethical awareness, means for ethical standards are higher with supervisors than with non-supervisors. The difference between means for supervisors and non-supervisors is larger for conflict of interest than the other types of misconduct with the least difference in means with respect to malfeasance. This was also the case with ethical awareness indicating more consensus amongst respondents with respect to malfeasance and less consensus with respect to conflict of interest.

As was the case within ethical awareness, gamma scores are moderately strong across all types of misconduct. Abuse of authority gamma weights are the lowest of the four scores indicating the weakest relationship. These results support a positive relationship between 
supervisory position and an officer's attitude towards punishment for misconduct. As noted in Chapter 4, rank will be explored further in the regression model later in this chapter.

What relationship, if any, will there be between years of service and punishment? A curvilinear relationship appeared in Chapter 4 between ethical awareness and years of service. Ethical standards, however, are different as previously pointed out. Years of service controlling for supervisory status is explored in Table 5.3 below.

Table 5.3: Ethical Standards and Years of Service Non-supervisors only

\begin{tabular}{|c|c|c|c|c|}
\hline \multicolumn{5}{|c|}{$\begin{array}{l}\text { (1) no punishment (2) verbal reprimand (3) written reprimand } \\
\text { (4) period of suspension without pay (5) demotion in rank (6) dismissal }\end{array}$} \\
\hline & $\begin{array}{l}\text { Conflict of } \\
\text { Interest }\end{array}$ & $\begin{array}{l}\text { Exploiting } \\
\text { Authority }\end{array}$ & $\begin{array}{l}\text { Abuse of } \\
\text { Authority }\end{array}$ & Malfeasance \\
\hline $\begin{array}{l}\text { Less than } 1 \text { Year } \\
\text { No punishment } 1.5 \\
\text { Verbal reprimand } 1.6-2.5 \\
\text { Written reprimand } 2.6-3.5 \\
\text { Suspension without pay } 3.6-4.5 \\
\text { Demotion or dismissal } 4.6-6\end{array}$ & $\begin{array}{l}29.5 \%(38) \\
48.1 \%(62)^{*} \\
14.7 \%(19) \\
5.4 \%(7) \\
2.3 \%(3)\end{array}$ & $\begin{array}{l}0.8 \%(1) \\
3.1 \%(4) \\
23.2 \%(30) \\
40.3 \%(52)^{*} \\
32.6 \%(42)\end{array}$ & $\begin{array}{l}2.3 \%(3) \\
24.0 \%(31) \\
29.5 \%(38)^{*} \\
22.5 \%(29) \\
21.7 \%(28)\end{array}$ & $\begin{array}{l}0.8 \%(1) \\
0.0 \%(0) \\
1.6 \%(2) \\
20.9 \%(27) \\
76.7 \%(99)^{*}\end{array}$ \\
\hline Means & 2.26 & 4.05 & $3.59^{*}$ & 5.11 \\
\hline $\begin{array}{l}1-2 \text { Years } \\
\text { No punishment } 1.5 \\
\text { Verbal reprimand } 1.6-2.5 \\
\text { Written reprimand } 2.6-3.5 \\
\text { Suspension without pay } 3.6-4.5 \\
\text { Demotion or dismissal } 4.6-6\end{array}$ & $\begin{array}{l}38.8 \%(93)^{*} \\
38.3 \%(92) \\
10.4 \%(25) \\
8.3 \%(20) \\
3.3 \%(10)\end{array}$ & $\begin{array}{l}1.2 \%(3) \\
5.7 \%(14) \\
31.8 \%(76) \\
36.4 \%(87)^{*} \\
24.7 \%(59)\end{array}$ & $\begin{array}{l}8.0 \%(19) \\
29.3 \%(70) \\
30.5 \%(73)^{*} \\
19.2 \%(46) \\
13.0 \%(31)\end{array}$ & $\begin{array}{l}0.4 \%(1) \\
0.4 \%(1) \\
5.4 \%(13) \\
22.9 \%(55) \\
70.9 \% \\
(170)^{*}\end{array}$ \\
\hline Means & 2.20 & 3.86 & 3.28 & 4.95 \\
\hline $\begin{array}{l}3-5 \text { Years } \\
\text { No punishment } 1.5 \\
\text { Verbal reprimand } 1.6-2.5 \\
\text { W ritten reprimand } 2.6-3.5 \\
\text { Suspension without pay } 3.6-4.5 \\
\text { Demotion or dismissal } 4.6-6\end{array}$ & $\begin{array}{l}38.9 \%(182) \\
41.4 \%(194)^{*} \\
15.6 \%(73) \\
2.4 \%(11) \\
1.7 \%(8)\end{array}$ & $\begin{array}{l}1.1 \%(5) \\
7.4 \%(35) \\
33.4 \%(157) \\
34.3 \%(161)^{*} \\
23.8 \%(112)\end{array}$ & $\begin{array}{l}13.4 \%(63) \\
24.9 \%(117) \\
31.3 \%(147)^{*} \\
21.5 \%(101) \\
8.9 \%(42)\end{array}$ & $\begin{array}{l}0.4 \%(2) \\
0.4 \%(2) \\
5.8 \%(27) \\
22.1 \%(104) \\
71.3 \% \\
(335) *\end{array}$ \\
\hline Means & 2.05 & 3.77 & 3.12 & 4.94 \\
\hline
\end{tabular}


Table 5.3 (continued)

(1) no punishment (2) verbal reprimand (3) written reprimand (4) period of suspension without pay (5) demotion in rank (6) dismissal

\begin{tabular}{|c|c|c|c|c|}
\hline $\begin{array}{l}6-10 \text { Years } \\
\text { No punishment } \leq 1.5 \\
\text { Verbal reprimand } 1.6-2.5 \\
\text { Written reprimand } 2.6-3.5 \\
\text { Suspension without pay } 3.6-4.5 \\
\text { Demotion or dismissal } 4.6-6\end{array}$ & $\begin{array}{l}34.0 \%(239) \\
45.5 \%(320)^{*} \\
15.7 \%(110) \\
3.7 \%(26) \\
1.1 \%(8)\end{array}$ & $\begin{array}{l}0.3 \%(2) \\
5.3 \%(37) \\
30.0 \%(210) \\
39.9 \%(280)^{*} \\
24.5 \%(172)\end{array}$ & $\begin{array}{l}9.9 \%(69) \\
24.1 \%(169) \\
35.7 \%(250)^{*} \\
22.3 \%(156) \\
8.0 \%(56)\end{array}$ & $\begin{array}{l}0.0 \%(0) \\
0.0 \%(0) \\
3.3 \%(23) \\
13.8 \%(97) \\
82.9 \% \\
(583)^{*}\end{array}$ \\
\hline Means & 2.12 & 3.88 & 3.18 & 5.19 \\
\hline $\begin{array}{l}11-15 \text { Years } \\
\text { No punishment } \leq 1.5 \\
\text { Verbal reprimand } 1.6-2.5 \\
\text { Written reprimand } 2.6-3.5 \\
\text { Suspension without pay } 3.6-4.5 \\
\text { Demotion or dismissal } 4.6-6\end{array}$ & $\begin{array}{l}28.9 \%(110) \\
44.1 \%(168)^{*} \\
17.8 \%(68) \\
8.4 \%(32) \\
0.8 \%(3)\end{array}$ & $\begin{array}{l}0.5 \%(2) \\
4.5 \%(17) \\
26.7 \%(102) \\
40.3 \%(154)^{*} \\
28.0 \%(107)\end{array}$ & $\begin{array}{l}11.0 \%(42) \\
23.3 \%(89) \\
35.6 \%(136)^{*} \\
21.2 \%(81) \\
8.9 \%(34)\end{array}$ & $\begin{array}{l}0.3 \%(1) \\
0.0 \%(0) \\
2.3 \%(9) \\
17.8 \%(68) \\
79.6 \% \\
(304)^{*}\end{array}$ \\
\hline Means & 2.26 & 3.99 & 3.17 & 5.17 \\
\hline $\begin{array}{l}\text { 16-20 Years } \\
\text { No punishment } 1.5 \\
\text { Verbal reprimand } 1.6-2.5 \\
\text { Written reprimand } 2.6-3.5 \\
\text { Suspension without pay } 3.6-4.5 \\
\text { Demotion or dismissal } 4.6-6\end{array}$ & $\begin{array}{l}28.7 \%(76) \\
41.9 \%(111)^{*} \\
20.8 \%(55) \\
7.5 \%(20) \\
1.1 \%(3)\end{array}$ & $\begin{array}{l}0.8 \%(2) \\
6.4 \%(17) \\
23.5 \%(62) \\
41.7 \%(110)^{*} \\
27.6 \%(73)\end{array}$ & $\begin{array}{l}9.5 \%(25) \\
25.7 \%(68) \\
32.6 \%(86)^{*} \\
23.1 \%(61) \\
9.1 \%(24)\end{array}$ & $\begin{array}{l}0.0 \%(0) \\
1.1 \%(3) \\
2.7 \%(7) \\
14.8 \%(39) \\
81.4 \% \\
(215)^{*}\end{array}$ \\
\hline Means & 2.31 & 3.93 & 3.23 & 5.25 \\
\hline $\begin{array}{l}\text { Over } 20 \text { Years } \\
\text { No punishment } 1.5 \\
\text { Verbal reprimand } 1.6-2.5 \\
\text { Written reprimand } 2.6-3.5 \\
\text { Suspension without pay } 3.6-4.5 \\
\text { Demotion or dismissal } 4.6-6\end{array}$ & $\begin{array}{l}22.1 \%(60) \\
40.4 \%(110)^{*} \\
25.7 \%(70) \\
7.0 \%(19) \\
4.8 \%(13)\end{array}$ & $\begin{array}{l}0.7 \%(2) \\
4.4 \%(12) \\
21.7 \%(59) \\
41.6 \%(113)^{*} \\
31.6 \%(86)\end{array}$ & $\begin{array}{l}6.6 \%(18) \\
24.3 \%(66) \\
35.3 \%(96)^{*} \\
25.0 \%(68) \\
8.8 \%(24)\end{array}$ & $\begin{array}{l}0.7 \%(2) \\
0.4 \%(1) \\
2.2 \%(6) \\
11.8 \%(32) \\
84.9 \% \\
(231)^{*}\end{array}$ \\
\hline Means & $2.56^{*}$ & $4.08 *$ & 3.29 & $5.32 *$ \\
\hline $\mathrm{Gamma}^{6}$ & $.116^{* *}$ & $.064 * *$ & -.001 & $.133 * *$ \\
\hline
\end{tabular}

*largest percentage/(n)/mean

${ }^{6}$ Gamma scores for supervisors are $.142 * *$ for conflict of interest, $.096 * *$ for exploiting authority, .068 for abuse of authority, and $.142 * *$ for malfeasance. 
Regardless of the number of years an officer has served, respondents rate exploiting authority as deserving more punishment than abuse of authority. These results contradict hypothesis seven with respect to the nature of the misconduct coinciding with ethical standards. A third of officers with less than one year of service and a third of officers with more than twenty years of service rate exploiting authority as deserving either demotion or dismissal as compared to about a quarter of officers with one to ten years of service rate exploiting authority as deserving either a written reprimand or suspension without pay. Gamma scores are weak as was the case with ethical awareness suggesting a non-linear relationship is possible. These results indicate a curvilinear relationship and support hypothesis eight.

There is no curvilinear relationship within conflict of interest or abuse of authority. There is, however, a fairly substantial gap between attitudes of officers with less than one year of service (48\% verbal reprimand) and officers with one to two years of service ( $38 \%$ verbal reprimand) with respect to conflict of interest. There is also a gap in attitudes between officers with three to five years of service (31\% written reprimand) and six to ten years of service (36\% written reprimand) with respect to abuse of authority. These results, however, contradict hypothesis nine.

As for malfeasance, there is little variation in this category of misconduct. A majority of all officers, regardless of years of service, believe that this type of misconduct deserves demotion or dismissal. The variation occurs in the percentages of officers who believe that this type of misconduct warrants suspension without pay or some other lesser punishment. Officers with one to five years of service $(71 \%)$ have the lowest percentages of officers that choose demotion or dismissal. Officers with less than one year of service (77\%) and officers 
with over six years of service (80-85\%) have higher percentages of respondents that recommend demotion or dismissal. These results show partial support for hypothesis nine that there is a curvilinear relationship between ethical standards and years of service.

As was the case with ethical awareness, there is gap in means across all types of misconduct between officers who have been in service for less than one year and officers who have been in service for one to two years. Means continue to drop with officers who have three to five years of service and then rise steadily after six years of service. The differences in means are less pronounced here than with ethical awareness. Still, these results show some support for hypothesis nine.

There was no relationship between ethical awareness and agency size. It is hypothesized that the same will be true with ethical standards. Table 5.4 below explores whether a relationship exists between agency size and an officer's ethical standards. 
Table 5.4: Ethical Standards and Agency Size

\begin{tabular}{|c|c|c|c|c|}
\hline \multicolumn{5}{|c|}{$\begin{array}{l}\text { (1) no punishment (2) verbal reprimand (3) written reprimand } \\
\text { (4) period of suspension without pay (5) demotion in rank (6) dismissal }\end{array}$} \\
\hline (n, \# of agencies) & $\begin{array}{l}\text { Conflict of } \\
\text { Interest }\end{array}$ & $\begin{array}{l}\text { Exploiting } \\
\text { Authority }\end{array}$ & $\begin{array}{l}\text { Abuse of } \\
\text { Authority }\end{array}$ & Malfeasance \\
\hline $\begin{array}{l}\text { Very Small, }<25 \text { officers }(87,8) \\
\text { No punishment } 1.5 \\
\text { Verbal reprimand } 1.6-2.5 \\
\text { Written reprimand } 2.6-3.5 \\
\text { Suspen sion without pay } 3.6-4.5 \\
\text { Demotion or dismissal } 4.6-6\end{array}$ & $\begin{array}{l}9.2 \%(8) \\
57.5 \%(50)^{*} \\
24.1 \%(21) \\
4.6 \%(4) \\
4.6 \%(4)\end{array}$ & $\begin{array}{l}0.0 \%(0) \\
9.2 \%(8) \\
28.7 \%(25) \\
36.8 \%(32)^{*} \\
25.3 \%(22)\end{array}$ & $\begin{array}{l}20.7 \%(18) \\
29.9 \%(26) \\
33.3 \%(29)^{*} \\
11.5 \%(10) \\
4.6 \%(4)\end{array}$ & $\begin{array}{l}0.0 \%(0) \\
0.0 \%(0) \\
3.4 \%(3) \\
23.0 \%(20) \\
73.6 \%(64)^{*}\end{array}$ \\
\hline Means & 2.59 & 3.81 & 2.68 & 4.96 \\
\hline $\begin{array}{l}\text { Small, } 25-75 \text { officers }(212,9) \\
\text { No punishment } 1.5 \\
\text { Verbal reprimand } 1.6-2.5 \\
\text { Written reprimand } 2.6-3.5 \\
\text { Suspension without pay } 3.6-4.5 \\
\text { Demotion or dismissal } 4.6-6\end{array}$ & $\begin{array}{l}26.4 \%(56) \\
51.4 \%(109)^{*} \\
17.5 \%(37) \\
3.8 \%(8) \\
0.9 \%(2)\end{array}$ & $\begin{array}{l}1.0 \%(2) \\
7.1 \%(15) \\
31.6 \%(67) \\
41.0 \%(87)^{*} \\
19.3 \%(41)\end{array}$ & $\begin{array}{l}16.0 \%(34) \\
38.2 \%(81)^{*} \\
28.8 \%(61) \\
12.3 \%(26) \\
4.7 \%(10)\end{array}$ & $\begin{array}{l}0.5 \%(1) \\
0.9 \%(2) \\
2.4 \%(5) \\
21.2 \%(45) \\
75.0 \%(159) *\end{array}$ \\
\hline Means & 2.22 & 3.74 & 2.75 & 4.99 \\
\hline $\begin{array}{l}\text { Medium, } 76-200 \text { officers }(344,6) \\
\text { No punishment } 1.5 \\
\text { Verbal reprimand } 1.6-2.5 \\
\text { Written reprimand } 2.6-3.5 \\
\text { Suspension without pay } 3.6-4.5 \\
\text { Demotion or dismissal } 4.6-6\end{array}$ & $\begin{array}{l}22.7 \%(78) \\
45.6 \%(157)^{*} \\
22.4 \%(77) \\
7.0 \%(24) \\
2.3 \%(8)\end{array}$ & $\begin{array}{l}0.3 \%(1) \\
2.6 \%(9) \\
30.9 \%(106) \\
33.8 \%(116)^{*} \\
32.4 \%(111)\end{array}$ & $\begin{array}{l}5.3 \%(18) \\
21.9 \%(75) \\
33.5 \%(115)^{*} \\
26.8 \%(92) \\
12.5 \%(43)\end{array}$ & $\begin{array}{l}0.0 \%(0) \\
0.0 \%(0) \\
2.9 \%(10) \\
15.2 \%(52) \\
81.9 \%(281)^{*}\end{array}$ \\
\hline Means & 2.42 & 4.07 & 3.43 & 5.28 \\
\hline $\begin{array}{l}\text { Large, } 201-500 \text { officers }(235,2) \\
\text { No punishment } 1.5 \\
\text { Verbal reprimand } 1.6-2.5 \\
\text { Written reprimand } 2.6-3.5 \\
\text { Suspen sion without pay } 3.6-4.5 \\
\text { Demotion or dismissal } 4.6-6\end{array}$ & $\begin{array}{l}12.8 \%(30) \\
35.5 \%(83)^{*} \\
20.5 \%(48) \\
20.9 \%(49) \\
10.3 \%(24)\end{array}$ & $\begin{array}{l}0.0 \%(0) \\
4.7 \%(11) \\
24.2 \%(57) \\
26.0 \%(61) \\
45.1 \%(106)^{*}\end{array}$ & $\begin{array}{l}8.5 \%(20) \\
18.7 \%(44) \\
24.7 \%(58) \\
29.4 \%(69)^{*} \\
18.7 \%(44)\end{array}$ & $\begin{array}{l}0.0 \%(0) \\
0.0 \%(0) \\
4.3 \%(10) \\
13.2 \%(31) \\
82.5 \%(194)^{*}\end{array}$ \\
\hline Means & $3.02 *$ & $4.24 *$ & $3.56^{*}$ & $5.30 *$ \\
\hline $\begin{array}{l}\text { Very Large, }>500 \text { officers }(2229,5) \\
\text { No punishment } 1.5 \\
\text { Verbal reprimand } 1.6-2.5 \\
\text { Written reprimand } 2.6-3.5 \\
\text { Suspen sion without pay } 3.6-4.5 \\
\text { Demotion or dismissal } 4.6-6\end{array}$ & $\begin{array}{l}32.2 \%(717) \\
41.0 \%(911)^{*} \\
18.7 \%(415) \\
6.1 \%(135) \\
2.0 \%(45)\end{array}$ & $\begin{array}{l}0.6 \%(14) \\
4.5 \%(100) \\
24.5 \%(545) \\
40.9 \%(909)^{*} \\
29.5 \%(655)\end{array}$ & $\begin{array}{l}8.1 \%(180) \\
22.0 \%(489) \\
34.6 \%(769)^{*} \\
25.3 \%(562) \\
10.0 \%(222)\end{array}$ & $\begin{array}{l}0.3 \%(6) \\
0.3 \%(6) \\
2.9 \%(64) \\
14.2 \%(316) \\
82.3 \%(1834)^{*}\end{array}$ \\
\hline Means & 2.24 & 4.00 & 3.31 & 5.23 \\
\hline Gamma & $-.147 * *$ & .030 & $.088 * *$ & $.059 * *$ \\
\hline
\end{tabular}

*largest percentage/(n)/mean 
Regardless of size of agency, a majority of respondents rate exploiting authority as deserving more punishment than abuse of authority. A third of respondents from large agencies rate abuse of authority as deserving suspension without pay as compared to only $12 \%$ of respondents in very small and small agencies. Medium and very large agencies had comparable results with $27 \%$ and $25 \%$ respectively. These results are also still below an expected objective measure of demotion or dismissal and in contradiction with hypothesis seven that the more serious the misconduct, the higher the officer's ethical standards.

Exploiting authority results are similar with $45 \%$ of respondents from large agencies rating exploiting authority as deserving demotion or dismissal. This is in comparison to $19 \%$ of respondents at small agencies and $25 \%$ of respondents at very small agencies. Respondents at medium size agencies and very large agencies fared a little better with 30$32 \%$ of respondents rating exploiting authority as deserving demotion or dismissal. The results for abuse of authority and exploiting authority show somewhat of a linear progression based on size of agency, however, this is the only trend that emerges from all of the results.

Conflict of interest results show no clear pattern. A majority of very small agencies (58\%) and small agencies (51\%) view conflict of interest as deserving a verbal reprimand. Meanwhile, respondents from medium to very large agencies had lower percentages ranging from $36-46 \%$ of respondents choosing verbal reprimand. Gamma scores are weak and somewhat mixed as with ethical awareness. These results support hypothesis nine showing no clear pattern particularly when compared with the results from the previous chapter on ethical awareness.

As with ethical awareness, large agencies have the highest overall means and medium 
agencies have the second highest overall means. Very small and small agencies hold the lowest overall means. These results were similar to ethical awareness overall. These results suggest there may be a relationship between agency size and ethical standards which contradicts hypothesis ten.

The trends that do occur include respondents rating exploiting authority, abuse of authority, and malfeasance as deserving more punishment than conflict of interest. Exploiting authority is rated as deserving more punishment than abuse of authority, and almost deserving as much punishment as malfeasance. While exploiting authority has a majority of officers rating it as deserving high levels of punishment, the percentages are much lower than those rating malfeasance as deserving the most serious punishment.

Officer perceptions of existing agency policy and officer perceptions of peer attitudes towards punishment will be utilized in the regression model explored in the section that follows. Correlations between agency policy and an officer's attitude towards punishment are shown in the table below. The strong correlations show that an officer's awareness of existing agency policies regarding punishment impacts the officer's attitudes towards punishment for misconduct.

Table 5.5: Correlations between Agency Policy and Officer Attitudes towards Punishment

\begin{tabular}{|l|l|}
\hline & \multicolumn{1}{|c|}{ Conflict of Interest } \\
\hline Conflict of Interest and knowledge of policy & $.549^{* *}$ \\
\hline Exploiting Authority and knowledge of policy & $.460^{* *}$ \\
\hline Abuse of Authority and knowledge of policy & $.477^{* *}$ \\
\hline Malfeasance and knowledge of policy & $.327^{* *}$ \\
\hline$* * \mathrm{p}<.05$ &
\end{tabular}

Correlations are very high as was the case with ethical awareness between an officer's 
perception of peer attitudes towards punishment and the officer's attitude towards

punishment.

Table 5.6: Correlations between Officer Attitudes and Perceptions of Peer Attitudes

\begin{tabular}{|l|l|}
\hline & \multicolumn{1}{|c|}{ Conflict of Interest } \\
\hline Conflict of Interest and peer attitudes & $.753^{* *}$ \\
\hline Exploiting Authority and peer attitudes & $.828^{* *}$ \\
\hline Abuse of Authority and peer attitudes & $.726^{* *}$ \\
\hline Malfeasance and peer attitudes & $.787^{* *}$ \\
\hline
\end{tabular}

$* * \mathrm{p}<.05$

\section{An Ethical Standards Regression Model}

Thus far, this chapter has explored supervisory position, years of service, and agency size with respect to ethical standards. What impact does the officer's perception of peer attitudes towards punishment have on the officer's attitude towards punishment? What impact does the officer's perception of policy have on the officer's ethical standards? The regression model that follows explores the predictive nature of these variables coupled with the variables explored in the previous section. 


\section{Table 5.7: Ethical Standards Regression}

\begin{tabular}{|c|c|c|c|c|}
\hline $\begin{array}{l}\text { Independent } \\
\text { Variables }\end{array}$ & $\begin{array}{l}\text { Conflict of } \\
\text { Interest } \\
\text { B(t) }\end{array}$ & $\begin{array}{l}\text { Exploiting } \\
\text { Authority } \\
\text { B(t) }\end{array}$ & $\begin{array}{c}\text { Abuse of } \\
\text { Authority } \\
\text { 乃(t) }\end{array}$ & Malfeasance \\
\hline Others Standards & $.510(40.604)^{* *}$ & $.698(65.149)^{* *}$ & $.526(41.135)^{* *}$ & $.713(60.162)^{* *}$ \\
\hline Own Seriousness & $.481(25.884)^{* *}$ & $.349(23.392)^{* *}$ & $.440(24.103)^{* *}$ & $.211(10.902)^{* *}$ \\
\hline Others Seriousness & $-.005(-.280)$ & $-.046(-3.111)^{* *}$ & $.027(1.476)$ & $-.005(-.296)$ \\
\hline Policy & $-.033(-2.623)^{* *}$ & $-.034(-3.099)^{* *}$ & $-.036(-2.919)^{* *}$ & $-.047(-2.870)^{* *}$ \\
\hline Rank & $.057(5.157)^{* *}$ & $.036(3.479)^{* *}$ & $.063(5.298)^{* *}$ & $.083(6.758)^{* *}$ \\
\hline Length of Service & $.015(1.362)$ & $.025(2.480)^{*}$ & $.012(1.065)$ & $.034(2.824)^{* *}$ \\
\hline Agency Size & $.000(.016)$ & $.015(1.650)$ & $-.006(-.620)$ & $.027(2.539)^{*}$ \\
\hline Adjusted $\mathrm{R}^{2}$ & .736 & .765 & .699 & .660 \\
\hline$F$ & 1210.331 & 1420.297 & 1008.897 & 848.011 \\
\hline s.e. & .512 & .463 & .597 & .494 \\
\hline
\end{tabular}

As with the ethical awareness models, high percentages of an officer's attitude towards punishment can be explained by the variables included in the model. Regardless of the nature of the misconduct, the factors that influence an officer's attitudes towards misconduct the most consistently are the officer's perception of peer attitudes towards punishing misconduct, the officer's perception of the seriousness of the misconduct, the officer's perception of whether a policy exists within their agency (although it is weak and negative), and the officer's rank. These results lend partial support to hypotheses twelve, eleven, eight, and nine respectively. 
The officer's perception of peer attitudes regarding punishment is the strongest predictor regardless of the type of misconduct. The officer's perception of whether a policy exists within their agency is a much weaker predictor than was the case within the ethical awareness models. The officer's perception of peer seriousness of misconduct, length of service, and agency size have mixed results with some influence depending upon the type of misconduct. Unstandardized coefficients yielded similar results. Using stepwise and hierarchical regression did not impact these results.

The regression model may be impacted by the high correlation between an officer's own attitudes regarding punishment and the officer's perception of the peer's attitudes towards punishment. ${ }^{7}$ Although high levels of collinearity $\left(\mathrm{R}^{2} \geq .80\right)$ are not present, $\mathrm{R}^{2}$ comes dangerously close to the threshold. None of the correlations between these variables exceeds .90 eliminating singularity or perfect multicollinearity (Tabachnick and Fidell 2001).

\section{Conclusions}

Hypothesis seven asserts that there is a relationship between types of misconduct and ethical standards. The more serious the misconduct, the higher an officer's ethical standards. There is partial support for this hypothesis as was the case with ethical awareness. Again, consistently across all analysis, officers found exploiting authority should warrant higher punishment than abuse of authority. Exploiting authority, abuse of authority, and malfeasance all rated higher than conflict of interest and malfeasance always rated the highest. Therefore, partial support could be found for hypothesis seven.

${ }^{7}$ A regression model that excludes perceptions regarding peer attitudes influences the results yielding an adjusted $\mathrm{R}^{2}$ of .582 for conflict of interest, .417 for exploiting authority, .518 for abuse of authority, and .225 for malfeasance. 
Hypothesis eight asserts that supervisory position will affect an officer's ethical standards. Hypothesis nine posits that an officer's ethical standards will have a curvilinear relationship to length of service. Partial support can be found for these hypotheses. Supervisors were found to have higher means and percentages compared to objective measures. Managers recommended harsher punishments than regular officers lending support for hypothesis eight. Officers with less than one year of service showed the same results as with ethical awareness recommending harsher punishment than officers with one to five years of experience. Officers with eleven years of service and higher did consistently recommend harsher punishment than officers with less experience.

Hypothesis ten asserts that there is no relationship between the size of agency and an officer's ethical standards. There is partial support for this hypothesis. There were some trends with ethical awareness and standards with respect to means suggesting that hypothesis ten is unsupported. However, analysis of percentages according to objective measures show only mixed results with no clear trends amongst percentages. The regression model also gives only mixed results showing little or no relationship between size of agency and ethical standards.

Hypothesis ten asserts a relationship between an officer's ethical standards and that officer's awareness of existing agency policies. The regression model shows a weak link with only limited support for hypothesis eleven. However, there is a strong relationship between an officer's ethical standards and an officer's perception of peer standards in support of hypothesis twelve. There is also a strong relationship between an officer's ethical standards and the officer's ethical awareness in support of hypothesis thirteen. 
Thus far this study has analyzed individual and organizational factors in order to determine the effect on an officer's ethical awareness and standards. Knowing the attitudes of officers regarding the severity of misconduct, the punishment that should follow misconduct, and the punishment that would follow misconduct, what impact does this information have on an officer's willingness to report the misconduct in question? 


\section{CHAPTER SIX}

Ethical Action 
This study theorizes that an officer's ethical action is shaped by attitudes towards misconduct and punishment. As mentioned in chapter three, an officer is more likely to break the code of silence if expected by his or her peers to do so and if it will be sustained by appropriate official disciplinary action. Thus far, this study has analyzed officer attitudes regarding seriousness of misconduct and punishment. The focus of this study now shifts to consider officer behavior, specifically, an officer's willingness to report peer misconduct.

Ethical action can take many forms. Officers could choose to counsel a fellow officer who has committed misconduct or seek help for the offending officer. Reporting misconduct is just one of many choices an officer can make under the circumstances. Within the context of this study, however, it is the only action available for analysis.

\section{A. Ethical Action Hypotheses}

Ethical action is impacted by the nature of the misconduct, individual factors, situational factors, and organizational factors. These variables are explored in the following hypotheses:

H14: The more serious the misconduct, the greater the likelihood of an officer's ethical action.

H15: Officers who are supervisor are more likely to take ethical action.

H16: An officer's length of service controlling for rank and supervisory status will have a curvilinear relationship to the officer's ethical action.

H17: The size of the police agency will have no relationship to an officer's ethical action.

H18: An officer's awareness of existing policies regarding misconduct will positively impact that officer's willingness to take ethical action.

H19: An officer's ethical and perceptions regarding peer ethical awareness, standards, and action will positively impact that officer's willingness to take ethical action. 
H20: The higher the officer's ethical awareness and standards, the greater the likelihood of an officer's ethical action.

The scenarios fall into four categories which include conflict of interest, exploiting authority, abuse of authority and malfeasance and means were used for the scenarios falling into each category.

\section{B. Ethical Action and Situational, Individual, and Organizational Variables}

Ethical action is measured similarly to ethical awareness. Respondents were asked how willing they would be to report the misconduct based on a five point Lykert-type scale with one equaling definitely unwilling to report and five equaling definitely willing to report. Objective measures would suggest that any violation of office policy, any misconduct would warrant reporting that misconduct. Histograms can be found in Appendix G.

Believing behavior is serious and deserves harsh punishment is much different from actually reporting misconduct. The same dependent variables are explored in this chapter as in the previous two chapters. The Lykert-type scale utilized gives respondents an opportunity to rate their level of willingness to report peer misconduct. Table 6.1 reports ethical action results. 
Table 6.1: Ethical Action Dependent Variable Summary

\begin{tabular}{|c|c|c|c|c|}
\hline \multicolumn{5}{|c|}{ (1) Definitely would not report - (5) Definitely would report } \\
\hline & $\begin{array}{l}\text { Conflict of } \\
\text { Interest }\end{array}$ & $\begin{array}{l}\text { Exploiting } \\
\text { Authority }\end{array}$ & $\begin{array}{l}\text { Abuse of } \\
\text { Authority }\end{array}$ & Malfeasance \\
\hline Definitely would not report $\leq 1.5$ & $48.5 \%(1503)^{*}$ & $8.2 \%(253)$ & $24.2 \%(749)$ & $5.0 \%(154)$ \\
\hline Probably would not report $1.6-2.5$ & $22.9 \%(710)$ & $10.4 \%(324)$ & $21.3 \%(659)$ & $4.8 \%(150)$ \\
\hline Might/might not report $2.6-3.5$ & $15.3 \%(475)$ & $17.9 \%(554)$ & $27.2 \%(844)^{*}$ & $7.3 \%(226)$ \\
\hline Probably would report $3.6-4.5$ & $7.8 \%(243)$ & $28.6 \%(888)$ & $16.0 \%(497)$ & $17.7 \%(551)$ \\
\hline Definitely would report $4.6-5$ & $5.5 \%(171)$ & $34.9 \%(1082)^{*}$ & $11.3 \%(350)$ & $65.2 \%(2023)^{*}$ \\
\hline Means & 2.15 & 3.71 & 2.87 & 4.32 \\
\hline
\end{tabular}

*largest percentage/(n)

Respondents are more willing to report exploiting authority (35\%) than abuse of authority (11\%). This contradicts hypothesis twelve which asserts that the more serious the misconduct, the more likely an officer is willing to report it. In support of hypothesis twelve, a majority of respondents $(65 \%)$ are definitely willing to report malfeasance. Nearly a majority of respondents (49\%) are definitely unwilling to report conflict of interest misconduct.

Results are somewhat mixed for exploiting authority and abuse of authority. A little less than one-third of respondents (29\%) would probably report exploiting authority misconduct as compared to $16 \%$ of respondents who would probably report abuse of authority. A little more than a third $(35 \%)$ of respondents would definitely report exploiting authority misconduct as compared to $11 \%$ of respondents who would definitely report abuse of authority. As many as $24 \%$ of respondents are unwilling to report abuse of authority as 
compared to $8 \%$ of respondents who are unwilling to report exploiting authority. The largest percentage of respondents within abuse of authority (27\%) might be willing to report, but are not certain, as compared to $18 \%$ within the exploiting authority category. These results contradict objective measures that rate exploiting authority as serious and abuse of authority as very serious. These results also contradict hypothesis twelve which posits that the more serious the misconduct, the more willing officers will be to report that misconduct. In support of hypothesis twelve, respondents are most willing to report malfeasance and least willing to report conflict of interest. Also, respondents are more willing to report exploiting authority and abuse of authority than they are willing to report conflict of interest.

Reporting misconduct may be as difficult an action for supervisors as for officers. Supervisors ultimately are the persons responsible for carrying out punishment as noted in Chapter 5. Whether or not supervisors are more willing than officers to take ethical action is explored in Table 6.2 below. 
Table 6.2: Ethical Action and Supervisory Position

\begin{tabular}{|c|c|c|c|c|}
\hline \multicolumn{5}{|c|}{ (1) Definitely would not report - (5) Definitely would report } \\
\hline & $\begin{array}{l}\text { Conflict of } \\
\text { Interest }\end{array}$ & $\begin{array}{l}\text { Exploiting } \\
\text { Authority }\end{array}$ & $\begin{array}{l}\text { Abuse of } \\
\text { Authority }\end{array}$ & Malfeasance \\
\hline $\begin{array}{l}\text { Supervisor } \\
\text { Definitely would not report } 1.5 \\
\text { Probably would not report } 1.6-2.5 \\
\text { Might/might not report } 2.6-3.5 \\
\text { Probably would report } 3.6-4.5 \\
\text { Definitely would report } 4.6-5\end{array}$ & $\begin{array}{l}22.1 \%(136) \\
21.1 \%(129) \\
22.4 \%(138)^{*} \\
17.1 \%(105) \\
17.3 \%(106)\end{array}$ & $\begin{array}{l}1.5 \%(9) \\
3.9 \%(24) \\
6.2 \%(38) \\
24.6 \%(151) \\
63.8 \%(392)^{*}\end{array}$ & $\begin{array}{l}12.4 \%(76) \\
15.8 \%(97) \\
26.7 \%(164)^{*} \\
22.8 \%(140) \\
22.3 \%(137)\end{array}$ & $\begin{array}{l}1.0 \%(6) \\
1.3 \%(8) \\
2.1 \%(13) \\
7.2 \%(44) \\
88.4 \%(543)^{*}\end{array}$ \\
\hline Means & $3.03 *$ & $4.45^{*}$ & $3.45 *$ & $4.79 *$ \\
\hline $\begin{array}{l}\text { Non-Supervisor } \\
\text { Definitely would not report } 1.5 \\
\text { Probably would not report } 1.6-2.5 \\
\text { Might/might not report } 2.6-3.5 \\
\text { Probably would report } 3.6-4.5 \\
\text { Definitely would report } 4.6-5\end{array}$ & $\begin{array}{l}55.1 \% \\
(1363)^{*} \\
23.4 \%(577) \\
13.4 \%(331) \\
5.5 \%(136) \\
2.6 \%(64)\end{array}$ & $\begin{array}{l}9.9 \%(244) \\
12.1 \%(299) \\
20.8 \%(514) \\
29.6 \%(732)^{*} \\
27.6 \%(681)\end{array}$ & $\begin{array}{l}27.2 \%(671) \\
22.8 \%(561) \\
27.3 \%(674)^{*} \\
14.3 \%(354) \\
8.4 \%(208)\end{array}$ & $\begin{array}{l}6.0 \%(148) \\
5.7 \%(142) \\
8.6 \%(212) \\
20.4 \%(504) \\
59.3 \%(1467)^{*}\end{array}$ \\
\hline Means & 1.93 & 3.53 & 2.72 & 4.20 \\
\hline Gamma & $.529 * *$ & $.548 * *$ & $.362 * *$ & $.604 * *$ \\
\hline
\end{tabular}

*largest percentage/(n)/mean

In support of hypothesis fifteen, there is a difference between supervisor and nonsupervisor ethical action. A majority of supervisors (64\%) would definitely report exploiting authority as compared to less than a third (28\%) of non-supervisors. An overwhelming majority of supervisors ( $88 \%$ ) would definitely report malfeasance as opposed to $59 \%$ of non-supervisors. As for conflict of interest, $34 \%$ of supervisors probably would or definitely would report whereas only $8 \%$ of non-supervisors feel the same way.

Means are consistent with results reported for ethical awareness and standards. 
Supervisors have higher means than non-supervisors. Meanwhile, gamma scores are higher here than in any variables explored thus far. Gamma weights for abuse of authority remain the weakest. Regardless of supervisory position, respondents are more willing to report exploiting authority than abuse of authority which contradicts hypothesis fourteen. These results are consistent with ethical awareness and standards.

Will new officers be willing to report misconduct? Considering that most, if not all, new officers are on probation during the first six months or so of their careers, it is unclear whether the curvilinear relationship will hold up within ethical action. Table 6.3 below explores the impact years of service has on ethical action when controlling for supervisory position.

\section{Table 6.3: Ethical Action and Years of Service Non-supervisors only}

\begin{tabular}{|c|c|c|c|c|}
\hline \multicolumn{5}{|c|}{ (1) Definitely would not report - (5) Definitely would report } \\
\hline & $\begin{array}{l}\text { Conflict of } \\
\text { Interest }\end{array}$ & $\begin{array}{l}\text { Exploiting } \\
\text { Authority }\end{array}$ & $\begin{array}{l}\text { Abuse of } \\
\text { Authority }\end{array}$ & Malfeasance \\
\hline Less than 1 Year & & & & \\
\hline Definitely would not report 1.5 & $48.1 \%(62)$ & $3.1 \%(4)$ & $15.5 \%(20)$ & $1.6 \%(2)$ \\
\hline Probably would not report $1.6-2.5$ & $33.3 \%(43)$ & $8.5 \%(11)$ & $22.5 \%(29)$ & $2.3 \%(3)$ \\
\hline Might/might not report $2.6-3.5$ & $9.3 \%(12)$ & $24.8 \%(32)$ & $26.3 \%(34)^{*}$ & $10.8 \%(14)$ \\
\hline Probably would report $3.6-4.5$ & $8.5 \%(11)$ & $35.7 \%(46)^{*}$ & $24.8 \%(32)$ & $22.5 \%(29)$ \\
\hline Definitely would report $4.6-5$ & $0.8 \%(1)$ & $27.9 \%(36)$ & $10.9 \%(14)$ & $62.8 \%(81)^{*}$ \\
\hline Means & 1.97 & 3.74 & $3.11 *$ & 4.37 \\
\hline 1-2 Years & & & & \\
\hline Definitely would not report 1.5 & $55.4 \%(133)^{*}$ & $11.3 \%(27)$ & $27.6 \%(66)$ & $7.1 \%(17)$ \\
\hline Probably would not report $1.6-2.5$ & $25.4 \%(61)$ & $16.7 \%(40)$ & $23.0 \%(55)$ & $8.3 \%(20)$ \\
\hline Might/might not report $2.6-3.5$ & $11.7 \%(28)$ & $21.8 \%(52)$ & $28.5 \%(68)^{*}$ & $10.4 \%(25)$ \\
\hline Probably would report $3.6-4.5$ & $5.0 \%(12)$ & $28.9 \%(69)^{*}$ & $13.0 \%(31)$ & $24.2 \%(58)$ \\
\hline Definitely would report 4.6 - 5 & $2.5 \%(6)$ & $21.3 \%(51)$ & $7.9 \%(19)$ & $50.0 \%(120)^{*}$ \\
\hline Means & 1.89 & 3.32 & 2.71 & 4.02 \\
\hline
\end{tabular}


Table 6.3 (continued)

\begin{tabular}{|c|c|c|c|c|}
\hline \multicolumn{5}{|c|}{ (1) Definitely would not report - (5) Definitely would report } \\
\hline $\begin{array}{l}3-5 \text { Years } \\
\text { Definitely would not report } 1.5 \\
\text { Probably would not report } 1.6-2.5 \\
\text { Might/might not report } 2.6-3.5 \\
\text { Probably would report } 3.6-4.5 \\
\text { Definitely would report } 4.6-5\end{array}$ & $\begin{array}{l}61.5 \%(288)^{*} \\
20.7 \%(97) \\
12.2 \%(57) \\
3.9 \%(18) \\
1.7 \%(8)\end{array}$ & $\begin{array}{l}13.8 \%(65) \\
13.6 \%(64) \\
23.0 \%(108) \\
28.9 \%(136)^{*} \\
20.7 \%(97)\end{array}$ & $\begin{array}{l}34.2 \%(161)^{*} \\
19.6 \%(92) \\
24.7 \%(116) \\
13.0 \%(61) \\
8.5 \%(40)\end{array}$ & $\begin{array}{l}9.2 \%(43) \\
8.5 \%(40) \\
11.3 \%(53) \\
24.0 \%(113) \\
47.0 \%(221)^{*}\end{array}$ \\
\hline Means & 1.79 & 3.30 & 2.60 & 3.89 \\
\hline $\begin{array}{l}\text { 6-10 Years } \\
\text { Definitely would not report } 1.5 \\
\text { Probably would not report } 1.6-2.5 \\
\text { Might/might not report } 2.6-3.5 \\
\text { Probably would report } 3.6-4.5 \\
\text { Definitely would report } 4.6-5\end{array}$ & $\begin{array}{l}55.5 \%(390)^{*} \\
24.7 \%(174) \\
13.1 \%(92) \\
5.0 \%(35) \\
1.7 \%(12)\end{array}$ & $\begin{array}{l}9.0 \%(63) \\
12.4 \%(87) \\
22.2 \%(156) \\
30.1 \%(211)^{*} \\
26.3 \%(185)\end{array}$ & $\begin{array}{l}27.2 \%(191)^{*} \\
25.7 \%(180) \\
26.3 \%(184) \\
13.4 \%(94) \\
7.4 \%(52)\end{array}$ & $\begin{array}{l}4.6 \%(32) \\
4.7 \%(33) \\
9.4 \%(66) \\
22.0 \%(155) \\
59.3 \%(417)^{*}\end{array}$ \\
\hline Means & 1.88 & 3.52 & 2.66 & 4.26 \\
\hline $\begin{array}{l}\text { 11-15 Years } \\
\text { Definitely would not report } 1.5 \\
\text { Probably would not report } 1.6-2.5 \\
\text { Might/might not report } 2.6-3.5 \\
\text { Probably would report } 3.6-4.5 \\
\text { Definitely would report } 4.6-5\end{array}$ & $\begin{array}{l}59.2 \%(226)^{*} \\
22.5 \%(86) \\
13.3 \%(51) \\
2.9 \%(11) \\
2.1 \%(8)\end{array}$ & $\begin{array}{l}11.0 \%(42) \\
11.5 \%(44) \\
16.5 \%(63) \\
29.1 \%(111) \\
31.9 \%(122)^{*}\end{array}$ & $\begin{array}{l}28.6 \%(109)^{*} \\
21.8 \%(83) \\
27.6 \%(105) \\
15.2 \%(58) \\
6.8 \%(26)\end{array}$ & $\begin{array}{l}7.6 \%(29) \\
5.2 \%(20) \\
7.1 \%(27) \\
17.8 \%(68) \\
62.3 \%(238)^{*}\end{array}$ \\
\hline Means & 1.83 & 3.59 & 2.67 & 4.21 \\
\hline $\begin{array}{l}\text { 16-20 Years } \\
\text { Definitely would not report } 1.5 \\
\text { Probably would not report } 1.6-2.5 \\
\text { Might/might not report } 2.6-3.5 \\
\text { Probably would report } 3.6-4.5 \\
\text { Definitely would report } 4.6-5\end{array}$ & $\begin{array}{l}52.4 \%(139)^{*} \\
22.3 \%(59) \\
15.5 \%(41) \\
5.7 \%(15) \\
4.1 \%(11)\end{array}$ & $\begin{array}{l}8.7 \%(23) \\
10.6 \%(28) \\
20.1 \%(53) \\
29.9 \%(79) \\
30.7 \%(81)^{*}\end{array}$ & $\begin{array}{l}27.3 \%(72) \\
21.2 \%(56) \\
29.9 \%(79)^{*} \\
13.6 \%(36) \\
8.0 \%(21)\end{array}$ & $\begin{array}{l}4.9 \%(13) \\
5.7 \%(15) \\
6.8 \%(18) \\
13.2 \%(35) \\
69.4 \%(184)^{*}\end{array}$ \\
\hline Means & 2.01 & 3.62 & 2.69 & 4.35 \\
\hline $\begin{array}{l}\text { Over } 20 \text { Years } \\
\text { Definitely would not report } 1.5 \\
\text { Probably would not report } 1.6-2.5 \\
\text { Might/might not report } 2.6-3.5 \\
\text { Probably would report } 3.6-4.5 \\
\text { Definitely would report } 4.6-5\end{array}$ & $\begin{array}{l}44.1 \%(120)^{*} \\
20.2 \%(55) \\
18.0 \%(49) \\
11.4 \%(31) \\
6.3 \%(17)\end{array}$ & $\begin{array}{l}7.3 \%(20) \\
8.5 \%(23) \\
17.6 \%(48) \\
28.7 \%(78) \\
37.9 \%(103)^{*}\end{array}$ & $\begin{array}{l}18.8 \%(51) \\
23.9 \%(65) \\
30.5 \%(83)^{*} \\
14.3 \%(39) \\
12.5 \%(34)\end{array}$ & $\begin{array}{l}4.4 \%(12) \\
4.1 \%(11) \\
3.3 \%(9) \\
15.8 \%(43) \\
72.4 \%(197)^{*}\end{array}$ \\
\hline Means & $2.33^{*}$ & $3.82 *$ & 2.94 & $4.45^{*}$ \\
\hline $\mathrm{Gamma}^{8}$ & $.069 * *$ & $.094 * *$ & .013 & $.161^{* *}$ \\
\hline
\end{tabular}

*largest percentage/(n)/mean

${ }^{8}$ Gamma scores for supervisors are $.211^{* *}$ for conflict of interest, $.216^{* *}$ for exploiting authority, . $180^{* *}$ for abuse of authority, and $.200^{* *}$ for malfeasance. 
Years of service has mixed results. Generally, regardless of years of service, respondents are more willing to report exploiting authority than abuse of authority in contradiction to hypothesis fourteen. A majority of respondents, regardless of years of service, would definitely report malfeasance. A majority of respondents with one to fifteen years of service would definitely not report conflict of interest. Respondents are more willing to report exploiting authority, abuse of authority and malfeasance in support of hypothesis fourteen. These results are somewhat consistent with ethical awareness and standards results. Results are less clear with respect to exploiting authority and abuse of authority. A majority of officers with six to twenty years of service probably would report or definitely would report exploiting authority misconduct while a majority of respondents with more than twenty years of service would definitely report misconduct. The remaining respondents are split between might/might not report, probably would report, and definitely would report misconduct. These results contradict the curvilinear relationship predicted in hypothesis fourteen. Exploring means, however, support a curvilinear relationship within length of service with officers who have less than one year of service holding means consistent with officers who have more than ten years of service. Figure 6.1 Percentage who would definitely report by length of service below shows the percentage of respondents who would definitely report misconduct by length of service. 


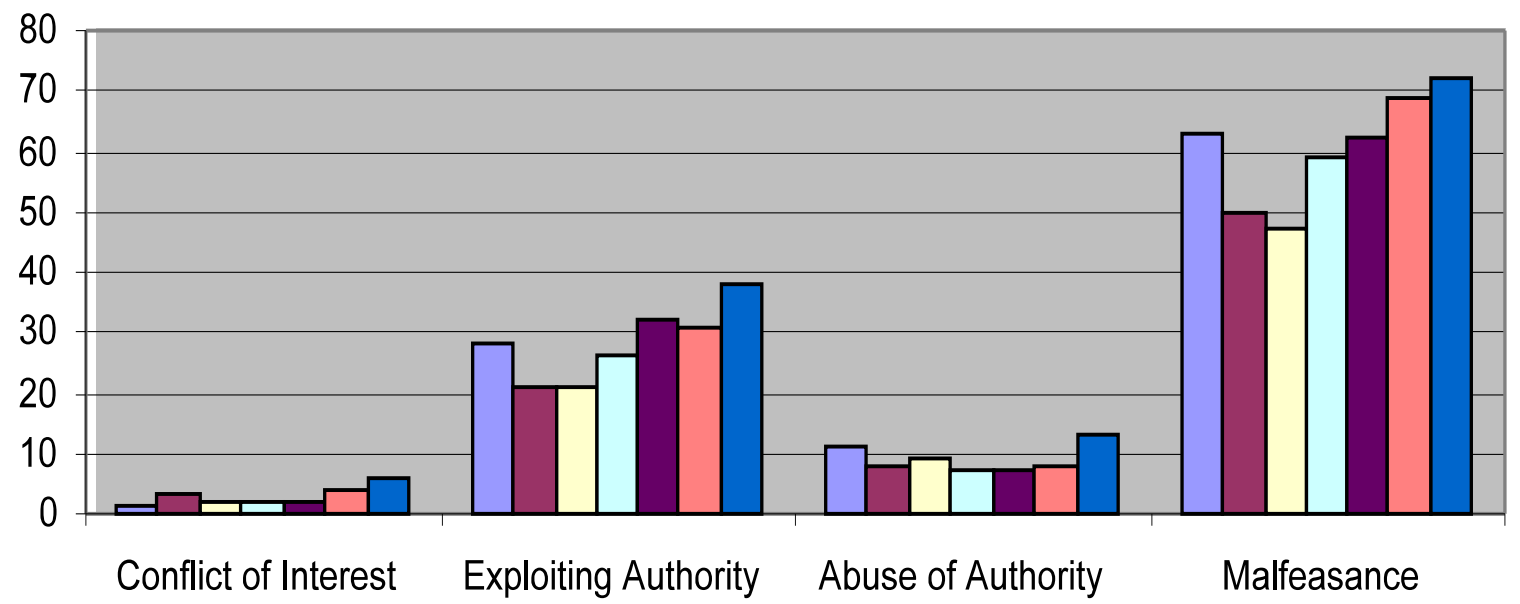

\section{$\square$ Less $1 \square 1-2 \square 3-5 \square 6-10 \square 11-15 \square$ 15-20 $\square 20+$}

Figure 6.1: Percentage who would definitely report by length of service

The results are even more spread out within abuse of authority. Officers with less than one year of service are split between probably would not report $(22 \%)$, might/might not report (26\%), and probably would report (25\%). Respondents with anywhere from one to twenty years of service are split between definitely would not report, probably would not report, and might/might not report. Meanwhile, officers with more than twenty years are spread across four categories with the highest percentage within might/might not report. Officers with less than one year of service are split between probably would not report, might/might not report, and probably would report. Abuse of authority results do not lend support to hypothesis fourteen.

Ethical awareness and standards found no relationship with agency size. This study 
hypothesizes that the same will be true for ethical action. Whether reporting behavior is impacted by agency size is explored below in Table 6.4. 
Table 6.4: Ethical Action and Agency Size

\begin{tabular}{|c|c|c|c|c|}
\hline \multicolumn{5}{|c|}{ (1) Definitely would not report - (5) Definitely would report } \\
\hline (n, \# of agencies) & $\begin{array}{l}\text { Conflict of } \\
\text { Interest }\end{array}$ & $\begin{array}{l}\text { Exploiting } \\
\text { Authority }\end{array}$ & $\begin{array}{l}\text { Abuse of } \\
\text { Authority }\end{array}$ & Malfeasance \\
\hline $\begin{array}{l}\text { Very Small, }<25 \text { officers }(87,8) \\
\text { Definitely would not report } 1.5 \\
\text { Probably would not report } 1.6-2.5 \\
\text { Might/might not report } 2.6-3.5 \\
\text { Probably would report } 3.6-4.5 \\
\text { Definitely would report } 4.6-5\end{array}$ & $\begin{array}{l}31.0 \%(27)^{*} \\
26.4 \%(23) \\
23.0 \%(20) \\
5.8 \%(5) \\
13.8 \%(12)\end{array}$ & $\begin{array}{l}11.5 \%(10) \\
13.8 \%(12) \\
18.4 \%(16) \\
13.8 \%(12) \\
42.5 \%(37)^{*}\end{array}$ & $\begin{array}{l}42.5 \%(37)^{*} \\
31.0 \%(27) \\
10.4 \%(9) \\
11.5 \%(10) \\
4.6 \%(4)\end{array}$ & $\begin{array}{l}6.9 \%(6) \\
5.7 \%(5) \\
13.8 \%(12) \\
24.2 \%(21) \\
49.4 \%(43)^{*}\end{array}$ \\
\hline Means & 2.60 & 3.61 & 2.22 & 4.05 \\
\hline $\begin{array}{l}\text { Small, } 25-75 \text { officers }(212,9) \\
\text { Definitely would not report } 1.5 \\
\text { Probably would not report } 1.6-2.5 \\
\text { Might/might not report } 2.6-3.5 \\
\text { Probably would report } 3.6-4.5 \\
\text { Definitely would report } 4.6-5\end{array}$ & $\begin{array}{l}59.4 \%(126)^{*} \\
17.5 \%(37) \\
15.1 \%(32) \\
5.2 \%(11) \\
2.8 \%(6)\end{array}$ & $\begin{array}{l}15.1 \%(32) \\
17.0 \%(36) \\
21.7 \%(46) \\
20.3 \%(43) \\
25.9 \%(55)^{*}\end{array}$ & $\begin{array}{l}49.6 \%(105)^{*} \\
21.3 \%(45) \\
20.8 \%(44) \\
6.1 \%(13) \\
2.4 \%(5)\end{array}$ & $\begin{array}{l}11.8 \%(25) \\
7.6 \%(16) \\
11.8 \%(25) \\
21.2 \%(45) \\
47.6 \%(101)^{*}\end{array}$ \\
\hline Means & 1.89 & 3.28 & 2.06 & 3.85 \\
\hline $\begin{array}{l}\text { Medium, } 76-200 \text { officers }(344,6) \\
\text { Definitely would not report } 1.5 \\
\text { Probably would not report } 1.6-2.5 \\
\text { Might/might not report } 2.6-3.5 \\
\text { Probably would report } 3.6-4.5 \\
\text { Definitely would report } 4.6-5\end{array}$ & $\begin{array}{l}41.6 \%(143)^{*} \\
22.4 \%(77) \\
18.6 \%(64) \\
8.7 \%(30) \\
8.7 \%(30)\end{array}$ & $\begin{array}{l}8.2 \%(28) \\
10.8 \%(37) \\
15.7 \%(54) \\
25.4 \%(87) \\
39.9 \%(137)^{*}\end{array}$ & $\begin{array}{l}21.6 \%(74) \\
21.3 \%(73) \\
24.0 \%(82)^{*} \\
19.3 \%(66) \\
14.0 \%(48)\end{array}$ & $\begin{array}{l}4.4 \%(15) \\
4.9 \%(17) \\
8.4 \%(29) \\
16.3 \%(56) \\
66.0 \%(227)^{*}\end{array}$ \\
\hline Means & 2.38 & $3.76^{*}$ & $3.01 *$ & 4.32 \\
\hline $\begin{array}{l}\text { Large, } 201-500 \text { officers }(235,2) \\
\text { Definitely would not report } 1.5 \\
\text { Probably would not report } 1.6-2.5 \\
\text { Might/might not report } 2.6-3.5 \\
\text { Probably would report } 3.6-4.5 \\
\text { Definitely would report } 4.6-5\end{array}$ & $\begin{array}{l}32.7 \%(77)^{*} \\
21.7 \%(51) \\
18.7 \%(44) \\
17.5 \%(41) \\
9.4 \%(22)\end{array}$ & $\begin{array}{l}13.2 \%(31) \\
8.5 \%(20) \\
16.6 \%(39) \\
26.4 \%(62) \\
35.3 \%(83)^{*}\end{array}$ & $\begin{array}{l}23.4 \%(55) \\
17.0 \%(40) \\
25.5 \%(60)^{*} \\
19.2 \%(45) \\
14.9 \%(35)\end{array}$ & $\begin{array}{l}8.9 \%(21) \\
5.1 \%(12) \\
8.5 \%(20) \\
16.2 \%(38) \\
61.3 \%(144)^{*}\end{array}$ \\
\hline Means & $2.66^{*}$ & 3.61 & $3.01 *$ & 4.15 \\
\hline $\begin{array}{l}\text { Very Large, }>500 \text { officers }(2229,5) \\
\text { Definitely would not report } 1.5 \\
\text { Probably would not report } 1.6-2.5 \\
\text { Might/might not report } 2.6-3.5 \\
\text { Probably would report } 3.6-4.5 \\
\text { Definitely would report } 4.6-5\end{array}$ & $\begin{array}{l}50.8 \%(1130)^{*} \\
23.5 \%(522) \\
14.2 \%(315) \\
7.0 \%(156) \\
4.5 \%(101)\end{array}$ & $\begin{array}{l}6.8 \%(152) \\
9.9 \%(219) \\
17.9 \%(399) \\
30.8 \%(684) \\
34.6 \%(770)^{*}\end{array}$ & $\begin{array}{l}21.5 \%(478) \\
21.3 \%(474) \\
29.2 \%(649)^{*} \\
16.4 \%(363) \\
11.6 \%(258)\end{array}$ & $\begin{array}{l}3.9 \%(87) \\
4.5 \%(100) \\
6.3 \%(140) \\
17.6 \%(391) \\
67.7 \%(1508)^{*}\end{array}$ \\
\hline Means & 2.07 & $3.76^{*}$ & 2.93 & $4.39^{*}$ \\
\hline Gamma & $-.108 * *$ & $.056^{* *}$ & $.138 * *$ & $.144 * *$ \\
\hline
\end{tabular}

*largest percentage/(n)/mean 
The results for agency size only partially support hypothesis fifteen which asserts that there is no relationship between agency size and willingness to report misconduct. There are no clear trends and many results show splits along different levels of willingness to report. For example, a majority of respondents from medium (65\%), large (62\%), and very large agencies $(65 \%)$ would either probably or definitely report a peer who exploited authority as compared to $46 \%$ of respondents from small agencies and $56 \%$ respondents from very small agencies. Overall, the percentages indicate more willingness to report exploiting authority than abuse of authority regardless of size of agency. These results are consistent with ethical awareness and standards and contradict hypothesis seventeen.

There was more division in opinion regarding whether to report abuse of authority. Officers from medium and very large agencies were split between definitely would not report, probably would not report, and might/might not report for abuse of authority. Almost half of respondents from small agencies (50\%) and very small agencies (43\%) definitely would not report abuse of authority. Respondents from large agencies were split between definitely not reporting abuse of authority (23\%) and maybe reporting abuse of authority (26\%). These results are consistent with previous results found in this chapter, less consensus amongst respondents regarding whether or not to report abuse of authority. These results offer the clearest relationship between size and the dependent variables. Small and very small departments appear to have more solidarity with respect to an unwillingness to report misconduct.

As with previous results for ethical awareness and standards, a majority of officers from medium (66\%), large (61\%), and very large agencies (68\%) would definitely report 
malfeasance. Almost a majority of respondents from very small (49\%) and small agencies (48\%) would definitely report malfeasance. These differences between agencies are much greater than those found within ethical awareness and standards. However, these results do lend support for hypothesis fourteen in that officers are more willing to report malfeasance than the other types of misconduct.

Conflict of interest results also lend support to hypothesis twelve in that respondents are less likely to report it than the other types of misconduct. There is one interesting exception within very small agencies where a higher percentage of respondents definitely would not report abuse of authority (43\%) than conflict of interest (31\%). Again, no clear pattern emerges within conflict of interest lending further support for hypothesis fifteen that there is no relationship between an officer's ethical action and the size of the agency.

The regression model explored later in this chapter includes two important variables explored previously in Chapters 4 and5. These variables include (1) officer perceptions of existing agency policy and officer perceptions of peer attitudes towards reporting misconduct and (2) officer willingness to report misconduct and officer perception of peer willingness to report misconduct. Correlations between agency policy and an officer's attitude towards reporting are shown in the table below. The strong correlations show that an officer's awareness of existing agency policies impacts the officer's attitudes towards reporting misconduct. 
Table 6.5: Correlations between Agency Policy and Ethical Action

\begin{tabular}{|l|l|}
\hline & \multicolumn{1}{|c|}{ Conflict of Interest } \\
\hline Conflict of Interest and knowledge of policy & $.435^{* *}$ \\
\hline Exploiting Authority and knowledge of policy & $.417^{* *}$ \\
\hline Abuse of Authority and knowledge of policy & $.357^{* *}$ \\
\hline Malfeasance and knowledge of policy & $.252^{* *}$ \\
\hline
\end{tabular}

Correlations between an officer's willingness to take action and perceptions of peer action are explored in the table below. These correlations are the highest of all such variables explored thus far. Multicollinearity issues arise with the extremely high correlations, and this condition will be considered when interpreting the regression model presented later in this chapter.

Table 6.6: Correlations between Officer Action and Perceptions of Peer Action

\begin{tabular}{|l|l|}
\hline & \\
\hline Conflict of Interest and peer attitudes & $.931^{* *}$ \\
\hline Exploiting Authority and peer attitudes & $.818^{* *}$ \\
\hline Abuse of Authority and peer attitudes & $.757^{* *}$ \\
\hline Malfeasance and peer attitudes & $.825^{* *}$ \\
\hline
\end{tabular}

These very high correlations may reflect conformity within an agency. It is also possible that respondents were attempting to justify their responses regarding willingness to report by responding that others would do the same. Police literature suggests that these high correlations reflect conformity or solidarity amongst officers (Troutman 1997; Klockars).

\section{An Ethical Action Regression Model}

Thus far, this chapter has explored supervisory position, rank, years of service, promotion, and agency size with respect to ethical awareness. We have seen that the officer's 
perception of peer attitudes very closely matches their own willingness to report misconduct.

What additional impact does the officer's perception of policy, their attitudes, and their personal and organizational characteristics have on the officer's ethical action? The regression model that follows explores the predictive nature of these variables.

Table 6.7: Ethical Action Regression

\begin{tabular}{|c|c|c|c|c|}
\hline $\begin{array}{l}\text { Independent } \\
\text { Variables }\end{array}$ & $\begin{array}{c}\text { Conflict of } \\
\text { Interest } \\
\text { B(t) }\end{array}$ & $\begin{array}{c}\text { Exploiting } \\
\text { Authority } \\
\qquad(t)\end{array}$ & $\begin{array}{c}\text { Abuse of } \\
\text { Authority } \\
\text { B(t) }\end{array}$ & $\begin{array}{c}\text { Malfeasance } \\
\text { B(t) }\end{array}$ \\
\hline Others Reporting & $.841(93.085)^{* *}$ & $.709(58.204)^{* *}$ & $.617(49.893)^{* *}$ & $.784(67.809)^{* *}$ \\
\hline Own Standards & $.069(6.159)^{* *}$ & $.199(11.589)^{* *}$ & $.166(11.149)^{* *}$ & $.236(14.738)^{* *}$ \\
\hline Others Standards & $-.049(-5.184)^{* *}$ & $-.103(-6.498)^{* *}$ & $-.044(-3.434)^{* *}$ & $-.139(-9.014)^{* *}$ \\
\hline Own Seriousness & $.257(20.441)^{* *}$ & $.386(25.276)^{* *}$ & $.563(34.804)^{* *}$ & $.219(12.654)^{* *}$ \\
\hline Others Seriousness & $\begin{array}{l}-.186(- \\
16.243)^{* *}\end{array}$ & $-.276(-18.107)^{* *}$ & $-.324(-19.289)^{* *}$ & $-.185(-12.613)^{* *}$ \\
\hline Policy & $-.002(-.306)$ & $.002(.218)$ & $-.047(-4.651)^{* *}$ & $-.028(-1.933)$ \\
\hline Rank & $.086(12.677)^{* *}$ & $.100(10.160)^{* *}$ & $.094(9.816)^{* *}$ & $.071(6.562)^{* *}$ \\
\hline Length of Service & $.002(.300)$ & $.023(2.380)^{*}$ & $.016(1.702)$ & $.013(1.259)$ \\
\hline Agency Size & $.020(3.537)^{* *}$ & $.038(4.457)^{* *}$ & $.044(5.260)^{* *}$ & $.046(4.868)^{* *}$ \\
\hline Adjusted $\mathrm{R}^{2}$ & .903 & .791 & .804 & .741 \\
\hline$F$ & 3147.851 & 1285.068 & 1383.336 & 969.702 \\
\hline s.e. & .377 & .566 & .572 & .559 \\
\hline
\end{tabular}




\begin{tabular}{l|l|l|l|l}
\hline \multicolumn{5}{c}{ Table 6.8: Ethical Standards Regression Comparison } \\
\hline Others Standards & $.510(40.604)^{* *}$ & $.698(65.149)^{* *}$ & $.526(41.135)^{* *}$ & .713 \\
& & & & $(60.162)^{* *}$ \\
\hline Own Seriousness & $.481(25.884)^{* *}$ & $.349(23.392)^{* *}$ & $.440(24.103)^{* *}$ & .211 \\
& & & & $(10.902)^{* *}$ \\
\hline Others Seriousness & $-.005(-.280)$ & $-.046(-3.111)^{* *}$ & $.027(1.476)$ & $-.005(-.296)$ \\
\hline
\end{tabular}

Comparing regression results from the Standards model in the previous chapter shows that how serious the respondent believes the misconduct (own seriousness) still has roughly the same impact on how much punishment should follow and the officer's willingness to report that misconduct. The officer's perception of peer standards (others standards) drops substantially and changes from a positive to a negative impact on an officer's willingness to report misconduct. Meanwhile, the officer's perception of peer awareness (others seriousness) becomes strongly negative with respect to willingness to report as compared to only marginally negative with respect to standards. ${ }^{9}$

These results highlight the difference in factors that affect attitudes versus behavior. The officer's ethical awareness affects the officer's willingness to report misconduct moreso than the officer's perceptions of peer attitudes. This suggests that impacting the officer's attitudes towards the seriousness of misconduct may impact the officer's willingness to report that misconduct.

According to the conflict of interest model, $90 \%$ of an officer's attitude towards the

${ }^{9}$ A regression model that excludes perceptions regarding peer attitudes influences the results yielding an adjusted $\mathrm{R}^{2}$ of .611 for conflict of interest, .548 for exploiting authority, .635 for abuse of authority, and .334 for malfeasance. 
seriousness of this type of misconduct can be explained by the variables included in the model. This is the only regression model with variables that exceed multicollinearity limits. There is collinearity between an officer's willingness to report conflict of interest and the officer's perception of whether others would report conflict of interest misconduct ( $\beta=.841)$. Unstandardized coefficients yielded similar results.

The other types of misconduct had high percentages, as well, but no multicollinearity issues. The regression model may be impacted by the high correlation between an officer's own attitudes regarding the misconduct and the officer's perception of the peer's willingness to report misconduct. This is the case within conflict of interest, however, high levels of collinearity $\left(\mathrm{R}^{2} \geq .80\right)$ are not present within the remaining types of misconduct. None of the correlations between these variables exceeds .90 for the remaining types of misconduct eliminating singularity or perfect multicollinearity (Tabachnick and Fidell 2001).

Regardless of the nature of the misconduct, all of the independent variables influence an officer's attitudes towards misconduct with the exception of policy and length of service. As was apparent in the correlation analysis, the officer's perception of whether peers would report misconduct is the strongest predictor for conflict of interest $(\beta=.841)$, exploiting authority $(\beta=.709)$, abuse of authority $(\beta=.617)$, and malfeasance $(\beta=.784)$. Rank continues to have a consistent and modest impact on willingness to report. The officer's own standards also has a modest impact on willingness to report. Length of service and the officer's awareness of agency policy appear to have little, if any, impact on an officer's ethical action. When it comes to reporting, agency size does make some difference. Unstandardized coefficients yielded similar results. Using stepwise and hierarchical regression did not impact 
these results.

\section{Conclusions}

This chapter has found partial support for hypotheses fourteen through twenty. Hypothesis fourteen asserts that the more serious the misconduct, the more likely the officer will be willing to take ethical action. Partial support for this hypothesis was found in each of the analysis within this chapter. Officers are more willing to report exploiting authority, abuse of authority and malfeasance than conflict of interest. Officers are more willing to report malfeasance than any other type of misconduct. The one contradiction that consistently showed up in the analysis was that officer's are less willing to report abuse of authority than exploiting authority misconduct.

Hypothesis fifteen asserts that officers who are supervisor are more likely to take ethical action. These results proved to be true across the different types of misconduct. There is partial support for hypothesis sixteen that posits a curvilinear relationship between ethical action and years of service. Overall, officers with less than one year of service were more likely to report misconduct than officers with one to five years of service. As officers remain in service after six years, they become more willing to report misconduct.

Hypothesis seventeen asserts that there is no relationship between the size of agency and an officer's willingness to report misconduct. There is partial support for this hypothesis. Very few patterns emerge when analyzing means and percentages for agency size. For example there is no linear relationship or even curvilinear relationship. In addition, agency size did not prove important in the regression model. Still, in contrast to the lack of consistency in the relationship between size and the other dependent variables, officers in 
smaller agencies are less likely to report the most serious forms of ethical misconduct.

According to hypothesis eighteen, an officer's awareness of existing policies regarding misconduct will positively impact that officer's willingness to take ethical action. Unlike ethical awareness and standards, however, policy did not appear to impact an officer's willingness to take action. Hypothesis nineteen asserts that an officer's perceptions regarding peer ethical awareness, standards, and action will positively impact that officer's willingness to take action and the regression model shows some support for this hypothesis.

Hypothesis twenty theorizes that the higher the officer's ethical awareness and standards, the greater the likelihood of an officer's ethical action. The regression model offers support for this hypothesis. The officer's own attitudes towards misconduct appear to impact the officer's willingness to report misconduct. Awareness is, however, a stronger factor than standards. 


\section{CHAPTER SEVEN}

Conclusions, Implications, Recommendations and Summary 


\section{A. Conclusions}

This study explores an officer's ethical awareness, standards, and action to determine what type of officer has above mean attitudes, mean, or below mean attitudes regarding misconduct. This study also explores what type of agency has officers who have above mean, mean, and below mean attitudes towards misconduct. Findings support the conclusion that an officer's ethical awareness, or attitude towards the seriousness of misconduct, impacts that officer's standards and action.

This places a great deal of importance on an officer's ethical awareness. Attitudes towards misconduct have the potential to affect not just the officer, but the entire agency. Given that people generally resist reporting illegal and/or immoral behavior, ethical awareness is the foundation that determines to some degree whether a person, specifically an officer, will be willing to take ethical action.

While the size of the agency appears to have no impact on how officers view misconduct, an officer's supervisory position does appear to impact how serious that officer views misconduct. Supervisors view misconduct as more serious than non-supervisors which is not surprising considering supervisors have been on the job longer and may be the individuals responsible for administering punishment for officer misconduct. Being on the job longer does not necessarily mean officers view misconduct more seriously as their careers progress. There is a curvilinear relationship between an officer's attitudes towards misconduct and years of service controlling for supervisory position. The findings highlight a socialization process and/or negative experiences during the first six years of service that undercut the ideals of new recruits. 
Particularly disturbing were the results with respect to abuse of authority where all respondents viewed this type of misconduct as less serious than exploiting authority. These findings show a systematic unwillingness to recognize the severity of this type of misconduct. These results indicate a failure to provide the solid ethical foundation necessary to promote an officer's willingness to take ethical action.

Ethical standards are another important factor impacting an officer's willingness to report misconduct. Ethical awareness helps shape the officer's attitude towards the seriousness of the misconduct. The ethical awareness attitude in turn helps shape the officer's attitude towards what punishment is appropriate. There is slippage between an officer's attitude regarding the seriousness of peer misconduct and the appropriate level of punishment. The officer's peers and supervisors, as well as the officer's agency each help shape both the officer's ethical awareness and ethical standards.

Ethical standards show similar results as those explored in ethical awareness. There is no relationship between size of agency and ethical standards but there is a relationship between an officer's supervisory position and ethical standards. The curvilinear relationship between years of service and ethical standards is also present, though less pronounced than with ethical awareness. There is a strong reluctance by non-supervisors with one to five years of service to administer the harshest punishments of demotion and dismissal for even the worst type of misconduct, malfeasance. The across-the-board unwillingness to administer harsher punishment for abuse of authority misconduct further erodes the strong ethical foundation necessary to promote peer reporting of misconduct.

Ultimately an officer's willingness to report misconduct is a key issue explored in this 
study. The same factors that affect an officer's ethical action are the same factors that affect an officer's ethical awareness and ethical standards. These factors affect an officer's ethical action in much the same way they affect the officer's ethical awareness and standards, but with further slippage. For example, supervisors believe the misconduct in question is more serious than non-supervisors, they believe harsher punishment is required than nonsupervisors, and they are more willing to report misconduct than non-supervisors. Again, this emphasizes the importance of attitudes - attitudes towards seriousness of the offense and appropriate punishment - and the impact those attitudes have on actual behavior - an officer's willingness to report misconduct.

One finding that is different from results found with awareness and standards occurs in the regression model. There is clearly a greater reluctance to report abuse of authority and malfeasance in very small and small agencies as compared to larger ones. Very small and small agencies may attribute these results to a greater solidarity among peers coupled with less willingness to use formal discipline.

The most compelling findings are with respect to the nature of the misconduct and promotion. Regardless of rank, years in service, supervisory position, or size of agency, abuse of authority is rated as less serious, deserving less punishment, and officers were less willing to report. Equally alarming are the non-reporting patterns: 10 out of 11 officers would definitely not report abuse of authority; 2 out of 5 officers would not report malfeasance; and 3 out of 4 supervisors would not report abuse of authority. The implications of these findings are explored more fully in the section that follows.

All of the officer characteristics explored in this study impacted attitudes and 
behavior. The individual characteristics studied herein include whether an officer is a supervisor, the officer's rank, and length of service. The organizational factor examined in this study is the size of the agency. These variables unfortunately do not include age, race, and gender. The NIJ survey did not include questions regarding age, race or gender. This study has focused on individual and organizational characteristics that clearly deserve more attention in the literature.

\section{B. Implications}

The two variables that had the biggest impact on officer attitudes overall were officer perceptions of peer attitudes and an officer's knowledge of existing agency policy. The results of this study show that respondents tend to view others as being like themselves whatever their level of awareness, standards, and willingness to report. This is evidenced by the extremely high correlations between the respondent's attitudes towards misconduct/punishment/reporting and the corresponding officer perceptions of peer responses. These findings show the importance of peer relationships within an agency. The second most important variable was an officer's knowledge of existing policy. This finding emphasizes the need for increased officer training with respect to agency policy.

The findings also suggest critical points on which police managers should focus attention during the career of their officers. First, the transition from new recruit to an officer who has more than one year of service coincides with the end of probation for new officers and is one critical point in an officer's career. A second critical point occurs when an officer has between three and five years of service. Here, one of several events potentially takes place for those officers that fall below the mean. An officer may commit misconduct, get 
caught, be fired or quit, or the officer might change his/her attitude towards misconduct.

Also, officers who are passed on promotion after six years of service reach a critical point in their careers whereas officers who are above the mean are more likely to have the opportunity to accept promotions. Ethics training for officers strategically placed at these critical junctures could impact officer attitudes and behavior with respect to police misconduct. All officers need training regarding misuse of force and professional courtesy.

Lipsky's work regarding street-level bureaucrats depicts officers as agents facing limited resources, non-voluntary clients, ambiguous goals, inadequate performance measures, and faced with alienated work. As a consequence of this tumultuous environment, police officers are likely to encounter some level of misconduct at some point during their careers. The results of this research at least partially support the conclusion that officers are reluctant to report misconduct regardless of rank and length of service. Although there is variation associated with these characteristics, one could argue that the proportions who will not report misconduct are unacceptably high.

The type of alienated work depicted by Lipsky does appear within the case scenarios which depict the police taking actions that deny clients their humanity. The police brutality scenario, stealing money, accepting bribes, theft of property are all examples of officers who are less concerned with their clients and professional or legal standards than with benefitting personally or collectively.

The impact socialization or sustained exposure to the factors Lipsky describes appears to affect ethical awareness, standards, and action. Recruits generally had higher means than officers within rank comparisons. Also, officers with less than one year of service generally 
had higher means than officers with one to two years of experience. Officers with three to five years of experience tended to have the lowest means across ethical awareness, standards, and action.

Research discussed in chapter two points out that officers enter the force with low levels of cynicism, but it steadily increases over the first ten years of service. Other research indicates that the typical officers prosecuted for misconduct has approximately five to ten years of service. The results of this study see a sharp decline in non-supervisor attitudes towards misconduct when an officer has three to five years of service. These results combined with previous research indicate that officer's are most vulnerable to misconduct during the early stages of their careers.

Controlling for supervisory position reveals that promotion may be the variable directly impacting these results. Officers who have been in service for five or more years and who are not promoted dramatically depart from their promoted counterparts with respect to attitudes towards misconduct, punishment, and reporting.

Future research analyzing officer stages of moral development controlling for promotion and years of service could lend further support to the results found herein. Kohlberg's stages of moral development may shed some light on these results regarding promotion and supervisory position. The findings suggest that promotion may impact how and whether an officer progresses from a conventional to a post-conventional stage of moral development.

Sutherland might agree with the possibility of socialization effects as described above. Sutherland would argue that peers shape officer attitudes. This is how below mean officers 
are created within the socialization process. The results of this study seem to support Sutherland's theory as opposed to Hirschi's theory. Hirschi's theory would suggest that officers come to the force corrupt and lack of controls allow these officers to commit misconduct. The literature, however, does not provide any evidence supporting this view of the police. One alternative would be that the new officer is corrupt before entering the force, but there have been adequate controls his/her entire life. Upon entering the force, these controls become inadequate allowing some officers to commit misconduct. This explanation seems less likely and contradicts the findings with respect to new officers having higher means.

One way to combat these negative socialization effects is through officer training. Currently, all officers undergo a basic set of training courses when they enter police service. Not all training courses include ethics training and many devote only an hour or two at most to ethics. Continual ethics training throughout the officer's career is virtually nonexistent for police officers.

As for Paoline's (2001) five types of police officers which include Tough-Cops, Clean-Beat Crime-Fighters, Avoiders, Problem-Solvers, and Professionals, these findings suggest either some changes to the five types or the creation of some other types of officers. Paoline's (2001) five types of officers do not consider officer attitudes towards misconduct, punishment or willingness to report officer misconduct. His types do not consider the important role promotion plays in shaping officer attitudes nor do the types include the impact of situational variables (nature of the misconduct). Each of the five types needs to consider the officer's attitude towards misconduct, punishment, and willingness to report. 
The five types should be expanded to include the Agency Custodians. These are the supervisors and higher ranked officers who are removed from the front-line conditions of the first four types. As the five types point out potential shortcomings in officers, identifying where officers fall within these categories would be an important tool for shaping officer ethics training.

Given the four types of misconduct within this study, abuse of authority showed the most consequential results. The scenarios themselves are unique in that officers who engage in abuse of authority like the scenarios within this study do more than commit misconduct. Both scenarios involve conspiratorial behavior that at least partially supports Klockars' (2004) idea of police solidarity. Both scenarios involve officers engaged in illegal behavior. Neither scenario involves an officer receiving economic benefit highlighting the importance of the psychic benefits the officer receives. This combination - conspiratorial behavior, police solidarity, illegal behavior, psychic benefits - distinguishes abuse of authority from the other types of misconduct.

The results for abuse of authority also distinguish abuse of authority from the other types of misconduct. The results for abuse of authority are important given that all officers, regardless of rank, years of service, and size of agency ranked exploiting authority misconduct as more serious, deserving of stronger discipline, and ultimately more worthy or reporting to authorities. Yet, abuse of authority is more serious given the nature of the illegal behavior depicted in each of the two scenarios. Within abuse of authority for non-supervisors according to length of service, solidarity overrides the normal curvilinear effect. This result reinforces the interpretation of these cases as tests of how officers feel about taking action 
that upholds the authority of the badge or protects a fellow officer. This sense gets stronger with greater length of service through moderately long periods of time and only slightly declines after that point. It is the one area in which the most experienced non-supervisory officers have levels of awareness that are lower than new and recent recruits.

It is unclear whether other types of abuse of authority would find the same results. Consider an officer who coerces sexual favors from a prostitute in exchange for avoiding arrest or an officer who extends professional courtesy to an officer caught molesting a child. These types of abuse of authority might not evoke the same level of sympathy or willingness to shield the abusing officer from peers. Future research needs to explore other abuse of authority scenarios in order to determine the limits of officer solidarity.

Size of agency results were somewhat perplexing. The results do not show a linear or even a curvilinear relationship for officer attitudes according to size of agency. Generally, small agencies consistently showed low means across awareness, standards, and action while large agencies showed consistently high means across awareness, standards, and action. The results for the remaining agencies were inconsistent revealing no pattern. The importance of these results is that size of agency does not appear to greatly impact officer attitudes and behavior regarding misconduct.

This study has strong implications for new recruit and continual ethics training within law enforcement. There are many other issues other than those raised in this section that deserve further attention. The section that follows explores these issues.

\section{Recommendations}

With respect to training, this study highlights specific areas of need within law 
enforcement. The results of this study show that patrol officers and officers with three to five years of service are in the greatest need of ethics training. Senior Managers may need some ethics training specific to their needs, because they are in a position to impact all officers in their agencies, to lead by example, to impact policy changes, and to implement necessary ethics training. All officers need counseling with respect to abuse of authority. This study is a good tool for surveying officers within an agency prior to assessing that agency's ethics training needs. Future research could focus on existing ethics training for law enforcement and utilize the survey instrument within agencies as an ethics assessment tool. It is important to explore other ethical issues through expansion of the list of scenarios utilized in the NIJ study in order to continually update and improve training efforts recommended here. For example, officers who are tempted to misrepresent information on official reports or to commit perjury.

Ethical standards for the purposes of this study have focused on formal punishments as these were the only punishments utilized by the survey instrument. Other formal forms of punishment excluded from the survey include transferring officers, fines, counseling, and delays in promotion. Informal forms of punishment for misconduct include ostracizing officers socially and on-the-job. Future research could analyze the impact other forms of punishment, both formal and informal, have on an officer's attitude towards misconduct.

Ethical action within the context of this study focused on an officer's willingness to report misconduct. Future research could look into other ethical actions officer's might take with respect to misconduct. For example, instead of reporting an officer for misconduct, an officer could offer counsel or seek counseling for the officer in question. The officer could 
also be given an opportunity to turn himself/herself in to supervisors.

Wilson's three styles of policing - the watchman, legalistic and service styles - is another source of future research. How does the officer incorporate the attitudes and behavior explored in this study into his/her daily job activities? Do Wilson's styles of policing each have an ethics profile depicting the officer's ethical attitude and behavior? How would an officer in an agency that employs the watchman style of policing respond to the survey instrument? A future study identifying agencies that utilize Wilson's style of policing could be asked to complete the survey instrument to create the appropriate ethics profile with the corresponding style of policing.

Paoline's five types of police officers - Tough-Cops, Clean-Beat Crime-Fighters, Avoiders, Problem-Solvers, and Professionals, as well as the suggested new type Agency Custodians - are another source of future research. How do each of Paoline's types of police officers respond to the survey instrument? Can an ethics profile be developed for each of Paoline's types of police officers? It is expected that Tough-Cops and Avoiders would have the lowest ethical awareness, standards and action while Professionals and Agency Custodians would have the highest levels of ethical awareness, standards and action. Future research identifying officers within Paoline's five types of police officers could then administer the survey instrument to those officers and create an ethics profile with the corresponding type of police officer.

Kohlberg's stages of moral development - pre-conventional, conventional, and postconventional - are another source of future research. What are the ethical characteristics of officers at each level of moral development? Officers could complete the DIT 2 test followed 
by the survey instrument to determine whether a connection exists between moral development and ethical development.

It has been nine years since the NIJ survey was first conducted. Since that time, policing has changed given the events of $9 / 11$. The scenarios need to be updated to reflect these changes, and to include different aspects of each type of misconduct. Independent variables left out in the first study should be included in future studies such as age, race, gender, marital status. These controls are important factors and their impact should be considered in future research.

The future research possible from this study is limitless. The NIJ research that is the subject of this study has not been fully exhausted itself.

\section{Summary}

The questions analyzed by this study are fundamental to administrative ethics. What causes differences in ethical attitudes and behaviors in street-level bureaucrats? For police officers several factors impact their ethical decision-making. An officer's perceptions regarding peer attitudes impacts that officer's attitudes and behaviors. What do my peers think? What would my peers do? These results show how important a role solidarity plays in a law enforcement agency.

An officer's knowledge of existing policy impacts that officer's attitudes and behavior. These results show the important role training plays in an agency. Just knowing a policy exists and the punishment that will follow has an effect on the foundation - an officer's attitude towards that misconduct - and the action - an officer's willingness to report the misconduct. 
Length of service has some impact on officer attitudes and behavior. New officers with less than one year of service have high ethical awareness and standards, but are reluctant to report misconduct. This is understandable considering new recruits are on probation and may not be familiar with what happens to officers who report misconduct. Non-supervisory officers with one to six years of service are less likely to report misconduct than officers who have been in service longer. These officers, non-supervisors with zero to six years of service, are the officers who are in the best position to report misconduct as they are the street-level bureaucrat witnessing misconduct first-hand. These results suggest focusing attention on reporting behavior in non-supervisory officers in the early stages of their careers.

The nature of the misconduct itself is an important factor to consider. Officers responses to misconduct are situationally dependent. Whether an officer makes an arrest, uses force, or reports peer misconduct is very much dependent upon the nature of the misconduct itself. All of the scenarios explored in this study are violations of office policy, however, the respondents were most impacted by the type of misconduct when considering whether or not to report. The more serious the misconduct did not equal an increase in the willingness to report given the results with respect to abuse of authority.

The focus of this study has been ethical decision-making in the areas of misconduct, corruption, ethics, and moral reasoning within government, in particular, police ethics. Understanding the police officer's attitudes towards misconduct is an important step towards understanding ethical and unethical behavior within their ranks. Misconduct is hard to investigate due to an unwillingness on the part of public officials to admit wrong-doing. That is why this study is so important to reaching an understanding of police ethics. 


\section{Reference List}

Anonymous. (1998, February 15). Officers Had Sex Chats with Teen. The Atlanta Journal and Constitution, 6A

Adams, G.B., \& Balfour, D.L. (1998). Unmasking Administrative Evil. Thousand Oaks: Sage Publications.

Adcox, K.L. (2000, January). Doing Bad Things for Good Reasons. The Police Chief, 17-28.

Alpert, G.P., \& MacDonald, J.M. (2001). Police Use of Force: An Analysis of Organizational Characteristics. Justice Quarterly, 18(2), 393-409.

Bowen, D.E., Ledford Jr., G.E., \& Nathan, B.R. (1991). Hiring for the Organization, Not the Job. Academy of Management Executive, 5(4), 35-51.

Brewer, G.A., \& Selden, S.C. (1998). Whistle Blowers in the Federal Civil Service: New Evidence of the Public Service Ethic. Journal of Public Administration Research and Theory, 8, 413-439.

Bristow, A.P. (1975). You...and the Law Enforcement Code of Ethics. (ed.). Santa Cruz: Davis Publishing Co.

Brown, B., \& Benedict, W.R. (2002). Perceptions of the Police: Past findings, methodological issues, conceptual issues and policy implications. Policing: An International Journal of Police Strategies and Management, 25(3), 543-580.

Brown, L., \& Willis, A. (1985). Authoritarianism in British Police Recruits Importation, Socialization or Myth. Journal of Occupational Psychology, 58(2), 97-108.

Brunet, J.R. Blurring the Line Between Public and Private Sectors: The Case of Police Off-Duty Employment. In Anonymous.

Buenger, V., Daft, R.L., Conlon, E.J., \& Austin, J. (1996). Competing Values in Organizations: Contextual Influences and Structural Consequences. Organization Science, 7(5), 557-576.

Caiden, G.E., \& Caiden, N.J. (1977). Developments in Research: Administrative Corruption. Public Administration Review, 301-309.

Cancino, J.M. (2001). Walking Among Giants 50 Years Later: An Exploratory Analysis of Patrol Officer Use of Violence. Policing: An International Journal of Police Strategies and Management, 24(2), 144-161. 
Cancino, J.M., \& Enriquez, R. (2004). A Qualitative Analysis of Officer Peer Retaliation. Policing: An International Journal of Police Strategies and Management, 27(3), 320-340.

Cao, L., \& Frank, J.a.C.F.T. (1996). Race, Community context, and Confidence in Police. American Journal of Police, 15, 3-22.

Cao, L., Deng, X., \& Barton, S. (2000). A test of Lundman's organizational product thesis with data on citizen complaints. Policing: An International Journal of Police Strategies and Management, 23(3), 356-373.

Cao, L., \& Huang, B. (2000). Determinants of citizen complaints against police abuse of power. Journal of Criminal Justice, 28, 203-213.

Carlson, H.M., \& Sutton, M.S. (1975). The Effects of Different Police Roles on Attitudes and Values. The Journal of Psychology, 91, 57-64.

Catlin, D.W., \& Maupin, J.R. (2004). A Two Cohort Study of the Ethical Orientations of State Police Officers. Policing: An International Journal of Police Strategies and Management, 27(3), 289-301.

Chappell, A.T., \& Piquero, A.R. (2004). Applying Social Learning Theory to Police Misconduct. Deviant Behavior, 25, 89-108.

Chatterton, M. (1983). Police Work and Assault Charges in the Police Organization. ( ed.). Cambridge, MA: MIT Press.

Chermak, S., \& McGarrell, E.F. (2001). C Citizens' Perceptions of Aggressive Traffic Enforcement Strategies. Justice Quarterly, 18, 365-391.

Cheurprakobkit, S., \& and Bartsch, R.A. (1999). Police Work and the Police Profession: Assessing Attitudes of City Officials, Spanish-Speaking Hispanics, and their English-Speaking Counterparts. Journal of Criminal Justice, 27, 87-100.

Coleman, R., \& Wilkins, L. (2002). Searching for the Ethical Journalist: An Exploratory Study of the Moral Development of News Workers. Journal of Mass Media Ethics, 17(3), 209-225. International.

Crawshaw, R. (1998). Human Rights and Policing. ( ed.). Boston: Kluwer Law

Van Wart, M. (1998). The Role of Organizational Values. New York: Garland Publishing, Inc. 81-115 p.

Delattre, E.J. (2002). Character and Cops: Ethics in Policing. ( ed.). Jackson: American Enterprise Institute Press. 
Donahue, M.E., \& Felts, A.A. (1993). Police Ethics - A Critical Perspective. Journal of Criminal Justice, 21(4), 339-352.

Engel, R.S. (2003). Explaining Suspects' Resistance and Disrespect Toward Police. Journal of Criminal Justice, 31, 475-492.

Engel, R.S., \& Worden, R.E. (2003). Police Officers' Attitudes, Behavior, and Supervisory Influences: An Analysis of Problem Solving. Criminology, 41(1), 131-166.

Etzioni, A. (1975). A Comparative Analysis of Complex Organizations. (ed.). New York, NY: Free Press.

Farrell, D. (1983). Exit, Voice, Loyalty, and Neglect as Responses to Job Dissatisfaction - A Multidimensional-Scaling Study. Academy of Management Journal, 26(4), 596-607.

Finn, M.A., Blackwell, B.S., Stalans, L.J., Studdard, S., \& Dugan, L. (2004). Dual Arrest Decisions in Domestic Violence Cases: The Influence of Departmental Policies. Crime \& Delinquency, 50(4), 565-589.

Friedrich, R.J. (1977). The Impact of Organizational, Individual, and Situational Factors on Police Behavior. University of Michigan;

Garner, J.H., Buchanan, J., Schade, T., \& Hepburn, J. (1996). Understanding the Continuum of Force by and Against the Police. National Institute of Justice,

Garner, J.H., Maxwell, C.D., \& Heraux, C.G. (2002). Characteristics Associated with the Prevalence and Severity of Force Used by the Police. Justice Quarterly, 19(4), 705746.

Genz, J.L., \& Lester, D. (1976). Authoritarianism in Policemen as a Function of Experience. Journal of Police Science and Administration, 4, 9-13.

Guy, M.E. (1991). Using High Reliability Management to Promote Ethical Decision Making. In Anonymous, (pp. 185-204). San Francisco: Jossey-Bass.

Hageman, M.J. (1979). Who Joins the Force for What Reasons: An Argument for "The New Breed". Journal of Police Science and Administration, 7, 206-210.

Hale, D.C. (1989). Ideology of Police Misbehavior: Analysis and Recommendations. Quarterly Journal of Ideology, 12, 59-85.

Harrison, B. (1999). Noble Cause Corruption and the Police Ethic. FBI Law Enforcement Bulletin , 1-7.

Hassell, K.D., \& Zhao, J.S. (2003). Structural Arrangements in Large Municipal 
Police Organizations. Policing: An International Journal of Police Strategies and Management, 26(2), 231-250.

Henkel, J., \& Sheehan, E.P. (1997). Relation of Police Misconduct to Authoritarianism. Journal of Social Behavior \& Personality, 12(2), 551-556.

Hickman, M.J., Piquero, A.R., Lawton, B.A., \& Greene, J.R. (2001). Applying Tittle's Control Balance Theory to Police Deviance. Policing: An International Journal of Police Strategies and Management, 24(4), 497-519.

Hickman, M.J., Piquero, N.L., \& Piquero, A.R. (2004). The Validity of Niederhoffer's Cynicism Scale. Journal of Criminal Justice, 32, 1-13. California Press.

Hirschi, T. (2002). Causes of Delinquency. ( ed.). Berkeley: University of

Hirschman, A.O. (1970). Exit, Voice and Loyalty: Responses to Decline in Firms, Organizations and States. (ed.). Boston: Harvard University Press.

Hodgson, J.F. (2001). Police Violence in Canada and the USA: Analysis and Management. Policing: An International Journal of Police Strategies and Management, 24(4), 520-549.

Huddleston, M.W., \& Sands, J.C. (1995). Enforcing Administrative Ethics. The Annals of the American Academy of Political and Social Science, 537, 139-149.

Hughes, T.T. (2003). Jordan v. The City of New London, Police Hiring and IQ. Policing: An International Journal of Police Strategies and Management, 26(2), 298-312.

Human Rights Watch. (1998). Shielded from Justice: Police Brutality and Accountability in the United States. ( ed.). New York:

International Association of Chiefs of Police. (1992, January). The Evolution of the Law Enforcement Code of Ethics. The Police Chief, 14-17.

International Association of Chiefs of Police (IACP). (1998, January). Ethics Training in Law Enforcement. The Police Chief, LXV, 14-24.

International Association of Chiefs of Police National Law Enforcement Policy Center. Standards of Conduct.

Jiao, A.Y. (1998). Matching Police-Community Expectations: A Method of Determining Policing Models. Journal of Criminal Justice, 26(4), 291-306. University;

Kavanagh, J. (1994). The Occurrence of Force in Arrest Encounters. Rutgers 
Kenney, D.J., \& McNamara, R.P. (1999). Police and Policing: Contemporary Issues. (ed.). Westport: Praeger.

Kleinig, J. (1999). The Ethics of Policing. ( ed.). New York: Cambridge University Press.

Klinger, D.A. (2004). Environment and Organization: Reviving a Perspective on the Police. The Annals of the American Academy of Political and Social Science, 593, 119136.

Klockars, C.B., Ivkovic, S.K., \& Haberfeld, M. (2004). The Contours of Police Integrity. ( ed.). Thousand Oaks: SAGE Publications.

Klockars, C.B., Ivkovich, S.K., \& Haberfeld, M.R. What All Police Chiefs Should Know About Integrity in their Agency and What They Should Do When They Find Out. In Anonymous.

Klockars, C.B., Ivkovich, S.K., Harver, W.E., \& Haberfeld, M.R. The Measurement of Police Integrity. (2000, May). Anonymous. National Institute of Justice.

Kohlberg, L. (1984). The Psychology of Moral Development: The Nature and Validity of Moral Stages. ( ed.). San Francisco: Harper \& Row.

Kornhauser, R.R. (1978). Social Sources of Delinquency. ( ed.). Chicago: University of Chicago Press.

Kraska, P.B., \& Kappeler, V.E. (1997). Militarizing American Police: The Rise and Normalization of Paramilitary Units. Social Problems, 44, 1-18.

Kraska, P.B., \& Kappeler, V.E. (1998). A Textual Critique of Community Policing: Police Adaptation to High Modernity. Policing: An International Journal of Police Strategies and Management, 21(2), 293-313.

Kristof-Brown, A.L. (2000). Perceived Applicant Fit: Distinguishing Between Recruiters' Perceptions of Person-Job and Person-Organization Fit. Personnel Psychology, 53 (3), 643-671.

Langworthy, R.H. (1986). The Structure of Police Organizations. ( ed.). Westport, CT: Praeger.

Lefkowitz, J. (1974). Job Attitudes of Police: Overall Description and Demographic Correlates. Journal of Vocational Behavior, 5, 221-230.

Lewis, C. (1991). The Ethics Challenge in Public Service. (ed.). San Francisco: Jossey-Bass, Inc. 
Lipsky, M. (1980). Street-Level Bureaucracy: Dilemmas of the Individual in Public Services. ( ed.). New York: Russell Sage Foundation.

Lundman, R.J. (1980). Police and Policing: An Introduction. ( ed.). New York: Holt, Rinehart and Winston.

Lundman, R.J. (1980). Police Behavior. ( ed.). New York: Oxford University Press.

Hall.

Lyman, M. (1999). The Police: An Introduction. ( ed.). New York: Prentice

Lynch, R.G., \& McMahon, R.R. (1984). Getting to Know Policemen Personally. ( ed.). Chapel Hill: Institute of Government.

Mastrofski, S.D., \& Ritti, R.R. (1996). Police Training and the Effects of Organization on Drunk Driving Enforcement. Justice Quarterly, 13(2), 291-320.

Mastrofski, S.D., Worden, R.E., \& Snipes, J.B. (1995). Law Enforcement in a Time of Community Policing. Criminology, 33(4), 539-603.

Maynard-Moody, S., \& Musheno, M. (2000). State Agent or Citizen Agent: Two Narratives of Discretion. Journal of Public Administration Research and Theory, 10(3), 329358.

Maynard-Moody, S., Musheno, M., \& Palumbo, D. (1990). Street-Wise Social Policy: Resolving the Dilemma of Street-Level Influence and Successful Implementation. The Western Political Quarterly, 43(4), 833-848.

McElvain, J.P., \& Kposowa, A.J. (2004). Police Officer Characteristics and Internal Affairs Investigations for Use of Force Allegations. Journal of Criminal Justice, 32, 265-279.

McNamara, J. (1967). The Police: Six Sociological Essays. In D. Bordua (Ed.), Uncertainties in Police Work: The Relevance of Police Recruits. (pp. 163-252). New York: John Wiley.

Nolan, T.W. (2000). Toward Probity: The Moral Milieu of the Police Station House. Boston University;

Novak, K., Hartman, J., Holsinger, A.J., \& Turner, M.G. (1999). The Effects of Aggressive Policing of Disorder on Serious Crime. Policing: An International Journal of Police Strategies and Management, 22(2), 171-190.

Novak, K.J., Frank, J., Smith, B.W., \& Engel, R.S. (2002). Revisiting the Decision to Arrest: Comparing Beat and Community Officers. Crime \& Delinquency, 48(1), 
70-98.

Paoline III, E.A. (2001). Rethinking Police Culture: Officers' Occupational Attitudes. ( ed.). New York: LFB Scholarly Publishing LLC.

Paoline III, E.A. (2003). Taking Stock: Toward a Richer Understanding of Police Culture. Journal of Criminal Justice, 31, 199-214.

Paoline III, E.A., Myers, S.M., \& Worden, R.E. (2000). Police Culture, Individualism, and Community Policing: Evidence from Two Police Departments . Justice Quarterly, 17(3), 575-605.

Priest, T.B., \& and Carter, D.B. (1999). Evaluations of Police Performance in African-American Sample. Journal of Criminal Justice, 27, 457-465.

Quinn, R.E. (1984). Applying the Competing Values Approach to Leadership. New York: Pergamon Press.

Quinn, R.E. \& Hall, R.H. (1983). Environments, Organizations, and Policymakers: Toward an Integrative Framework. Beverly Hills: Sage Publications, Inc.

Quinn, R.E., \& Rohrbaugh, J. (1981). A Competing Values Approach to Organizational Effectiveness. Public Productivity Review, 5, 122-140.

Raines, J.B. (2005). Law Enforcement Policy: Use of Force. Law Enforcement Executive Forum, 5(4), 97-104.

Rest, J.R., Narvaez, D., Thoma, S.J., \& Bebeau, M.J. (2000). A neo-Kohlbergian approach to morality research. Journal of Moral Education, 29(4), 381-395.

Riksheim, E.C., \& Chermak, S.M. (1993). Causes of Police Behavior Revisited. Journal of Criminal Justice, 21, 353-382.

Robinette, H.M. (1991, January). Police Ethics: Leadership and Ethics Training for Police Administrators. The Police Chief, 42-47.

Robinson, A.L. (2003). The Impact of Police Social Capital on Officer Performance of Community Policing. Policing: An International Journal of Police Strategies and Management, 26(4), 656-689.

Robinson, A.L., \& Chandek, M.S. (2000). The Domestic Violence Arrest Decision: Examining Demographic, Attitudinal, and Situational Variables. Crime \& Delinquency, 46(1), 18-37.

Rohr, J.A. (1978). Ethics for Bureaucrats: An Essay on Law and Values. New York: Marcel Dekker. 
Rusbult, C.E., Farrell, D., Rogers, G., \& Mainous, A.G. (1988). Impact of Exchange Variables on Exit, Voice, Loyalty, and Neglect - An Integrative Model of Responses to Declining Job-Satisfaction. Academy of Management Journal, 31(3), 599-627.

Rusbult, C.E., Zembrodt, I.M., \& Gunn, L.K. (1982). Exit, Voice, Loyalty, and Neglect - Responses To Dissatisfaction in Romantic Involvements. Journal of Personality and Social Psychology, 43(6), 1230-1242.

Samaha, J. (2005). Criminal Law. ( ed.). Belmont, CA: Thomson Wadsworth.

Scarborough, K.E., Van Tubergen, G.N., Gaines, L.K., \& Whitlow, S.S. (1999). An Examination of Police Officers' Motivation to Participate in the Promotional Process. Police Quarterly, 2(3), 302-320.

Sherman, L. (1982). Learning Police Ethics. Criminal Justice Ethics, 1(1), 10-19.

Simon, R. (1995). Control in an Age of Empowerment. Harvard Business Review, 73(2), 80-88.

Skolnick, J., \& Bayley, D. (1986). The New Blue Line: Police Innovation in Six American Cities. (ed.). New York: Free Press.

Skolnick, J., \& Fyfe, J. (1993). Above the Law: Police and the Excessive Use of Force. (ed.). New York: Maxwell MacMillan International.

Slovak, J.S. (1986). Styles of Urban Policing: Organization, Environment, and Police Styles in Selected American Cities. ( ed.). New York, NY: New York University Press. $\underline{22}(1), 19-38$.

Smith, D.A. (1984). The Organizational Context of Legal Control. Criminology,

Steinberg, S.S., \& Austern, D.T. (1990). Government, Ethics, and Managers: A Guide to Solving Ethical Dilemmas in the Public Sector. (ed.). Westport: Praeger.

Stewart, D.W., \& Sprinthall, N.A. (1994). Moral Development in Public Administration. In T. Cooper (Ed.), Handbook of Administrative Ethics. (pp. 325-348). New York: Marcel Dekker.

Stewart, D.W., \& Sprinthall, N.A. (1991). Strengthening Ethical Judgment in Public Administration. (Ethical Frontiers in Public Management ed.). Jossey-Bass.

Sutherland, E.H., Cressey, D.R., \& Luckenbill, D.F. (1970). Principles of Criminology. (ed.). Philadelphia: Lippincott.

Svara, J. (1997). The Ethical Triangle: Synthesizing the Bases of Administrative 
Ethics. Public Integrity Annual, 33-41.

Sykes, G.W. (1994, Summer). That's the Way We Do Things Around Here. Law Enforcement Ethics Center Newsletter,

Tabachnick, B.G., \& Fidell, L.S. (2001). Using Multivariate Statistics. (ed.). Needham Heights, MA: Allyn \& Bacon.

Terrill, W., \& Mastrofski, S.D. (2002). Situational and Officer-Based Determinants of Police Coercion. Justice Quarterly, 19(2), 215-248.

Terrill, W., Paoline III, E.A., \& Manning, P.K. (2003). Police Culture and Coercion. Criminology, 41(4), 1003-1034.

Terrill, W., \& Reisig, M.D. (2003). Journal of Research in Crime and Delinquency, 40(3), 291-321.

Tittle, C.R. (1995). Control Balance: Toward a General Theory of Deviance (Crime and Society). ( ed.). New York: Westview Press.

Trautman, N.E. The National Law Enforcement Officer Disciplinary Research Project. (1997). Anonymous. The Ethics Institute.

Truelson, J.A. (1991). New Strategies for Institutional Controls. In Anonymous, (pp. 225-242). San Francisco: Jossey-Bass.

U.S. Department of Justice. (1991, January). Police Ethics: Building Integrity and Reducing Drug Corruption. The Police Chief, 27-41.

U.S. Department of Justice, Bureau of Statistics. Law Enforcement Management and Administrative Statistics (LEMAS). 2000.

Van Maanen, J. (1973). Observations of the Maknig of a Policeman. Human Organization, 32, 407-418.

Van Wart, M. (1998). Changing Public Sector Values. ( ed.). New York: Garland Publishing, Inc.

Vila, B., \& Morris, C. (1999). The Role of Police in American Society: A Documentary History. ( ed.). Westport: Greenwood Press.

Walker, S. Best Practices in Policing. (2004, January). Anonymous. Oakland, CA: University of Nebraska at Omaha.

Walker, S., Alpert, G.P., \& Kenney, D.J. Early Warning Systems: Responding to the Problem Police Officer. (2001, July). Anonymous. National Institute of Justice. 
Weber, D.C. Warrior Cops: The Ominous Growth of Paramilitarism in American Police Departments. (1999, August 26). Anonymous. CATO Institute.

Whetstone, T.S. (2001). Copping Out: Why Police Officers Decline to Participate in the Sergeant's Promotional Process. American Journal of Criminal Justice, 25(2), 147 159.

Wilson, J.Q. (1989). Bureaucracy: What Government Agencies Do and Why They Do It. ( ed.). New York: Basic Books.

Wilson, J.Q. (1968). Varities of Police Behavior. ( ed.). New York: Antheneum.

Wilson, J.M. (2003). Measurement and Association in the Structure of Municipal Police Organizations. Policing: An International Journal of Police Strategies and Management, 26(2), 276-297.

Wilson, K.L., Rest, J.R., Boldizar, J.P., \& Deemer, D.K. (1992). Moral Judgment Development: The Effects of Education and Occupation. Social Justice Research, 5(1), 3148.

Withey, M.J., \& Cooper, W.H. (1989). Predicting Exit, Voice, Loyalty, and Neglect. Administrative Science Quarterly, 34(4), 521-539.

Worden, R.E. The Causes of Police Brutality: Theory and Evidence on Police Use of Force. In W. Geller \& H. Toch (Ed.). Washington, DC: Police Executive Research Forum.

Zipparo, L. (1999). Factors which Deter Public Officials from Reporting Corruption. Crime, Law \& Social Change, 30, 273-287. 
APPENDIX A 


\section{tas rom

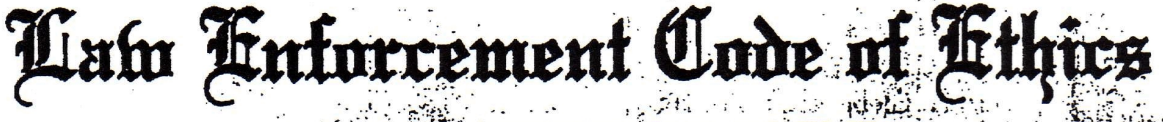

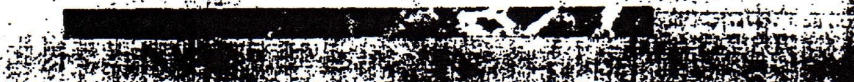

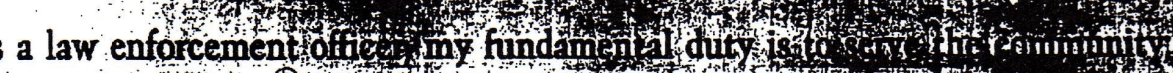

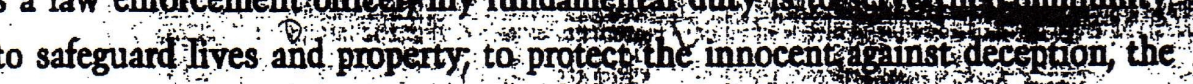
the peaceful againtatom disorder, and to respect the constitutional rights of all to liberty, equality and astice. I will keep my private life unsullied as an example to all and will behave in a manner that does not bring discredit to me or to my agency. I will maintain courageouls calm in the face of danger, scom or ridicule; develop self-restraint; and be constantly mindful of the welfare of others. Honest in thought and deed both in my personal and official life, I will be exemplary in obeying the law and the regulations of my department. Whatever I see or hear of a confidential nature or that is confided to me in my official capacity will be kept ever secret unless revelation is necessary in the performance of my duty.

I will never act officiously or permit personal feelings, prejudices, political beliefs, aspirations, animosities or friendships to influence my decisions. With no compromise for crime and with relentless prosecution of criminals, I will enforce the law courteously and appropriately without fear or favor, malice or ill will, never employing unnecessary force or violence and never accepting gratuities.

I recognize the badge of my office as a symbol of public faith, and I accept it as a public trist to be held so long as I am true to the ethics of police service. I will never engage in acts of comuption or bribery, nor will I condone such acts by other police officers. I will cooperate with all legally authorized agencies and their representatives in the pursuit of justice.

I know that I alone am responsible for my own standard of professional performance and will take every reasonable opportunity to enhance and improve my level of knowledge and competence.

I will constantly strive to achieve these objectives and ideals, dedicating myself before God to my chosen profession ... law enforcement. 
APPENDIX B 


\section{$\cdots$

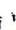

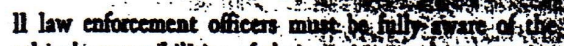 ethical responsibitities of their poition and mist strife - contantly to live up to the highest powible atandards of professional policing. \\ The International Associntion of Chief of Police believes it important that police officess have clear atvice and counsel avilable to assist them in performing their duties consiatent with these standards, and has adopted the following ethical mandates as guidelines to meet these ends.}

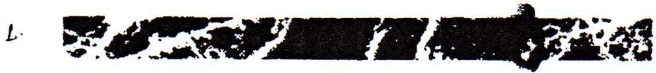

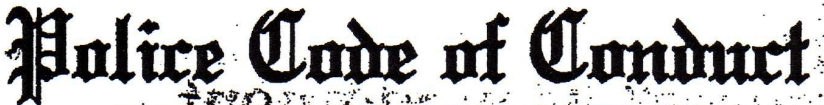 S. r 然}

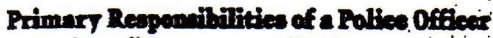

A police officer acts as an official repreventetive of govienment who is required and trusted to work within the in. The officer's powers and duties ariconferred by atatute The fundamental doties of a police officer include serving the comintifity, safecturating lives and property, protecting the innocent, keeping the pesce and ensuring the rights of all to liberty, equality and justice.

\section{Performmee of the Duties of a Police Officer}

A police officer shall perform all deties impartially, without favor or affection or ill will and without ragard to status, ser, rece, religion, political belief or aspiration. All citizens will be eated equally with courtesy, consideration and dignity.

Officers will never allow personal feelings, animosities or friendships to influence official conduct. Law will be enforced appropriately and courteoushy and, in carrying ont their responsibilities, officers will strive to obtrin maximum coppention from the public. They will conduct themselves in appernance and deportment in such a manner as to inspire confidence and respect for the position of public trust they hold.

\section{Diseretion}

A police officer will use responsibly the discretion vested in his position and exereise it within the law. The principle of reasonableness will guide the efficer's determinations, and the officer will consider all surrounding circumatinces in determining whether any lezal action shall be taken.

Consistent and wise use of discretion, based on professional policing competence, will do much to preserve sood relationships and retain the confidence of the public. There can be difficulty in choosing between conflicting courses of action. It is important to remember that a timely word of advice rather than arrestwhich may be correct in appropriate cireumstances-can be a more effective means of achieving a desired end.

\section{Use of Eores}

A police officer will never euploy unnecesery force or vialence and will use only such force in the diecharge of duty as is reonable in ill eircumotances.

The ase of fosee should be used only with the greateat restraint and only after diceusaion, negotiation and pentuasion have been found to be inapprogniate or ineffective. While the we of force

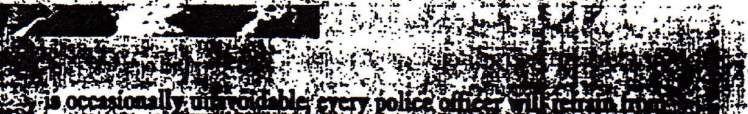

Whatever a police offices sees, hears or learns of that is of a confidential nature will be kept secret uniess the performance: of duty or legal provision requires otherwise.

Members of the priblic have a right io security and pirich and information obtained abous them must not be improperty.

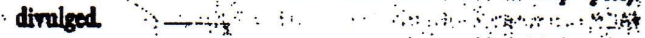

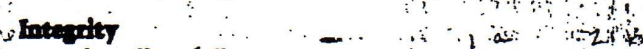
A police officer will not engez in ects of corruption or hribjiy: nor will an officer condone such 'sets by other police officen. The problie demands that the integrity of police officers be above reprosech. Police officess must, therefore, avoid ant conduet that might compromise integritz and thus nndercut the public confidence in a law enforcement azency. Officers will refuse to ecepteny gifts, presents, subscriptions, favos, gratuities or promises that could be interpreted as seeking to cause the officer to refrain from performing official responsibilities honesth and within the law. Police officers must not receive private or special adrentape from their official statis. Respect from the prblic cannot be bonght, it can only be earned and cultivated.

Cooperation with Other Police Officens and Apenelea

Police officers will cooperate with all legally anthorized agencies and their representatives is the pursuit of justice.

An officer or agency may be one among many organizations that may provide law enforcement services to a juriediction If is imperative that a police officer ascist colleagues fully and completely with respect and consideration at all times.

\section{Personal-Profemional Cepabilitilen}

Police officen will be responsible for their own standard of professional performance and will take every reasonable opportunity to enhance and improve their level of knowledge and competence.

Through stady and experience, a police officer can acquire the high level of knowledge and competence that is essential for the efficient and effective performance of duty. The acquisition of knowledge is a neverending process of personal and professional developiment that should be puraned constantly.

\section{Privatife}

Police officens will behave in a manner that does not bring discredit to their aseineies or themselves.

A police officer's chanceter and condwet while off duty must ahrays be excouplan, thos maintrining a position of respect in the comminaity in which be or abe lives and server. The officer's personal behavior mint be beyond reprosech 
APPENDIX C 
1. A police officer runs his own private businass in which ho sefls and installs securtity devices, such es alarms, special locks, elc. He does this

1. How serious do YOU consider this behavtor to be?
Not at all
serious
Very

\section{INSTRUCTIONS}

On the following pages you will be asked to evaluate eleven descriptions of police officer behavior that may depart from official department policy.

In each instance you should assume that the officer in question has been a police officer for five years, has not been previously disciplined, and that the officer has a satisfaciory work record. Please do not make any other the officer.

For each incident you will be asked the same set of seven questions. These questions ask you to give your opinion the seriousness of the behavior the discipline, any, it merits, or the likelihood it would be reported.

To do so you must CIRCLE a number on the five-point scale that appears beneath each question.

Please remember that we are only asking for your PERSONAL OPINIONS on these matters. Your answers do not in any way imply that you have participated in or are aware of any such behavior in your agency.
2. How serfous would MOST POLICE OFFICERS IN YOUR AGENCY coneidor the
behavior to be?

Not at all $2434 \begin{gathered}\text { Very } \\ \text { serious }\end{gathered}$

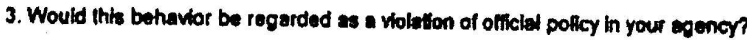
Defintely Definkely not $123 \quad 3 \quad \frac{1}{3}$

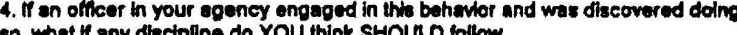

4. NOME APERO OF SUSPENSION 2. VEREAL REPRIMAND
3. WRTTEN REPRIMAND

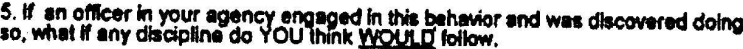
1.NONE NERERRAMAND

PERIOD OF SUSPENSION 5. MEMTOUTONAY RANK

6. Do you think YOU would report a fellow police officer who engagod in the
behevor? Definitety 1.2 23 Deflnhety
rese
5

7. Do you think MOST POLICE OFFCERS IN YOUR AGENCY would report a Definitely Definilely 23 45 
2. A police officer routinely accepls free meais, cigarettes, and othar items of small value from merchants on his beat. He does not solicit these gitts and is careful not to abuse the generosity of those who give gitts to him.

How serious do You consider this behavior to be?

Not at all
serious

$$
\begin{aligned}
& \text { Very } \\
& \text { senious } \\
& 5
\end{aligned}
$$

2. How serlous wound MOST POLICE OFFICERS IN YOUR AGENCY Consider this
behavior to bo? Not at all

$$
\begin{aligned}
& \text { Very } \\
& \text { serious }
\end{aligned}
$$

3. Would this bethavior regarded as a violabion of official pollicy in your agener? Definitely

$$
\begin{gathered}
\text { Definitely } \\
\text { yes } \\
\text { s }
\end{gathered}
$$

\section{If an officer in your agency ongaged in this behavior}

so, what if any disctipline do YOU think SHOULO follow.

1. NONE
2. WERBL REPRIMANO
3. WRITENEREPIMAND

4. PERIOD OF SUSPENSION 5. WEMOTITONAN RANK 5. If an officer in your agency ongaged in this behavior and was discovered doing
so, what ff any discipting do You think woult

1. NONE VRR REPRIMAND
3. WRITEN REPRIMAND

4. PERIOD OF SUSPENSION

4. PERTOO OF SUSPENS
WITHOUT PAY
5. DEMOTION IN RANK

6. Do you think YOU would report a fellow police officer who engaged in this
behavion?

Definitely

ot

$$
2
$$$$
3
$$$$
\text { Yesinitely }
$$

7. Do you think MOST POUICE OFFICERS IN YOUR AGENCY would report a Definitely

$$
\text { Definitely }
$$

3. A police officer stops a motorist for speedting. The offleer agrees to issuing a cthetion.

1. How serious do You consider this behavior to be?

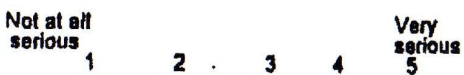

2. How serious would MOST POLICE OFFICERS N YOUR AGENCY COnalder the
behavilor to be? Not at all

$$
34 \begin{gathered}
\text { Very } \\
\text { serious }
\end{gathered}
$$

3. Would this behavior be rogarded as a volation of ofictal pollcy in your ageners? Delinkely

$$
\text { Dellnitoly }
$$

4. 1 an officer in your ageney angaged in this behavior and was discovared doing so, what $K$ any discipline do YOU think SHOUR. follow.

1. NONE

4. PERIOD OF SUSPENSHON

3. VERBAL REPRIMAND 5. DEMOTTON IN RANK

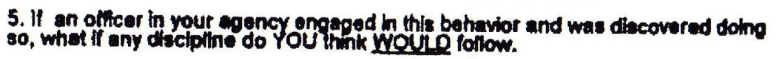

1. NONE

WEREAL REPRMANO

4. PERTOO OF SUSPENEION

s. DEMOTION IN RanK

6. Do you think YOU would report a follow pallce officer who engeged in the
behavior?

Doffinitely

$$
23
$$$$
\text { Deflintely }
$$

7. Do you think MOST POLICE OFFICERS IN YOUR AGENCY would roport a Definitely Definllety Definitely
not 
4. A pollee offtcer bs wobly liked in the community, and on holldays loeal merchants and resteusrant and bar oweers show their approclatton for $h$

1. How sertious do You conalder this behavior to be?

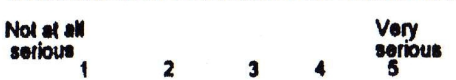

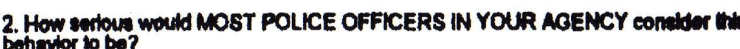

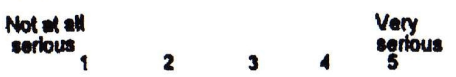

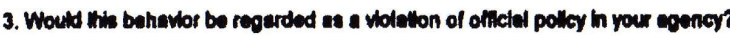
Dothontely

$$
\text { not } 1234 \underset{5}{\substack{v_{0} \\ 5}}
$$

A. If an offleer in your ageney engaged in this behavior and was discovered dolng

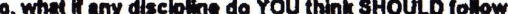

1. NONE

4. PERJOD OF SUSPENSION

WRITEN REPRINAND

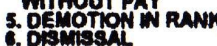

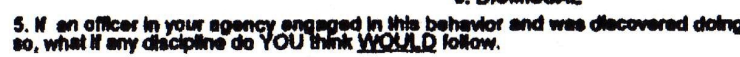

1. NONE

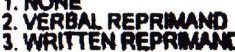

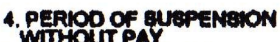

5. Memoutron park

6. Do you think YoU would report a lollow polltes oflacer who engeged in the Demint<smiles>[AlH2]</smiles>

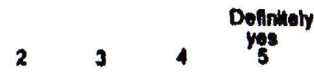

7. Do you Hithk MOST POLICE OFFICERS W YOUR AGENCY would roport * Defnitely Definkly
1. A polles officer finds a bar on his bose which is atw sorving drinks a hall

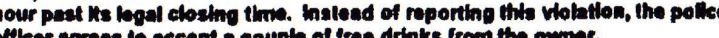

1. How sorlous do YOU conekder the behavtor to be?

Not at and Very
sertous

2. How cerlous would MOST POUCE OFFICERS IN YOUR AGENCY conelder the

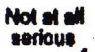
Very 3. Would the behavior be regarded as a violaton of offectal poltcy in your moenen Dofinotion

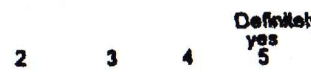

1.7f an officer in your agency engaged in this behavtor snd was discovered doing so, what If any disclpilue do rou think sHOULD follow.

1. NONE KEM REPRIMND 4. PERYOO OF SLISPENSION

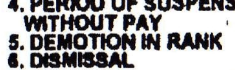

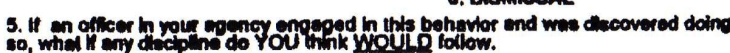

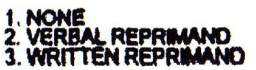

4. PERROP OF SUSPENGHON 5. DEMOTION W RANK
6. DishsSAL.

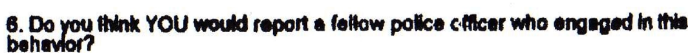
Dofinitioly

$$
34 \underbrace{\substack{\text { Defingely } \\ \text { yes }}}_{5}
$$

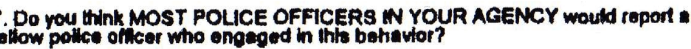
Dofnitoly Definkely 
6. A police offlicer has a privale arrangoment whth s local auto body shop to celer the owners of cass demeged in aceldents to the shop. in exchange tor asch reforral, he recolves a payment of $5 \%$ of the ropair bill from the shop owner.

1. How serious do YoU consider this behavior to be?

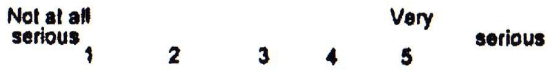

2. How serious would MOST POLICE OFFICERS IN YOUR AGENCY consider this
behavior to be? Not at all
settous

3. Would this behavior be regarded as a violattion of offecial polley in your goency? $\begin{array}{ccccc}\text { Definhtely } \\ \text { not } & 2 & 3 & 4 & \begin{array}{c}\text { Definitely } \\ \text { yes } \\ 5\end{array}\end{array}$

4. If an officer in your agency engaged in this behavior and was discovered doing so, what if any disciphine do YOU think SHOULD follow.

$\begin{array}{ll}\text { 1. NONE } & \text { 4. PERIOD OF SUSPENSION } \\ \text { 2. VERBA REPRIMAND } & \text { WITHOUT PAY RANK } \\ \text { 3. WRITTENREPRIMAND } & \text { 5. DEMOTIONIN RANK }\end{array}$

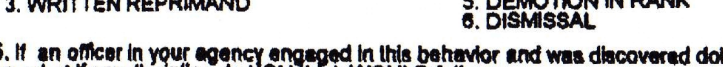

NONE

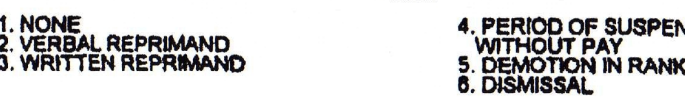

6. Do you think YOU would report a fellow pofice officer who engeged in this
behevior? $\begin{array}{ccccc}\text { Deffnitely } \\ \text { not } \\ 1 & 2 & 3 & 4 & \begin{array}{c}\text { Definitely } \\ \text { yess }\end{array}\end{array}$

7. Do you inink MOST POUICE OFFICERS IN YOUR AGENCY would report a. Definite
not

yes
7. A pollice offlicer, who happens to be a very good auto mechanic, ts schoduled to work during coming holldays. A supervis or offers to give the these days off, ith he agrees to tune-up his supervisor's personal car. Evaluate the SUPERVISOR'S behavior.

1. How serious do You consider this behavior to be?

Not at all
serltaus

2. How serbus would MOST POLICE OFFICERS IN YOUR AGENCY conslder II
bohavior to bo?

$\begin{gathered}\text { Not at all } \\ \text { serious }\end{gathered}$
1 $\quad 2 \quad 3 \quad 4 \quad \begin{gathered}\text { Very } \\ \text { serfious } \\ 5\end{gathered}$

3. Would this behavior be regarded as a volaton of offictal polley in your egeney Doffilitely

$\begin{array}{lllll}1 & 2 & 3 & 5\end{array}$

4. If an officer in your agency engaged in this behavior and was discovered dolng so, what if any discipline do YOU think SHOULD follow.

1. NONE
2. VEREAL REPRIMAND
3. WRITTEN REPRRMAND

4. PERIOD OF SUSPENSTON

3. WRITTEN REPRIMAND

5. WITHOUTT PAY IN RANK

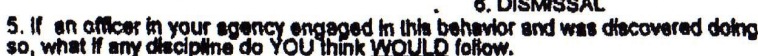

1. NONE

2. VERRAL REPRIMAND

4. PERIOD OF SUSPENSION

5. WEMOUTY PAY RANK

6. Do you think YOU would roport a fellow police officer who engaged in this
Definitely
2
Dofinitery
ress

7. Do you think MOST POLICE OFFICERS IN YOUR AGENGY would report a Derinhely

Definitery 
8. Al 2 A poltce oftleer, who is on duly, is drtving his petteot car on a

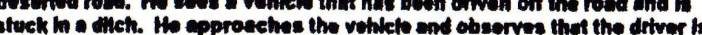

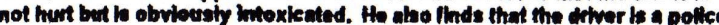
officer. matoad of repering this aceldent and offenase he trenaports the detwer to his nom

1. How sertous do YOU consider the behantor 10 be?

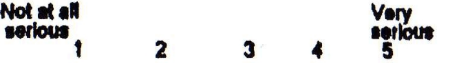

2. How gertong would MOST POUICE OFFICEAS IN YOUR AGENCY conalder the Not al wall

Very

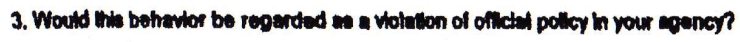
Donimily

4. II an offecer in your souncy engaped in mhe behentor and wes decovered doing

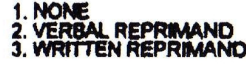

4. PERIOD OF SUSPENSTON

WRITEN REPRIMANO

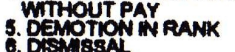

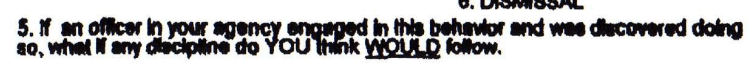

2. NONE

4. PERROD of gUSPENGTON

3. WiTHOUT PAY RAMK

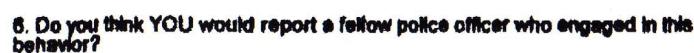

DeAniluby

$$
3
$$

4

$$
\underset{5}{\text { Dofintoly }}
$$

7. Do You Hink MOST POUCE OFFICERS WN YOUR ACENCY woukd roport a Dofinitery Dentoty

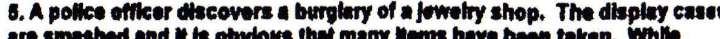
are smestred and 4 te obvioves thai many hems have boen taken. Whis

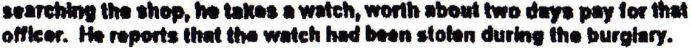

1. How serious do YOU constider the behentor to ba?

Nol at all
sertous

very

2. How sertous wound MOST POLICE OFFICERS IN YOUR AGENCY consider the
behowhor to be? Noef at ent

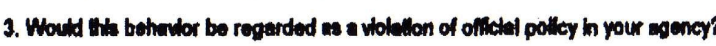
Domiluty intilety

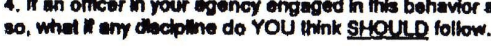

1. NONE
3. WRTITENEPREMAND

4. PERIOD OF SUSPENSION S. DEMOTIONAY RANK

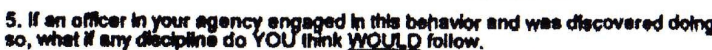

1. NONE

4. PERTOD OF SUSPENSION

WERRAL REPRMMAND

5. DENOTON IN RANK

B. Do you think YOU would report a follow pollice officer who engaged in the behavion? Dofintely
not
1.2

34 Dofinimoty 7. Do you think MOST POLCE OFFICERS IN YOUR AGENCY would repont
ielliow police oflicer who ongeged in the behavior?
Defintloty
Delinilehy 
10. Two- - officors on fool patrol surprise a man who ls attempling to

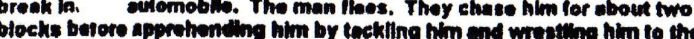
ground. After he is under centrol both oflikers punch itm e coupto of the in the stomech es promishement for theoing and reshing

1. How serbovs do YOU conetder this behmort to be?

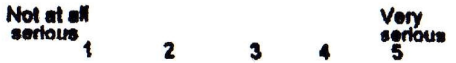

2. How soplous would MOST POUICE OFFICERS WN YOUR AOENCY condder the Not al all

$$
34 \text { vertous }
$$

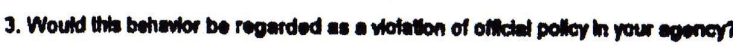
Dofontely Dolininaty

4. 1 an officer in your ageney engeged in this behavior and was dhecovered dolng 10, what ll any disciothe do roU think SHOULR lollow.

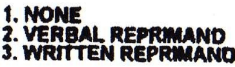

4. PERTOP OF SUSPENSHON Oftorion rank

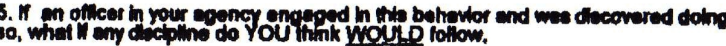

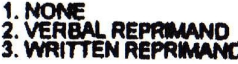

1. PERTOO OF SUGPENGION

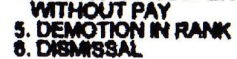

6. Do you think YOU woukd report a lollow pollces officer who engeged in the

Deflntely

P. Do you think MOST POLICE OFFCERS IN YOUR AGENCY woutd report a Dentnkety

Dotancen
3. A pollce offiker stops a molorise for spending. The offike ces to

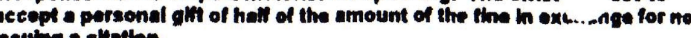

1. How serrous do YOU conelder thas behertor to be?

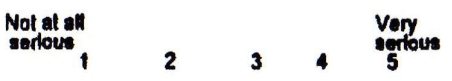

2. How recloug woutd MOST POLICE OFFICERS W YOUR AGENCY COnelder wh

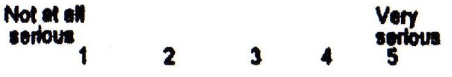

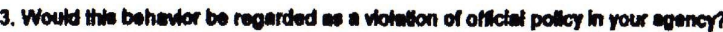
Donolity Delimiloty

$\begin{array}{lllll}1 & 2 & 4 & 5\end{array}$

4. In mn officer in your ageney enpoged in this bohovior snd was discovered dothe

1. NOME

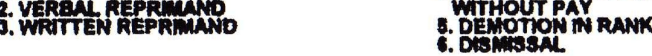

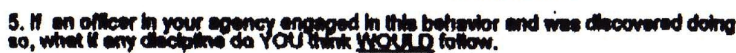

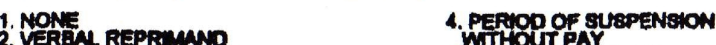

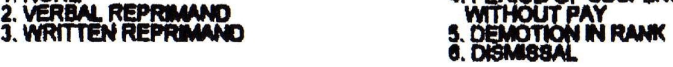

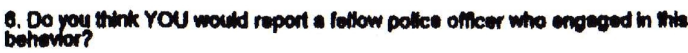

Dollntily

yeses

23

4

5

7.Do you think MOST POLICE OFFICERS N YOUR AGENCY would report a Defnillely

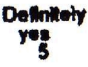


Please circle, underthe, of fill out your response

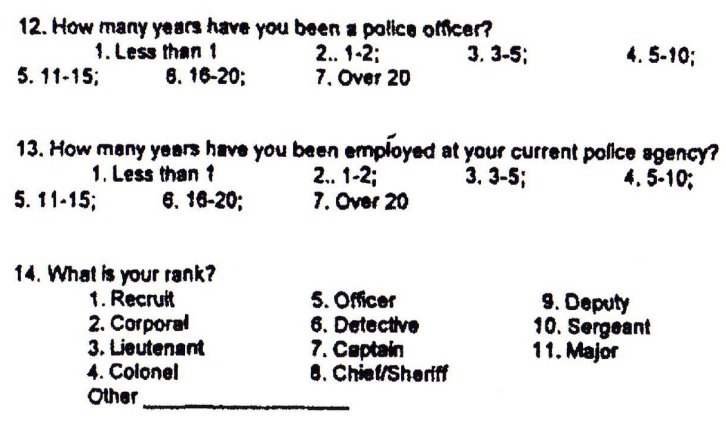

15. Which of the following best describes your current assionmente

$$
\text { 1. Patrol }
$$

3. Spectivi Operations (vice, juvenile, etc.)

4. Communications

Other

\section{Are you a supervisor or nen-supentison?}

1. Non-Supentsor

2. Supenvisor (unk supentisor, group supervisor, chleftsherim)

17. Which of the following best describes your police agency?

1. Very Large Munictpal Pollce (more then 500 swoin officers)

2. Large Municipal Pollce (201-500 gwom officenrs)

. Tmetil

5. Very Small Municipal Police (less than 25 sworn officens)

6. State Pollice

7. Sheriff

8. County Police
18. Do you think that MOST POLICE OFFICERS would give their honest opinions in filling out this questionnaire?
Yes
No

19. Did you?

$\begin{array}{cc}\text { Yes } & \text { No } \\ 1 & 2\end{array}$

20. Please use this space for any comments you would like to make about this questionnaire.

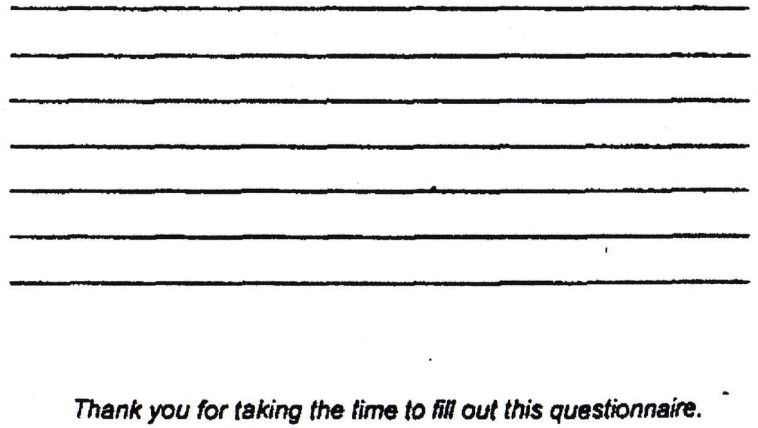

Thank you for faking the fime to fll out this questionnaire. 
APPENDIX D 


\section{Conflict of Interest - Ethical Awareness}

Correlations

\begin{tabular}{|c|c|c|c|}
\hline & & $\begin{array}{l}\text { C2 MEALS - } \\
\text { OWN } \\
\text { SERIOUSNE } \\
\text { SS OF BEH }\end{array}$ & $\begin{array}{l}\text { C4 HOLIDAYS } \\
\text { - OWN } \\
\text { SERIOUSNES } \\
\text { S OF BEH }\end{array}$ \\
\hline $\begin{array}{l}\text { C2 MEALS - OWN } \\
\text { SERIOUSNESS OF BEH }\end{array}$ & $\begin{array}{l}\text { Pearson Correlation } \\
\text { Sig. (2-tailed) } \\
\mathrm{N}\end{array}$ & $\begin{array}{r}1 \\
3087\end{array}$ & $\begin{array}{c}.581^{\star \star} \\
.000 \\
3059\end{array}$ \\
\hline $\begin{array}{l}\text { C4 HOLIDAYS - OWN } \\
\text { SERIOUSNESS OF BEH }\end{array}$ & $\begin{array}{l}\text { Pearson Correlation } \\
\text { Sig. (2-tailed) } \\
\mathrm{N}\end{array}$ & $\begin{array}{l}.581^{\star \star} \\
.000 \\
3059\end{array}$ & $\begin{array}{r}1 \\
3075\end{array}$ \\
\hline
\end{tabular}

**. Correlation is significant at the 0.01 level (2-tailed).

\section{Conflict of Interest - Ethical Standards}

\section{Correlations}

\begin{tabular}{|c|c|c|c|}
\hline & & $\begin{array}{l}\text { C2 MEALS - } \\
\text { DISCIPLINE - } \\
\text { SHOULD } \\
\text { FOLLOW }\end{array}$ & $\begin{array}{l}\text { C4 HOLIDAYS } \\
\text { - DISCIPLINE } \\
\text { - SHOULD } \\
\text { FOLLOW } \\
\end{array}$ \\
\hline $\begin{array}{l}\text { C2 MEALS - DISCIPLINE } \\
\text { - SHOULD FOLLOW }\end{array}$ & $\begin{array}{l}\text { Pearson Correlation } \\
\text { Sig. (2-tailed) } \\
\mathrm{N}\end{array}$ & $\begin{array}{r}1 \\
3081\end{array}$ & $\begin{array}{l}.527^{\star \star} \\
.000 \\
3053\end{array}$ \\
\hline $\begin{array}{l}\text { C4 HOLIDAYS - } \\
\text { DISCIPLINE - SHOULD } \\
\text { FOLLOW }\end{array}$ & $\begin{array}{l}\text { Pearson Correlation } \\
\text { Sig. (2-tailed) } \\
\mathrm{N}\end{array}$ & $\begin{array}{l}.527^{\star \star} \\
.000 \\
3053\end{array}$ & 3072 \\
\hline
\end{tabular}

**. Correlation is significant at the 0.01 level (2-tailed).

\section{Conflict of Interest - Ethical Action}

Correlations

\begin{tabular}{|ll|r|r|}
\hline & $\begin{array}{c}\text { C2 MEALS - } \\
\text { OWN } \\
\text { REPORTING }\end{array}$ & $\begin{array}{c}\text { C4 HOLIDAYS } \\
\text { - OWN } \\
\text { REPORTING }\end{array}$ \\
\hline C2 MEALS - OWN & Pearson Correlation & 1 & $.635^{\star \star}$ \\
REPORTING & Sig. (2-tailed) & 3087 & .000 \\
& $\mathrm{~N}$ & $.635^{\star \star}$ & 3056 \\
\hline C4 HOLIDAYS - & Pearson Correlation & .000 & 1 \\
OWN REPORTING & Sig. (2-tailed) & 3056 & 3071 \\
\hline
\end{tabular}

**. Correlation is significant at the 0.01 level (2-tailed). 


\section{Exploiting Authority - Ethical Awareness}

Correlations

\begin{tabular}{|ll|r|r|}
\hline & & $\begin{array}{c}\text { C7 } \\
\text { C6 AUTO - } \\
\text { OWN } \\
\text { SERIOUSNE } \\
\text { SS OF BEH }\end{array}$ & $\begin{array}{c}\text { SUPERVISO } \\
\text { R - OWN } \\
\text { SERIOUSNE } \\
\text { SS OF BEH }\end{array}$ \\
\hline C6 AUTO - OWN & Pearson Correlation & 1 & $.395^{\star *}$ \\
SERIOUSNESS OF BEH & Sig. (2-tailed) & 3089 & .000 \\
& $\mathrm{~N}$ & $.395^{\star *}$ & 3079 \\
\hline C7 SUPERVISOR - OWN & Pearson Correlation & .000 & 1 \\
SERIOUSNESS OF BEH & Sig. (2-tailed) & 3079 & 3083 \\
\hline
\end{tabular}

${ }^{\star \star}$. Correlation is significant at the 0.01 level (2-tailed).

\section{Exploiting Authority - Ethical Standards}

\section{Correlations}

\begin{tabular}{|c|c|c|c|}
\hline & & $\begin{array}{l}\text { C6 AUTO - } \\
\text { DISCIPLINE - } \\
\text { SHOULD } \\
\text { FOLLOW }\end{array}$ & $\begin{array}{c}\text { C7 } \\
\text { SUPERVISOR } \\
\text {-DISCIPLINE } \\
\text {-SHOULD } \\
\text { FOLLOW }\end{array}$ \\
\hline $\begin{array}{l}\text { C6 AUTO - DISCIPLINE } \\
\text { - SHOULD FOLLOW }\end{array}$ & $\begin{array}{l}\text { Pearson Correlation } \\
\text { Sig. (2-tailed) } \\
\mathrm{N}\end{array}$ & $\begin{array}{r}1 \\
3079\end{array}$ & $\begin{array}{c}.430^{\star \star} \\
.000 \\
3068\end{array}$ \\
\hline $\begin{array}{l}\text { C7 SUPERVISOR } \\
\text {-DISCIPLINE -SHOULD } \\
\text { FOLLOW }\end{array}$ & $\begin{array}{l}\text { Pearson Correlation } \\
\text { Sig. (2-tailed) } \\
\mathrm{N}\end{array}$ & $\begin{array}{l}.430^{\star \star} \\
.000 \\
3068\end{array}$ & 3077 \\
\hline
\end{tabular}

${ }^{\star \star}$. Correlation is significant at the 0.01 level (2-tailed).

\section{Exploiting Authority - Ethical Action}

Correlations

\begin{tabular}{|ll|r|r|}
\hline & $\begin{array}{c}\text { C6 AUTO - } \\
\text { OWN } \\
\text { REPORTING }\end{array}$ & $\begin{array}{c}\text { C7 } \\
\text { SUPERVISOR } \\
\text { - OWN } \\
\text { REPORTING }\end{array}$ \\
\hline $\begin{array}{ll}\text { C6 AUTO - OWN } \\
\text { REPORTING }\end{array}$ & $\begin{array}{l}\text { Pearson Correlation } \\
\text { Sig. (2-tailed) }\end{array}$ & 1 & $.633^{* *}$ \\
& $\mathrm{~N}$ & 3082 & .000 \\
C7 SUPERVISOR - & Pearson Correlation & $.633^{* *}$ & 3071 \\
OWN REPORTING & Sig. (2-tailed) & .000 & 1 \\
& $\mathrm{~N}$ & 3071 & 3078 \\
\hline
\end{tabular}

${ }^{\star *}$. Correlation is significant at the 0.01 level (2-tailed). 


\section{Abuse of Authority - Ethical Awareness}

\section{Correlations}

\begin{tabular}{|c|c|c|c|c|}
\hline & & $\begin{array}{l}\text { C8 ALCOHOL } \\
\text { - OWN } \\
\text { SERIOUSNES } \\
\text { S OF BEH }\end{array}$ & $\begin{array}{c}\text { C9 BAR - } \\
\text { OWN } \\
\text { SERIOUSNE } \\
\text { SS OF BEH }\end{array}$ & $\begin{array}{c}\text { C10 } \\
\text { BRUTALITY - } \\
\text { OWN } \\
\text { SERIOUSNE } \\
\text { SS OF BEH }\end{array}$ \\
\hline \multirow{3}{*}{$\begin{array}{l}\text { C8 ALCOHOL - OWN } \\
\text { SERIOUSNESS OF BEH }\end{array}$} & Pearson Correlation & 1 & $.355^{\star \star}$ & $.407^{\star}$ \\
\hline & Sig. (2-tailed) & & .000 & .000 \\
\hline & $\mathrm{N}$ & 3077 & 3067 & 3058 \\
\hline \multirow{3}{*}{$\begin{array}{l}\text { C9 BAR - OWN } \\
\text { SERIOUSNESS OF BEH }\end{array}$} & Pearson Correlation & $.355^{\star \star}$ & 1 & $.452^{\star}$ \\
\hline & Sig. (2-tailed) & .000 & & .000 \\
\hline & $\mathrm{N}$ & 3067 & 3082 & 3068 \\
\hline \multirow{3}{*}{$\begin{array}{l}\text { C10 BRUTALITY - OWN } \\
\text { SERIOUSNESS OF BEH }\end{array}$} & Pearson Correlation & $.407^{\star *}$ & $.452^{\star \star}$ & 1 \\
\hline & Sig. (2-tailed) & .000 & .000 & \\
\hline & $\mathrm{N}$ & 3058 & 3068 & 3082 \\
\hline
\end{tabular}

${ }^{\star \star}$. Correlation is significant at the 0.01 level (2-tailed).

\section{Abuse of Authority - Ethical Standards}

Correlations

\begin{tabular}{|c|c|c|c|c|}
\hline & & $\begin{array}{l}\text { C8 ALCOHOL } \\
\text { - DISCIPLINE } \\
\text { - SHOULD } \\
\text { FOLLOW }\end{array}$ & $\begin{array}{l}\text { C9 BAR - } \\
\text { DISCIPLINE - } \\
\text { SHOULD } \\
\text { FOLLOW }\end{array}$ & $\begin{array}{c}\text { C10 } \\
\text { BRUTALITY } \\
\text {-DISCIPLINE } \\
\text {-SHOULD } \\
\text { FOLLOW } \\
\end{array}$ \\
\hline $\begin{array}{l}\text { C8 ALCOHOL - } \\
\text { DISCIPLINE - } \\
\text { SHOULD FOLLOW }\end{array}$ & $\begin{array}{l}\text { Pearson Correlation } \\
\text { Sig. (2-tailed) } \\
N\end{array}$ & 3069 & $\begin{array}{c}.356^{\star \star} \\
.000 \\
3054\end{array}$ & $\begin{array}{c}.386^{\star \star} \\
.000 \\
3051\end{array}$ \\
\hline $\begin{array}{l}\text { C9 BAR - DISCIPLINE } \\
\text { - SHOULD FOLLOW }\end{array}$ & $\begin{array}{l}\text { Pearson Correlation } \\
\text { Sig. (2-tailed) } \\
\mathrm{N}\end{array}$ & $\begin{array}{l}.356^{\star \star} \\
.000 \\
3054\end{array}$ & $\begin{array}{r}1 \\
3077\end{array}$ & $\begin{array}{l}.437^{\star \star} \\
.000 \\
3065\end{array}$ \\
\hline $\begin{array}{l}\text { C10 BRUTALITY } \\
\text {-DISCIPLINE } \\
\text {-SHOULD FOLLOW }\end{array}$ & $\begin{array}{l}\text { Pearson Correlation } \\
\text { Sig. (2-tailed) } \\
\mathrm{N}\end{array}$ & $\begin{array}{l}.386^{\star \star} \\
.000 \\
3051\end{array}$ & $\begin{array}{l}.437^{\star \star} \\
.000 \\
3065\end{array}$ & 3081 \\
\hline
\end{tabular}

**. Correlation is significant at the 0.01 level (2-tailed). 


\section{Abuse of Authority - Ethical Action}

\section{Correlations}

\begin{tabular}{|c|c|c|c|c|}
\hline & & $\begin{array}{c}\text { C8 ALCOHOL } \\
\text { - OWN } \\
\text { REPORTING }\end{array}$ & $\begin{array}{c}\text { C9 BAR - } \\
\text { OWN } \\
\text { REPORTING }\end{array}$ & $\begin{array}{c}\text { C10 } \\
\text { BRUTALITY - } \\
\text { OWN } \\
\text { REPORTING }\end{array}$ \\
\hline \multirow{3}{*}{$\begin{array}{l}\text { C8 ALCOHOL - } \\
\text { OWN REPORTING }\end{array}$} & Pearson Correlation & 1 & $.497^{\star}$ & $.512^{\star \star}$ \\
\hline & Sig. (2-tailed) & & .000 & .000 \\
\hline & $\mathrm{N}$ & 3071 & 3059 & 3051 \\
\hline \multirow{3}{*}{$\begin{array}{l}\text { C9 BAR - OWN } \\
\text { REPORTING }\end{array}$} & Pearson Correlation & $.497^{\star \star \star}$ & 1 & $.619^{\star \star}$ \\
\hline & Sig. (2-tailed) & .000 & & .000 \\
\hline & $\mathrm{N}$ & 3059 & 3080 & 3065 \\
\hline \multirow{3}{*}{$\begin{array}{l}\text { C10 BRUTALITY - } \\
\text { OWN REPORTING }\end{array}$} & Pearson Correlation & $.512^{\star \star}$ & $.619^{\star}$ & 1 \\
\hline & Sig. (2-tailed) & .000 & .000 & \\
\hline & $\mathrm{N}$ & 3051 & 3065 & 3079 \\
\hline
\end{tabular}

${ }^{* *}$. Correlation is significant at the 0.01 level (2-tailed).

\section{Malfeasance - Ethical Awareness}

\section{Correlations}

\begin{tabular}{|c|c|c|c|c|}
\hline & & $\begin{array}{l}\text { C3 SPEED - } \\
\text { OWN } \\
\text { SERIOUSNE } \\
\text { SS OF BEH }\end{array}$ & $\begin{array}{c}\text { C5 } \\
\text { BURGLARY - } \\
\text { OWN } \\
\text { SERIOUSNE } \\
\text { SS OF BEH }\end{array}$ & $\begin{array}{l}\text { C11 WALLET } \\
\text { - OWN } \\
\text { SERIOUSNES } \\
\text { S OF BEH }\end{array}$ \\
\hline $\begin{array}{l}\text { C3 SPEED - OWN } \\
\text { SERIOUSNESS OF BEH }\end{array}$ & $\begin{array}{l}\text { Pearson Correlation } \\
\text { Sig. (2-tailed) } \\
\mathrm{N}\end{array}$ & 1 & $\begin{array}{c}.649^{\star \star} \\
.000 \\
3077\end{array}$ & $\begin{array}{c}.441^{\star \star} \\
.000 \\
3081\end{array}$ \\
\hline $\begin{array}{l}\text { C5 BURGLARY - OWN } \\
\text { SERIOUSNESS OF BEH }\end{array}$ & $\begin{array}{l}\text { Pearson Correlation } \\
\text { Sig. (2-tailed) } \\
\mathrm{N}\end{array}$ & $\begin{array}{l}.649 * \star \\
.000 \\
3077\end{array}$ & $\begin{array}{r}1 \\
3091\end{array}$ & $\begin{array}{l}.507^{\star \star} \\
.000 \\
3084\end{array}$ \\
\hline $\begin{array}{l}\text { C11 WALLET - OWN } \\
\text { SERIOUSNESS OF BEH }\end{array}$ & $\begin{array}{l}\text { Pearson Correlation } \\
\text { Sig. (2-tailed) } \\
\text { N }\end{array}$ & $\begin{array}{l}.441^{* *} \\
.000 \\
3081\end{array}$ & $\begin{array}{l}.507^{\star \star} \\
.000 \\
3084\end{array}$ & 1 \\
\hline
\end{tabular}

${ }^{\star \star}$. Correlation is significant at the 0.01 level (2-tailed). 


\section{Malfeasance - Ethical Standards}

Correlations

\begin{tabular}{|c|c|c|c|c|}
\hline & & $\begin{array}{l}\text { C3 SPEED - } \\
\text { DISCIPLINE - } \\
\text { SHOULD } \\
\text { FOLLOW }\end{array}$ & $\begin{array}{l}\text { C5 } \\
\text { BURGLARY - } \\
\text { DISCIPLINE - } \\
\text { SHOULD } \\
\text { FOLLOW } \\
\end{array}$ & $\begin{array}{l}\text { C11 WALLET } \\
\text { - DISCIPLINE } \\
\text { - SHOULD } \\
\text { FOLLOW }\end{array}$ \\
\hline $\begin{array}{l}\text { C3 SPEED - DISCIPLINE } \\
\text { - SHOULD FOLLOW }\end{array}$ & $\begin{array}{l}\text { Pearson Correlation } \\
\text { Sig. (2-tailed) } \\
\mathrm{N}\end{array}$ & $\begin{array}{r}1 \\
3083\end{array}$ & $\begin{array}{c}.462^{\star \star} \\
.000 \\
3046\end{array}$ & $\begin{array}{c}.440^{\star \star} \\
.000 \\
3070\end{array}$ \\
\hline $\begin{array}{l}\text { C5 BURGLARY - } \\
\text { DISCIPLINE - SHOULD } \\
\text { FOLLOW }\end{array}$ & $\begin{array}{l}\text { Pearson Correlation } \\
\text { Sig. (2-tailed) } \\
\mathrm{N}\end{array}$ & $\begin{array}{l}.462^{\star \star} \\
.000 \\
3046\end{array}$ & 3063 & $\begin{array}{l}.498^{\star \star} \\
.000 \\
3051\end{array}$ \\
\hline $\begin{array}{l}\text { C11 WALLET - } \\
\text { DISCIPLINE - SHOULD } \\
\text { FOLLOW }\end{array}$ & $\begin{array}{l}\text { Pearson Correlation } \\
\text { Sig. (2-tailed) } \\
\mathrm{N}\end{array}$ & $\begin{array}{l}.440^{\star \star} \\
.000 \\
3070\end{array}$ & $\begin{array}{l}.498^{\star \star} \\
.000 \\
3051\end{array}$ & 3090 \\
\hline
\end{tabular}

**. Correlation is significant at the 0.01 level (2-tailed).

\section{Malfeasance - Ethical Action}

\begin{tabular}{|c|c|c|c|c|}
\hline \multicolumn{5}{|c|}{ Correlations } \\
\hline & & $\begin{array}{l}\text { C3 SPEED - } \\
\text { OWN } \\
\text { REPORTING }\end{array}$ & $\begin{array}{c}\text { C5 } \\
\text { BURGLARY - } \\
\text { OWN } \\
\text { REPORTING }\end{array}$ & $\begin{array}{l}\text { C11 WALLET } \\
\text { - OWN } \\
\text { REPORTING }\end{array}$ \\
\hline \multirow{3}{*}{$\begin{array}{l}\text { C3 SPEED - OWN } \\
\text { REPORTING }\end{array}$} & Pearson Correlation & 1 & $.757^{\star \star}$ & $.742^{\star \star}$ \\
\hline & Sig. (2-tailed) & & .000 & .000 \\
\hline & $\mathrm{N}$ & 3079 & 3064 & 3067 \\
\hline \multirow{3}{*}{$\begin{array}{l}\text { C5 BURGLARY - } \\
\text { OWN REPORTING }\end{array}$} & Pearson Correlation & $.757^{\star \star}$ & 1 & $.769 * \star$ \\
\hline & Sig. (2-tailed) & .000 & & .000 \\
\hline & $\mathrm{N}$ & 3064 & 3087 & 3077 \\
\hline \multirow{3}{*}{$\begin{array}{l}\text { C11 WALLET - } \\
\text { OWN REPORTING }\end{array}$} & Pearson Correlation & $.742^{\star \star}$ & $.769^{\star \star}$ & 1 \\
\hline & Sig. (2-tailed) & .000 & .000 & \\
\hline & $\mathrm{N}$ & 3067 & 3077 & 3092 \\
\hline
\end{tabular}

${ }^{\star *}$. Correlation is significant at the 0.01 level (2-tailed). 
Principal Components Factor Analysis

1 = Malfeasance; 2 = Abuse of Authority; 3 = Conflict of Interest; 4 = Exploiting Authority

\section{Ethical Awareness}

\section{Rotated Component Matrix}

\begin{tabular}{|c|c|c|c|c|}
\hline & \multicolumn{4}{|c|}{ Component } \\
\hline & 1 & 2 & 3 & 4 \\
\hline $\begin{array}{l}\text { C2 MEALS - OWN } \\
\text { SERIOUSNESS OF BEH }\end{array}$ & .051 & .137 & .876 & .103 \\
\hline $\begin{array}{l}\text { C3 SPEED - OWN } \\
\text { SERIOUSNESS OF BEH }\end{array}$ & .845 & .053 & .078 & .097 \\
\hline $\begin{array}{l}\text { C4 HOLIDAYS - OWN } \\
\text { SERIOUSNESS OF BEH }\end{array}$ & .065 & .191 & .827 & .208 \\
\hline $\begin{array}{l}\text { C5 BURGLARY - OWN } \\
\text { SERIOUSNESS OF BEH }\end{array}$ & .879 & .068 & .022 & .070 \\
\hline $\begin{array}{l}\text { C6 AUTO - OWN } \\
\text { SERIOUSNESS OF BEH }\end{array}$ & 248 & .200 & .208 & 686 \\
\hline $\begin{array}{l}\text { C7 SUPERVISOR - OWN } \\
\text { SERIOUSNESS OF BEH }\end{array}$ & .085 & .152 & .140 & .846 \\
\hline $\begin{array}{l}\text { C8 ALCOHOL - OWN } \\
\text { SERIOUSNESS OF BEH }\end{array}$ & -.024 & .708 & .268 & .183 \\
\hline $\begin{array}{l}\text { C9 BAR - OWN } \\
\text { SERIOUSNESS OF BEH }\end{array}$ & .352 & .621 & -.022 & .356 \\
\hline $\begin{array}{l}\text { C10 BRUTALITY - OWN } \\
\text { SERIOUSNESS OF BEH }\end{array}$ & 162 & .818 & .151 & .058 \\
\hline $\begin{array}{l}\text { C11 WALLET - OWN } \\
\text { SERIOUSNESS OF BEH }\end{array}$ & .689 & .222 & .045 & .213 \\
\hline
\end{tabular}

Extraction Method: Principal Component Analysis.

Rotation Method: Varimax with Kaiser Normalization.

a. Rotation converged in 5 iterations. 


\section{Ethical Standards}

\section{Rotated Component Matrix}

\begin{tabular}{|c|c|c|c|c|}
\hline & \multicolumn{4}{|c|}{ Component } \\
\hline & 1 & 2 & 3 & 4 \\
\hline $\begin{array}{l}\text { C2 MEALS - DISCIPLINE } \\
\text { - SHOULD FOLLOW }\end{array}$ & .095 & .112 & .874 & .069 \\
\hline $\begin{array}{l}\text { C3 SPEED - DISCIPLINE } \\
\text { - SHOULD FOLLOW }\end{array}$ & .712 & .026 & .212 & .265 \\
\hline $\begin{array}{l}\text { C4 HOLIDAYS - } \\
\text { DISCIPLINE - SHOULD } \\
\text { FOLLOW }\end{array}$ & .073 & 180 & .806 & .203 \\
\hline $\begin{array}{l}\text { C5 BURGLARY - } \\
\text { DISCIPLINE - SHOULD } \\
\text { FOLLOW }\end{array}$ & 811 & .114 & -.008 & .095 \\
\hline $\begin{array}{l}\text { C6 AUTO - DISCIPLINE - } \\
\text { SHOULD FOLLOW }\end{array}$ & .406 & 156 & .186 & .628 \\
\hline $\begin{array}{l}\text { C7 SUPERVISOR } \\
\text {-DISCIPLINE -SHOULD } \\
\text { FOLLOW }\end{array}$ & .097 & .148 & .142 & .873 \\
\hline $\begin{array}{l}\text { C8 ALCOHOL - } \\
\text { DISCIPLINE - SHOULD } \\
\text { FOLLOW }\end{array}$ & -.012 & .803 & 197. & .162 \\
\hline $\begin{array}{l}\text { C9 BAR - DISCIPLINE - } \\
\text { SHOULD FOLLOW }\end{array}$ & .388 & .513 & .058 & .411 \\
\hline $\begin{array}{l}\text { C10 BRUTALITY } \\
\text {-DISCIPLINE -SHOULD } \\
\text { FOLLOW }\end{array}$ & .336 & .728 & .116 & .059 \\
\hline $\begin{array}{l}\text { C11 WALLET - } \\
\text { DISCIPLINE - SHOULD } \\
\text { FOLLOW }\end{array}$ & .745 & .280 & .047 & .112 \\
\hline
\end{tabular}

Extraction Method: Principal Component Analysis.

Rotation Method: Varimax with Kaiser Normalization.

a. Rotation converged in 5 iterations. 


\section{Ethical Action}

Rotated Component Matrix

\begin{tabular}{|c|c|c|c|c|}
\hline & \multicolumn{4}{|c|}{ Component } \\
\hline & 1 & 2 & 3 & 4 \\
\hline $\begin{array}{l}\text { C2 MEALS - OWN } \\
\text { REPORTING }\end{array}$ & .156 & .872 & .216 & .074 \\
\hline $\begin{array}{l}\text { C3 SPEED - OWN } \\
\text { REPORTING }\end{array}$ & .829 & .214 & .135 & .215 \\
\hline $\begin{array}{l}\text { C4 HOLIDAYS - } \\
\text { OWN REPORTING }\end{array}$ & .212 & .829 & .179 & .210 \\
\hline $\begin{array}{l}\text { C5 BURGLARY - } \\
\text { OWN REPORTING }\end{array}$ & .890 & .102 & .087 & .140 \\
\hline $\begin{array}{l}\text { C6 AUTO - OWN } \\
\text { REPORTING }\end{array}$ & .700 & .238 & .182 & .437 \\
\hline $\begin{array}{l}\text { C7 SUPERVISOR - } \\
\text { OWN REPORTING }\end{array}$ & .399 & .224 & .216 & .801 \\
\hline $\begin{array}{l}\text { C8 ALCOHOL - } \\
\text { OWN REPORTING }\end{array}$ & .098 & .269 & .828 & .282 \\
\hline $\begin{array}{l}\text { C9 BAR - OWN } \\
\text { REPORTING }\end{array}$ & .639 & .204 & .405 & .365 \\
\hline $\begin{array}{l}\text { C10 BRUTALITY - } \\
\text { OWN REPORTING }\end{array}$ & .527 & .224 & .679 & -.023 \\
\hline $\begin{array}{l}\text { C11 WALLET - } \\
\text { OWN REPORTING }\end{array}$ & .852 & .147 & .240 & .148 \\
\hline
\end{tabular}

Extraction Method: Principal Component Analysis.

Rotation Method: Varimax with Kaiser Normalization.

a. Rotation converged in 5 iterations. 
APPENDIX E 
Skewness and Kurtosis results

\begin{tabular}{|l|l|l|l|l|}
\hline & Conflict of Interest & Abuse of Authority & Misfeasance & Bribery/Theft \\
\hline Awareness Skewness & .477 & -1.489 & -.421 & -6.050 \\
\hline Awareness Kurtosis & -.676 & 2.389 & -.645 & 50.259 \\
\hline Standards Skewness & .942 & .117 & .163 & -.916 \\
\hline Standards Kurtosis & 1.043 & -.151 & -.179 & .786 \\
\hline Action Skewness & 1.168 & -.556 & .225 & -1.461 \\
\hline Action Kurtosis & .554 & -.790 & -1.021 & 1.073 \\
\hline
\end{tabular}


Linearity ANOVA results

\begin{tabular}{|l|l|l|l|l|}
\hline & $\begin{array}{l}\text { Conflict of Interest } \\
\text { Awareness }\end{array}$ & $\begin{array}{l}\text { Abuse of Authority } \\
\text { Awareness }\end{array}$ & $\begin{array}{l}\text { Misfeasance } \\
\text { Awareness }\end{array}$ & $\begin{array}{l}\text { Bribery/Theft } \\
\text { Awareness }\end{array}$ \\
\hline Rank & $.000^{*}$ & $.000^{*}$ & $.000^{*}$ & .144 \\
\hline Supervisory Position & $.002^{*}$ & .245 & .554 & .647 \\
\hline Length of Service & $.001^{*}$ & .192 & $.000^{*}$ & .804 \\
\hline Size of Agency & $.000^{*}$ & $.010^{*}$ & $.004^{*}$ & .054 \\
\hline
\end{tabular}

* significant at the .05 level.

\begin{tabular}{|l|l|l|l|l|}
\hline & $\begin{array}{l}\text { Conflict of Interest } \\
\text { Standards }\end{array}$ & $\begin{array}{l}\text { Abuse of Authority } \\
\text { Standards }\end{array}$ & $\begin{array}{l}\text { Misfeasance } \\
\text { Standards }\end{array}$ & $\begin{array}{l}\text { Bribery/Theft } \\
\text { Standards }\end{array}$ \\
\hline Rank & $.000^{*}$ & $.000^{*}$ & $.000^{*}$ & $.000^{*}$ \\
\hline Supervisory Position & $.000^{*}$ & $.000^{*}$ & $.000^{*}$ & $.000^{*}$ \\
\hline Length of Service & $.000^{*}$ & $.000^{*}$ & $.011^{*}$ & $.000^{*}$ \\
\hline Size of Agency & $.000^{*}$ & $.020^{*}$ & .000 & $.001^{*}$ \\
\hline
\end{tabular}

* significant at the .05 level.

\begin{tabular}{|l|l|l|l|l|}
\hline & $\begin{array}{l}\text { Conflict of Interest } \\
\text { Action }\end{array}$ & $\begin{array}{l}\text { Abuse of Authority } \\
\text { Action }\end{array}$ & $\begin{array}{l}\text { Misfeasance } \\
\text { Action }\end{array}$ & $\begin{array}{l}\text { Bribery/Theft } \\
\text { Action }\end{array}$ \\
\hline Rank & $.000^{*}$ & $.000^{*}$ & $.000^{*}$ & $.000^{*}$ \\
\hline Supervisory Position & $.000^{*}$ & $.000^{*}$ & $.000^{*}$ & $.000^{*}$ \\
\hline Length of Service & $.000^{*}$ & $.000^{*}$ & $.000^{*}$ & $.000^{*}$ \\
\hline Size of Agency & $.000^{*}$ & $.000^{*}$ & $.000^{*}$ & $.000^{*}$ \\
\hline
\end{tabular}

* significant at the .05 level. 
APPENDIX F 


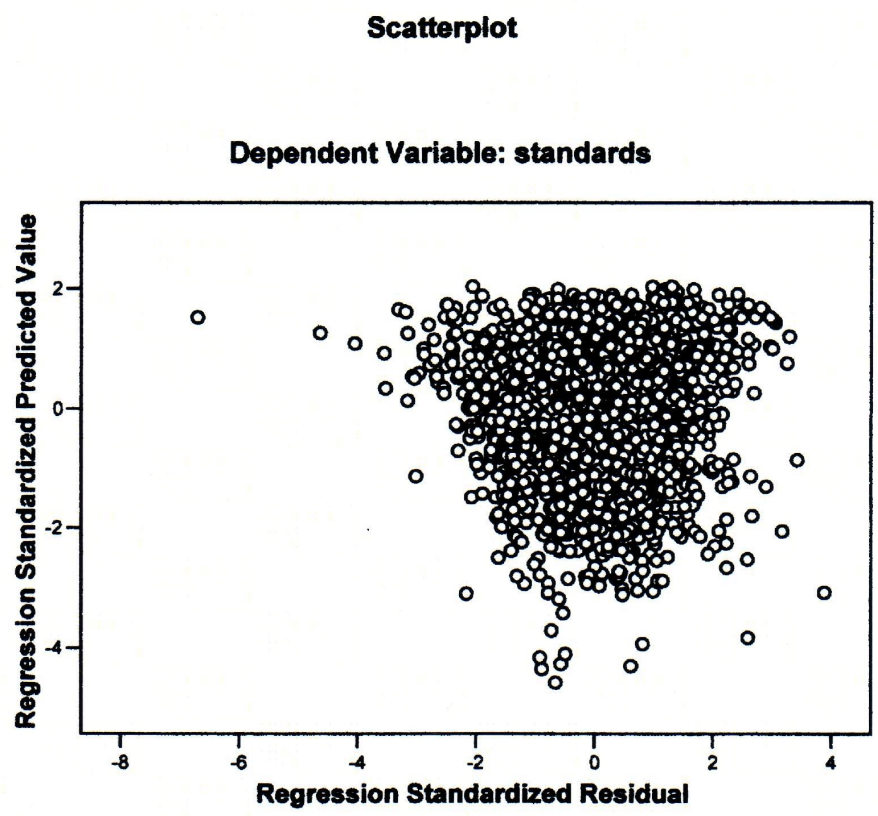


Scatterplot

Dependent Variable: action

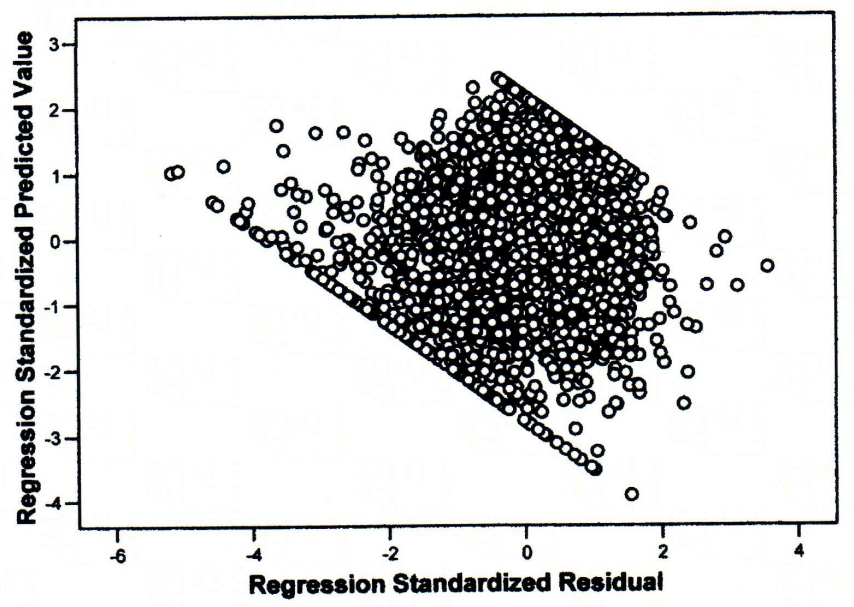


APPENDIX G 


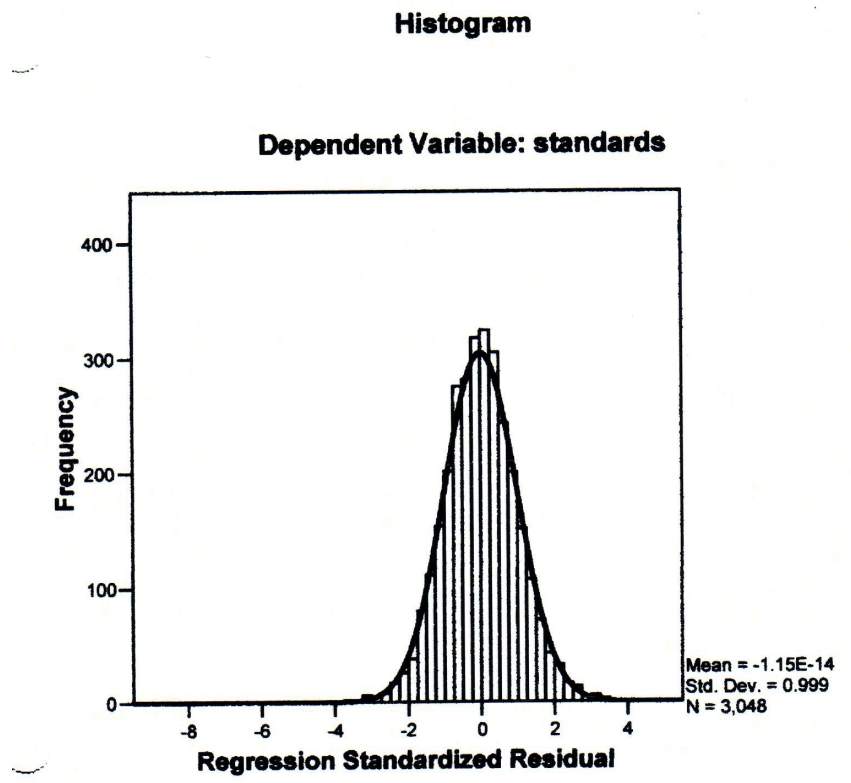




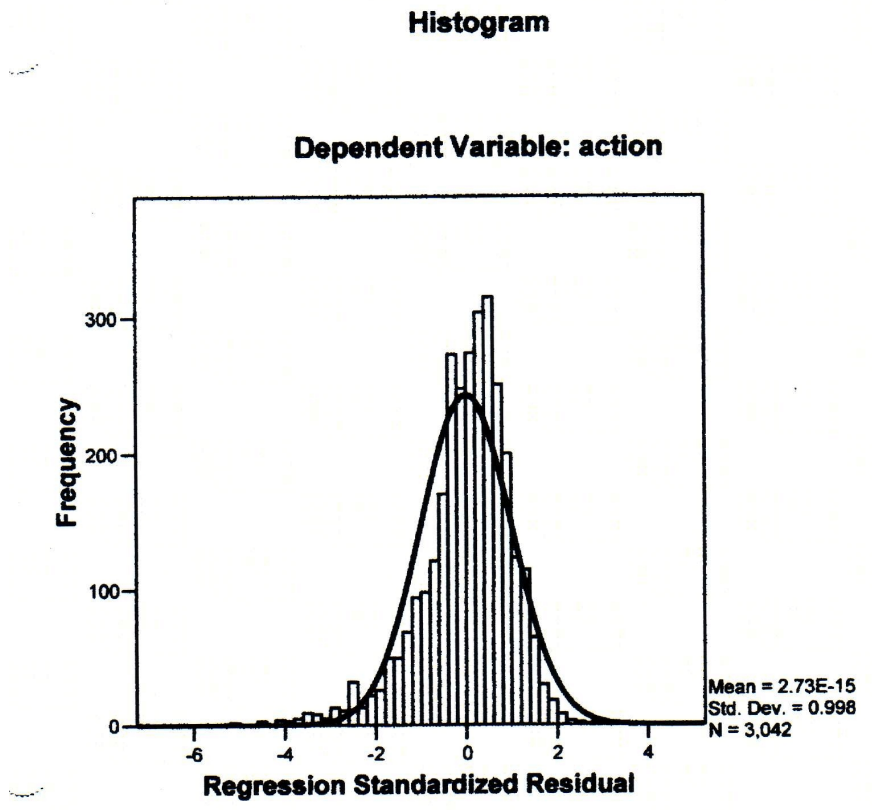

